\title{
PALÉONTOLOGIE(S) ET ÉVOLUTION AU DÉBUT DU XIXe SIÈCLE CUVIER ET LAMARCK
}

\author{
Goulven Laurent
}

Historien des Sciences, Brest, Francia

\section{RESUMEN}

La paleontología, desde su nacimiento, ha sido llamada a suministrar argumentos a favor y contra la teoría de la Evolución, que nació en la misma época. En efecto, Cuvier y Lamarck, los dos fundadores de la (de las) paleontología (s) — de los vertebrados y de los invertebrados-, utilizaron las decenas de fósiles que descubrieron como «piezas justificativas» de sus teorías. Sus artículos polemizaron contradictoriamente en páginas sucesivas de la misma revista, los Annales du muséum d'Histoire naturelle de París, y en sus obras de principios del siglo XIX.

\section{RÉSUMÉ}

La paléontologie, dès sa naissance, a été appelée à fournir des arguments pour ou contre la théorie de l'Évolution, qui venait aussi de naître à la même époque. En effet, Cuvier et Lamarck, les deux fondateurs de la (des) paléontologie(s) — celle des vertébrés et celle des invertébrés- ont utilisé les dizaines de fossiles qu'ils ont mis au jour comme «pièces justificatives» de leurs théories. Leurs articles se sont répondu contradictoirement dans les pages successives de la même revue, les Annales du Muséum d'Histoire naturelle de Paris, et dans leurs oeuvres du début du XIXe siècle.

Le tournant des XVllle-XIXe siècles représente le moment d'un des plus grands événements de l'histoire des Sciences de la Vie. A cette époque en effet les naturalistes mettent en chantier, simultanément, deux grandes entreprises scientifiques: d'un côté, la résurrection matérielle du passé, grâce à la paléontologie, et, de l'autre, sa reconstitution conceptuelle, grâce à la théorie de l'Évolution.

C'est dans ces années fin-début de deux siècles que le Muséum national d'Histoire naturelle de Paris fournit le lieu institutionnel de rencontre des travaux et de cristallisation des théories. La paléontologie —ou plutôt, comme nous l'avons déjà suggéré dans le titre, et comme nous le développerons plus loin- les paléontologies prennent leur essor à cette époque, et amassent les faits matériels sans lesquels une résurrection du passé ne peut être que jeu de l'imagination. Il est en effet remarquable de constater qu'il y a deux paléontologies qui se côtoient, celle des vertébrés, et celle 
des invertébrés, et deux paléontologues qui s'opposent, fondateurs chacun de l'une des deux disciplines. Au même moment surgit le besoin d'en donner une représentation théorique structurée et rationnelle. L'ancienne vision aristotélo-assyro-judéochrétienne ne suffisant évidemment plus - elle avait été forgée avant l'essor de la paléontologie, et forcément sans rapport avec ses données - deux théories rivales se manifestent et s'affrontent, dont l'une, celle de la transformation des espèces au cours des temps géologiques, est précisément celle qui est la nôtre aujourd'hui.

Cette histoire de la naissance et du développement simultanés de la paléontologie et de l'évolution est documentée principalement par les travaux de deux des plus grands savants de leur temps, Cuvier (1769-1832), et Lamarck (1744-1829). Pour raconter l'histoire de ces deux disciplines, l'historien se trouve dans une situation pour ainsi dire idéale, car non seulement les deux protagonistes travaillent et enseignent dans le même établissement, mais ils publient aussi leurs travaux dans les mêmes revues, et particulièrement dans les Annales (puis Mémoires ) du Muséum national d'Histoire naturelle de Paris. Il lui suffit donc souvent de tourner les pages d'un même numéro pour suivre pas à pas leurs découvertes et leurs prises de position, qui se répondent et s'opposent d'un numéro à l'autre, et parfois d'une page à l'autre. Il est intéressant d'ailleurs de constater que, dans la période que nous étudions, la quantité d'articles de paléontologie contenus dans cette revue montre un léger avantage en faveur de Lamarck, qui en fournit 41 , contre 40 venant de Cuvier! ${ }^{1}$

Chronologiquement, Lamarck étant plus âgé que Cuvier d'une génération -25 ans les séparent- on eût pu s'attendre à commencer le récit par lui. Il était même arrivé au Muséum avant Cuvier, en 1793. Mais, en prenant possession de sa chaire au Muséum, Lamarck avait beaucoup plus à apprendre - en fait presque tout- dans son domaine: celui des animaux «inférieurs», pour lesquels il inventa en 1797 la dénomination d'Invertébrés, qui fut adoptée immédiatement par presque tous les naturalistes. Cuvier, en revanche, était, grâce à ses études antérieures, déjà «opérationnel» avant son aîné du Muséum. C'est donc par lui que nous commencerons l'histoire des relations — conflictuelles dans son cas—entre la paléontologie et le transformisme.

\section{Cuvier 1795}

A son arrivée à Paris, à 26 ans, Cuvier possédait déjà un solide bagage de connaissances en Histoire naturelle. Il connaissait bien en particulier les animaux qu'il continuera pendant encore quelque temps à appeler animaux «à sang blanc». Il a déjà publié quelques études sur les Cloportes terrestres, la Patelle commune et les Diptères $^{2}$. Ces premiers travaux ne traitent pas de fossiles, mais d'animaux actuels, qu'il a

1 Cf. LAMBert C., Le BerRe S., HANRIOT D. (1992), Le Journal du Muséum d'Histoire naturelle, Quelques aspects de l'Evolution des Sciences naturelles en France entre 1802 et 1914, Mémoire de DEA, Université de Nantes, p. 36.

2 Journal d'Histoire naturelle, 1792, 2,18-31, 81-95, 253-258. 
recueillis sur les plages de Normandie, et qu'il a eu le loisir de disséquer pendant ses années de préceptorat dans une famille aristocratique protestante de la région. Il a aussi en poche quelques articles déjà rédigés, qu'il fera paraitre dès son arrivée dans la capitale. Il est du reste assez piquant (rétrospectivement) de constater que ces premiers articles ont été ou seront publiés dans le Journal d'Histoire naturelle de Lamarck, ou bien dans le Bulletin des sciences de la Société philomatique ou le Magasin encyclopédique, après avoir été lus à la Société d'Histoire naturelle, dont l'un des membres les plus en vue était aussi Lamarck. Cuvier va continuer pendant quelques années à faire paraître des études sur les invertébrés, mais, dans ce domaine, sa seule prise de position — très offensive, il est vrai- sur l'évolution n'apparaîtra qu'en 1817 dans l'article qu'il consacrera aux Céphalopodes dans ses Mémoires pour servir à l'histoire et à l'anatomie des Mollusques, et que nous retrouverons plus loin à leur date.

Cependant Cuvier avait commencé à s'intéresser à l'étude d'animaux vertébrés, des oiseaux et des tarsiers en particulier. Il se préoccupe déjà de montrer que les espèces qu'il décrit sont distinctes les unes des autres, qu'il s'agisse d'espèces actuelles ou d'espèces fossiles. Son projet est en effet de mettre en relief les caractères qui différencient les espèces et qui permettent de leur donner une identité spécifique.

C'est par les vertébrés aussi que Cuvier commence ses publications paléontologiques. Fidèle à sa méthode de distinction des espèces, il traite les espèces fossiles de la même manière que les espèces actuelles: elles sont différentes entre elles et différentes aussi des espèces actuelles.

\section{5}

En 1795 Cuvier publie, en collaboration avec Etienne Geoffroy Saint-Hilaire, une courte notice sur les Eléphants. Sa «méthode» est bien illustrée déjà dans cette publication: «Ces naturalistes ont prouvé qu'il existe au moins deux espèces bien distinctes d'éléphans» (celui d'Asie et celui d'Afrique). «Ils rapportent au genre des éléphans, l'animal dont on a trouvé des ossemens et des défenses fossiles dans le Canada... Enfin, ces citoyens ont découvert que le Mammouth, cet animal dont on trouve les ossemens en Sibérie et ailleurs, et qu'on avoit toujours regardé comme un éléphant, est bien du même genre, mais que, quoique très voisin de l'éléphant d'Asie, il en diffère assez pour être considéré comme une espèce distincte» ${ }^{3}$.

\section{6}

En 1796, Cuvier fait paraître une «Notice sur le squelette d'une très grande espèce de quadrupède inconnue jusqu'à présent, trouvé au Paraguay»: «J'ai cru, écrit-il,...

\footnotetext{
3 «Sur les espèces d'Eléphans», par les C.C. CUVIER et GEOFFrOY, Bulletin de la Société philomatique, 1791-1798, 1, 1ère partie, 90; p. 90; texte de thermidor an III (août 1795); souligné par nous, comme nous le ferons encore par la suite, pour bien mettre en évidence sa méthode.
} 
pouvoir lui donner le nom générique de Megatherium, et le nom trivial Megatherium americanum. Il ajoute aux faits nombreux qui nous annonce (sic) que les animaux de l'ancien monde différoient tous de ceux que nous voyons aujourd'hui sur la terre; car il n'est guères probable que si cet animal existoit encore, une espèce aussi remarquable eût pu échapper jusqu'ici aux recherches des naturalistes» ${ }^{4}$.

L'intervention capitale que Cuvier fit cette année, à ses propres yeux, fut la lecture qu'il fit devant l'Institut, le 1er pluviôse an IV (21 janvier 1796), d'un Mémoire concernant de nouveau les Eléphants. Le soin qu'il prend de publier ce mémoire dans le Magasin encyclopédique (1796), les Mémoires de l'Institut (1799) et le Journal de Physique (1800), montre l'importance qu'il attache aux idées qu'il y expose et à leur diffusion. Il y développe ses nouvelles conceptions concernant l'histoire de la terre et l'histoire de la vie, cette «histoire naturelle» qui, dit-il, «est placée, pour ainsi dire, sur la limite qui sépare les sciences de pur raisonnement d'avec celles qui ont pour objet les faits positifs» et qui «participe aux difficultés comme aux agrémens des unes et des autres» ${ }^{5}$.

Cuvier est conscient d'apporter à la science un point de vue et des éléments nouveaux. «Les ossemens des grands quadrupèdes, déclare-t-il, qu'on a trouvés fossiles dans presque toutes les contrées du globe, ont été examinés et décrits, depuis Tentzélius jusqu'à Pallas, par une multitude de zoologistes; tous les ont rapportés sans difficulté à l'espèce de l'éléphant, et les savans qui s'occupent de la théorie de la terre, regardent comme constant qu'il y a eu une époque où les éléphans qui ne se trouvent aujourd'hui que dans la zone torride de l'ancien hémisphère, habitoient les contrées septentrionales des deux continens» (p. 4).

Cuvier tient dès l'abord à montrer sa différence et l'originalité de sa position: «Je me crois pourtant en état de prouver, assure-t-il, qu'au moins une grande partie des dépouilles fossiles en question a appartenu à des animaux qui différoient bien évidemment pour l'espèce d'avec nos éléphans d'aujourd'hui, quoiqu'ils leur ressemblassent assez pour devoir être regardés comme du même genre» (p. 4).

En plus de l' elephas americanus et de l' elephas mammouteus (mammouth), qu'il vient d'étudier, Cuvier dispose déjà d'autres documents qui parlent dans le même sens: «Qu'on joigne à ces deux exemples d'animaux dont on ne retrouve pas les originaux, le crocodile de la montagne de Saint-Pierre à Maestricht, touchant lequel le citoyen Faujas prouvera, dans un ouvrage qui doit bientôt paraitre, qu'il diffère du crocodile du Nil et de celui du Gange; les quadrupèdes des cavernes de Gaylenreuth au pays d'Anspach, qu'on avoit rapportés à l'ours marin, et que je prouverai en diffé-

\footnotetext{
4 «Notice sur le squelette d'une très grande espèce de quadrupède inconnue jusqu'à présent, trouvé au Paraguay, et déposé au cabinet d'Histoire Naturelle de Madrid», Magasin encyclopédique, 2ème année, an IV, 1796, 1, 303-310; p. 310.

5 «Mémoire sur les espèces d'Eléphans vivantes et fossiles», Mémoires de l'Institut national des Sciences et des Arts, fructidor an VII (août-septembre 1799), 2, 1-22; p. 1.
} 
rer considérablement; les rhinocéros fossiles de Sibérie, que je prouverai n'être semblables ni à ceux d'Afrique ni à ceux des Indes, comme Camper, qui n'avoit pas vu de ces derniers adultes, le soupçonnoit; les bois pétrifiés d'une espèce du genre du cerf, mais qui ne sont ni d'un élan, ni d'un renne, ni d'aucune espèce connue, et qu'on trouve également dans la montagne de Saint-Pierre» (p. 20-21).

Dans la même intervention devant l'Institut national, Cuvier avait révélé une des premières conclusions qu'il pouvait tirer de ses études, qui, à son avis, réfutait la transformation géologique des espèces: «Quelque puisse être l'influence du climat pour faire varier les animaux, elle ne va sûrement pas aussi loin; et dire qu'elle peut changer toutes les proportions de la charpente osseuse et la contexture intime des dents, ce seroit avancer que tous les quadrupèdes peuvent ne dériver que d'une seule espèce; que les différences qu'ils présentent ne sont que des dégénérations successives: en un mot ce seroit réduire à rien toute l'histoire naturelle, puisque son objet ne consisteroit qu'en des formes variables et des types fugaces» ${ }^{6}$.

La conclusion finale de l'article est nette: «Qu'on se demande pourquoi on trouve tant de dépouilles d'animaux inconnus, tandis qu'on n'en trouve presque aucune dont on puisse dire qu'elle appartienne aux espèces que nous connoissons, et l'on verra combien il est probable qu'elles ont appartenu à des êtres d'un monde antérieur au nôtre, à des êtres détruits par quelques révolutions de ce globe; êtres dont ceux qui existent aujourd'hui ont rempli la place, pour se voir peut-être un jour également détruits et remplacés par d'autres» 7 .

Cuvier avait déjà publié cette intervention dans le Magasin encyclopédique, et les conclusions étaient évidemment les mêmes: «Que sont devenus ces deux énormes animaux» (les deux éléphants déjà cités: l'elephas americanus et l'elephas mammouteus) «dont on ne trouve plus de vestiges, et tant d'autres dont la terre nous offre partout les dépouilles, et dont peut-être aucun n'existe actuellement? Les rhinocéros fossiles de Sibérie sont très-différens de tous les rhinocéros connus. Il en est de même des prétendus ours fossiles d'Anspach, du crocodile fossile de Maëstricht, de l'espèce de cerf du même lieu, de l'animal de douze pieds de long sans dents incisives, à doigts armés de griffes, dont on vient de découvrir le squelette au Paraguay: aucun n'a d'analogue vivant. Pourquoi, enfin, ne trouve-t-on aucun os humain pétrifié?

6 «Mémoire sur les espèces d'Eléphans vivantes et fossiles», Journal de Physique, 1800, 50, 207 217; p. 212.

7 «Mémoire sur les espèces d'Eléphans vivantes et fossiles», Mémoires de l'Institut national des Sciences et des Arts, fructidor an VII (août-septembre 1799), 2, 1-22; p. 21; c'est nous qui soulignons. 
Tous ces faits, analogues entre eux, et auxquels on n'en peut opposer aucun de constaté, me paroissent prouver l'existence d'un monde antérieur au nôtre, détruit par une catastrophe quelconque» ${ }^{8}$.

Cuvier faisait remarquer que ces nouvelles découvertes le mettaient cependant devant de «nouvelles difficultés». En effet: «Mais quelle étoit cette terre primitive? quelle étoit cette nature qui n'étoit pas soumise à l'empire de l'homme? et quelle révolution a pu l'anéantir au point de n'en laisser pour trace que des ossemens à demidécomposés?» (p. 444).

Cuvier a déjà sa propre explication, qu'il développera bientôt. En attendant, il s'en prend, sans les désigner nommément, aux autres «théories de la terre». Le sujet des éléphants fossiles, assure-t-il, «quoique particulier, m'a paru digne de vous être présenté, et parce que l'éléphant est un animal si remarquable que tout ce qui concerne son histoire mérite notre attention, et parce que la détermination précise des espèces auxquelles ont appartenu les grandes dépouilles fossiles qui se trouvent presque partout, peut être d'une grande importance dans la théorie de la terre, peut servir à détruire des systèmes hasardés, et même à nous donner des lumières sur l'histoire si piquante et si obscure des révolutions de ce globe» ${ }^{9}$. Et il ajoute plus loin: «On sait combien les géologistes ont été féconds en hypothèses pour expliquer comment on trouve si abondamment dans le nord des ossemens d'animaux qui n'habitoient que la zone torride. Je crois qu'on feroit un grand pas vers la perfection de la théorie de la terre, si on parvenoit à prouver qu'aucun de ces animaux n'existe plus aujourd'hui ni dans la zone torride ni ailleurs» (p. 16).

S'il conclut modestement: «Ce n'est pas à nous qu'il appartient de nous engager dans le vaste champ de conjectures que ces questions présentent. Que des philosophes plus hardis l'entreprennent. La modeste anatomie, bornée à l'examen détaillé, à la comparaison scrupuleuse des objets soumis à ses yeux et à son scalpel, se contentera de l'honneur d'avoir ouvert cette nouvelle route au génie qui osera la parcourir» ${ }^{10}$, on sait que Cuvier n'hésitera pas longtemps à s'y lancer lui-même.

Cuvier soulignera l'importance de cette date 1796 dans le nouveau cours que prend sa pensée. Développant en 1821 son étude des crânes des éléphants fossiles, il s'attache surtout à l'un de ceux que Pallas a signalés, qui fut découvert «par le savant et courageux dantzickois Messerschmidt», dont la représentation dans les Philosophical

8 «Mémoire sur les espèces d'Eléphans tant vivantes que fossiles, lu à la séance publique de l'Institut national le 15 germinal an IV (4 avril 1796)», Magasin encyclopédique, 2de année,1796, 3, 440-445; p. 444; c'est encore nous qui soulignons.

9 «Mémoire sur les espèces d'Eléphans vivantes et fossiles». Mémoires de l'Institut national des Sciences et des Arts, fructidor an VII (août-septembre 1799), 2, p. 4.

10 «Mémoire sur les espèces d'Eléphans tant vivantes que fossiles, lu à la séance publique de l'Institut national le 15 germinal an IV (4 avril 1796)», Magasin encyclopédique, 2de année, 1796, 3,p. 444445 . 
Transactions a confirmé Cuvier dans sa conviction que les éléphants fossiles étaient bien d'une espèce différente des éléphants des Indes ${ }^{11}$. Cette confirmation fut capitale dans l'élaboration de sa théorie: «Cette idée, que j'annonçai à l'Institut, dès le mois de janvier 1796 (Mémoires de l'Institut, lère classe, tome II, p. 20 et 21), m'ouvrit des vues toutes nouvelles sur la théorie de la terre; un coup d'oeil rapide jetté $(s i c)$ sur d'autres os fossiles me fit présumer tout ce que j'ai découvert depuis, et me détermina à me consacrer aux longues recherches et aux travaux assidus qui m'ont occupé depuis vingt-cinq ans».

«Je dois donc reconnaître ici, poursuit-il, que c'est à ce dessin, resté pour ainsi dire oublié dans les Transactions philosophiques depuis soixante-dix ans, que je devrai celui de tous mes ouvrages auquel j'attache le plus de prix». On sait que cet ouvrage est celui des Recherches sur les Ossemens fossiles de Quadrupèdes, celui qu'il est justement en train de rééditer en 1821.

Voulant encore une assurance de plus, Cuvier écrivit à l'Académie de Saint Petersbourg, qui «répondit à mon voeu avec une générosité digne d'une compagnie à laquelle les sciences doivent tant de progrès» et « me fit faire un superbe dessin colorié et de grandeur naturelle... Ce dessin... me parvint au moment où je mettois la dernière main à la première impression de ce travail, et je fus, s'exclame Cuvier, transporté d'une joie que j'aurois peine à exprimer en y trouvant la confirmation de tout ce que celui de Messerschmidt m'avoit appris» (p. 178-179).

Ce qui transporte Cuvier de joie, c'est qu'il est sûr à partir de ce moment —c'est-àdire à partir de 1812, date de la réception de ce document- d'avoir désormais en mains les documents qui lui permettront de confirmer définitivement les prises de position sur le passé de la vie, qu'il avait déjà conçues dès 1796.

Ce sont en effet ces premiers mémoires relatifs à des fossiles de vertébrés qui vont décider de la carrière paléontologique de Cuvier. Ses principaux ouvrages vont être désormais consacrés aux «ossemens fossiles de quadrupèdes». La raison en sera clairement indiquée par Cuvier: ils fournissent l'instrument de démonstration idéal et irréfutable de sa propre «théorie de la terre». «Il falloit donc faire un choix, et nous le fîmes bientôt», déclarera-t-il en présentant ses travaux sur les fossiles de Quadrupèdes. «La classe de fossiles qui fait l'objet de cet ouvrage nous attacha dès le premier abord, parce que nous vîmes qu'elle est à la fois plus féconde en conséquences précises, et cependant moins connue, et plus riche en nouveaux sujets de recherches» ${ }^{12}$.

\footnotetext{
11 Recherches sur les Ossemens Fossiles, nouvelle édition, t.1, 1821, «Sur les Ossemens d'Eléphans», p. 177-178.

12 Recherches sur les Ossemens fossiles de Quadrupèdes, t. 1, 1812, Discours préliminaire, p. 36.
} 
Cuvier fait paraître, dans le Bulletin de la Société philomatique, une autre notice «Sur les différentes espèces de rhinocéros». Il y «montre que les rhinocéros fossiles de Sibérie et d'Allemagne différoient essentiellement des quatre espèces qui vivent aujourd'hui», et il annonce que cela «le conduit à différentes considérations géologiques», dont ses auditeurs et lecteurs savaient désormais en quoi elles consistaient ${ }^{13}$.

\section{8}

C'est dans la même perspective que Cuvier fait connaître à ses collègues de la Société Philomatique de Paris son intention de collecter tous les fossiles connus de Vertébrés, dans l'intention de bien montrer qu'ils avaient appartenu à un monde disparu $^{14}$. On notera le soin avec lequel il distingue les espèces les unes des autres et souligne, le cas échéant, qu'elles ne possèdent pas d' «analogue vivant». L'auteur, écrivait-il dans le compte rendu de son intervention à la Société, «s'est proposé dans ce mémoire de rassembler, autant qu'il lui a été possible, tous les os fossiles qui ont appartenu à chaque espèce, soit qu'il les ait vus par lui-même, ou qu'il en ait seulement trouvé la description dans les auteurs; de reformer les squelettes de ces espèces, et de les comparer avec celles qui existent à la surface du globe, pour en déterminer les rapports et les différences.

Voici la série des espèces sur lesquelles il a travaillé.

1. L'animal dont viennent les os et les défenses, nommés os, et cornes de mammouth par les Russes et les habitants de la Sibérie; on en trouve aussi des dépouilles fossiles dans plusieurs parties de l'Europe. C'est une espèce d'éléphant, voisine de l'éléphant d'Asie; mais qui en diffère... Son véritable analogue vivant n'est pas connu, quoiqu'on l'ait regardé jusqu'ici comme un éléphant ordinaire.

2. L'animal dont on trouve les dépouilles sur les bords de l'Ohio, dans l'Amérique septentrionale, et que les Américains et les Anglais ont aussi nommé mammouth, quoiqu'il diffère beaucoup du précédent. On en trouve aussi des restes en Europe et en Asie...

3. L'animal dont les dents, teintes par le cuivre, fournissent les turquoises, dont il y avoit une mine à Simore en Languedoc. On trouve des dépouilles de cette même espèce dans le département de l'Ain, au Pérou et ailleurs. Elle a dû être assez semblable à la précédente...

4. L'hippopotame. On trouve en France et ailleurs des dents et des fragmens de mâchoires, dans lesquels l'auteur n'a trouvé jusqu'ici rien qui diffère des hippopotames ordinaires. Comme il n'a cependant vu encore aucun os entier, il ne peut affirmer l'identité.

13 «Sur les différentes espèces de rhinocéros», Bulletin des Sciences de la Société philomatique, 1791-1798,1, 2è partie, texte de l'an 5, 1797, 17; p. 17.

14 Texte lu de même à la Société d'Histoire Naturelle, à laquelle appartenait aussi LAMARCK. 
5. L'espèce de rhinocéros à crânes allongés, que l'on trouve en Sibérie, en Allemagne et dans d'autres pays. L'auteur a vu des dents et des portions de mâchoires trouvées en France, qui lui paroissent aussi en provenir. Le principal caractère de cette espèce, consiste dans la cloison osseuse du nez; son analogue vivant est inconnu.

6. Une dent molaire, à deux éminences transversales..., ne ressemble ni aux dents, ni aux germes de dents d'aucun animal connu vivant ni fossile... Cette dent indique donc l'existence d'une sixième espèce fossile, dont l'analogue vivant est inconnu.

7. L'animal, de 12 pieds de longueur sur 6 de hauteur, dont le squelette trouvé sous terre au Paraguay, se conserve dans le cabinet du roi d'Espagne, à Madrid. L'auteur prouve, par une comparaison détaillée de ses os avec ceux de tous les quadrupèdes connus, que c'est une espèce propre et distincte...

8. L'animal dont on trouve les dépouilles dans des cavernes près de Gaylenreuth et de Muggendorf, dans le margraviat de Bayreuth en Franconie. Plusieurs l'ont regardé comme un ours marin, mais il en diffère, ainsi que de tous les ours connus...; cependant c'est des ours que cet animal se rapprochoit le plus.

9. L'animal carnassier dont on trouve des os dans la pierre à plâtre de Montmartre... Cette espèce devoit se rapporter au genre canis; cependant elle ne ressemble complètement à aucune espèce de ce genre... ${ }^{15}$

10. L'animal dont la mâchoire inférieure trouvée près de Véronne, a été regardée, par Joseph Monti, comme une portion du crâne de la vache marine; idée que tous les géologistes ont adoptée, quoiqu'elle soit contraire aux notions les plus simples de l'anatomie comparée. Cette mâchoire... a appartenu à un animal voisin, quoique différent spécifiquement, du mammouth, de l'animal de l'Ohio et de celui de Simore...

11. L'animal du genre du cerf, dont on trouve les os et les bois en Irlande, en Angleterre, à Maestricht, etc. Il est suffisamment distinct de tous les cerfs, et même de l'élan, auquel on l'a rapporté...

12. Le genre des boeufs fournit à lui seul plusieurs espèces fossiles. On trouve en Sibérie les crânes de deux, qui ont été décrits par Pallas. Il avoit rapporté les uns au Buffle ordinaire; mais depuis, il les a attribués à une espèce particulière, originaire du Thibet, nommée Arni. Le C. Cuvier prouve, par la comparaison ostéologique, que ces crânes ne proviennent point du Buffle...»

Des recherches qu'il avait entreprises depuis quelques années, Cuvier concluait: $\ll 1^{\circ}$. Qu'il n'est pas vrai de dire que les animaux du midi ont autrefois vécu dans le nord, leurs espèces n'etant pas parfaitement identiques. $2^{\circ}$. Qu'il a vécu dans toutes sortes de pays, des animaux qui n'y vivent plus aujourd'hui, et qui ne se retrouvent même nulle part dans les pays connus». Et il lançait ici de nouveau son avertissement: «Il laisse d'après cela aux géologistes à faire à leurs systèmes les changemens

15 Il s'agit en fait du palaeothérium, comme Cuvier devait le reconnaître plus tard. 
ou additions qu'ils croiront convenables pour expliquer les faits qu'il a ainsi constatés» ${ }^{16}$.

Cuvier s'affirme ainsi, dès les premières années de son arrivée à Paris, non seulement comme un maître en paléontologie des vertébrés, mais même comme le Maître d'une vision du monde. C'est lui en effet qui, l'un des premiers et le plus nettement, s'est appliqué à distinguer soigneusement les espèces fossiles d'avec les espèces existantes. Sur les onze espèces décrites dans la première partie des Recherches sur les Ossemens fossiles, «une seule», écrira-t-il, «le grand mastodonte, avoit été reconnue avant moi pour un animal perdu; deux autres, le rhinocéros et l' éléphant, avoient bien été déterminés quant au genre; mais je suis le premier qui ait montré avec quelque exactitude leurs différences spécifiques; sept... étoient entièrement inconnues avant mes recherches.... ${ }^{17}$. Les vingt-trois espèces qu'il se flatte d'avoir rétablies sont, assurera-t-il, «toutes bien certainement inconnues aujourd'hui» et «paroissent toutes avoir été détruites» ${ }^{18}$.

\section{Lamarck 1799}

Lamarck à cette date n'avait rien produit de comparable. Nommé en 1793 au Muséum, comme professeur chargé d'enseigner les Insectes et les Vers, il n'était pas à même de donner des analyses aussi détaillées que celles de Cuvier, ce qui explique sans doute qu'il accordait facilement à ce dernier accès aux matériaux qu'il possédait, comme ce fut le cas par exemple pour la Lingule ou le Sigaret ${ }^{19}$. A ce moment leur différend idéologique n'était pas encore déclaré.

Cependant Lamarck, au fur et à mesure qu'il prenait possession de son domaine, commençait aussi à affirmer sa différence. 11 mettait de l'ordre dans les Invertébrés, et il se tournait déjà vers les fossiles de ce sous-règne immense. S'il n'a pas encore publié d'études les concernant, il les a étudiés, assez du moins pour les introduire à leur place dans la classification qu'il propose dans l'ouvrage qu'il prépare, et qui paraîtra au début de 1801 sous le titre de Système des Animaux sans vertèbres.

Lamarck a déjà en effet en projet un plan général d'études, et il y introduit expressément dès le début la considération des fossiles, en soulignant l'importance épistémologique des espèces analogues. «On est à présent convaincu», assure-t-il, en réponse en quelque sorte à Cuvier, et en tout cas pour prendre date, «on est à présent

16 «Extrait d'un Mémoire sur les Ossemens fossiles de quadrupèdes», dans Bulletin des Sciences de la Sociéfé philomatique,1791-1798, 1, 2ème partie; texte de 1798, 137-139; p. 137-139.

17 Recherches sur les Ossemens fossiles de Quadrupèdes, t. 2, 1812, Résumé général, p. 2.

18 «Extrait d'un Ouvrage sur les Espèces de Quadrupèdes dont on a retrouvé les ossemens dans l'intérieur de la terre...», dans Journal de Physique, an 9, 1801, 52, 253-267; p. 261.

19 Cf. CUVIER G., Mémoires pour servir à l'histoire et à l'anatomie des Mollusques, 1817, Mémoire sur le Sigaret, p. 3, et Mémoire sur la Lingule, p. 2 (reproduction d'études réalisées ou publiées avant cette date). 
convaincu que la connoissance des coquilles est importante, non-seulement parce qu'on ne doit négliger l'étude d'aucune des productions de la nature, et que d'ailleurs la forme des coquilles est en général une indication de celle du mollusque qui l'a produite, ou de son organisation principale; mais encore qu'il est très-essentiel de rechercher et de déterminer les analogues vivans ou marins du grand nombre de coquilles fossiles qu'on trouve enfouies au milieu même de nos vastes continens. Or, les conséquences qu'on pourra tirer de ces déterminations, sont d'un si grand intérêt pour l'histoire naturelle, et sur-tout pour la théorie même du globe que nous habitons, puisqu'elles peuvent nous éclairer sur la nature des changemens qu'ont sucessivement éprouvés les différens points de sa superficie, qu'on sent que des erreurs, dans ces déterminations, seroient très-préjudiciables à nos recherches dans cette intéressante partie de l'histoire naturelle. Ce n'est donc que par la justesse des déterminations de ceux de nos coquillages vivans ou marins qui sont analogues aux fossiles de nos continens, qu'on pourra obtenir des conséquences solides et fondées sur plusieurs points importans de la théorie de notre globe. Or, l'exactitude et la justesse des déterminations dont il s'agit, dépendent nécessairement de l'étude approfondie des coquilles qui en sont l'objet; elles dépendent d'une bonne classification de ces coquilles, et ensuite d'une grande précision dans l'exposition des caractères, soit des ordres, soit des genres, soit enfin des espèces» ${ }^{20}$.

«En conséquence de ces vues, il m'a paru indispensable de donner au public, et particulièrement aux élèves qui suivent mes leçons au Muséum, des élémens de Conchyliologie, ouvrage dans lequel je compte présenter une exposition concise des principes relatifs à l'étude des coquilles, et à leur distinction en familles, genres et espèces; n'oubliant pas d'y indiquer, avec le lieu de leur habitation, les coquillages vivans ou marins qui sont véritablement analogues à certaines de nos coquilles fossiles» (p. 66-67).

\section{Cuvier 1800}

Fort de l'autorité qu'il avait déjà acquise dans le domaine de la paléontologie des vertébrés, Cuvier élargit la portée de son projet en s'adressant cette fois, à la fin de l'année 1800, à ses collègues de l'Institut. Parmi les assistants se trouvait Lamarck, qui achevait à ce moment la rédaction de son Système des Animaux sans Vertèbres, destiné à paraître au début de 1801. L'intervention de Cuvier frappa les Académiciens, qui décidèrent de la faire imprimer. Cuvier y demandait aux «amis des sciences» de l'aider: «Je ne leur demande», écrivait-il, «que ce qu'il est impossible d'obtenir autrement que de leur amitié: je veux dire des notices des os fossiles qui se trouvent dans leur possession ou à leur portée». Il n'en était pas d'ailleurs à ses débuts,

20 LamarcK J. B., «Prodrome d'une nouvelle classification des Coquilles», Mémoires de la Société d'Histoire naturelle de Paris, prairial an VII (1799), 1,63-91; p. 63-64. 
car il avait déjà obtenu de nombreuses collaborations parmi «les naturalistes étrangers les plus célèbres». Son travail était bien avancé: «J'ai déjà plus de trois cents dessins; cinquante planches sont gravées entièrement; plusieurs autres sont commencées; et je n'attends plus pour faire paroître mon livre, que les renseignemens que l'écrit actuel pourra me procurer» ${ }^{21}$. Ce qu'il sollicite, c'est évidemment les restes des fossiles qui sont désormais l'objet de ses recherches, car, rappelle-t-il, il est «plus facile d'obtenir un résultat décisif de l'examen des ossemens de quadrupèdes, que de tous les autres fossiles d'animaux» (p. 256).

Cuvier voulait de plus, devant les membres de l'Institut, élever le débat au-dessus de la simple étude de vieux ossements, aussi passionnante fût-elle. C'est toute une vision du passé de la Terre et de la Vie qu'il entendait leur proposer, et cette vision comportait comme élément principal l'affirmation du catastrophisme, mais d'un catastrophisme nouveau. Il ne se satisfait pas en effet des conceptions traditionnelles. «La question principale», proclame-t-il, est «de savoir jusqu'à quel point est allée la catastrophe qui a précédé la formation de nos continents actuels». Le problème à traiter ainsi nettement posé, il indique les documents scientifiques qui permettront de le résoudre: «Il s'agit sur-tout de rechercher si les espèces qui existoient alors ont été entièrement détruites, ou seulement si elles ont été modifiées dans leur forme, ou si elles ont simplement été transportées d'un climat dans un autre» (p. 256) ${ }^{22}$. Parmi les trois solutions présentées, dont on reconnaît la seconde pour être celle de Lamarck et la troisième, celle de Faujas et de bien d'autres, Cuvier a choisi la sienne: celle, non pas seulement de la disparition des espèces anciennes, mais de leur entière destruction. Ainsi Cuvier, dès les premiers pas de sa carrière scientifique, a résolu de prendre comme base de ses recherches paléontologiques le postulat du catastrophisme absolu. Toute sa «philosophie» s'unifie autour de cette double affirmation fondamentale de destruction totale de la Vie et de catastrophe universelle de la Terre ${ }^{23}$.

Cuvier entend d'ailleurs ne pas se laisser entrainer dans des problèmes d'origine. Après s'être demandé «comment ces êtres antiques furent-ils détruits?», et «comment ceux qui leur ont succédé furent-ils formés?», il se contente de répondre par une autre question: «La métaphysique même n'est-elle pas plus embarrassée encore par ces faits que la simple physique; et cette nouvelle production d'êtres organisés n'est-

21 «Extrait d'un Ouvrage sur les Espèces de Quadrupèdes dont on a retrouvé les ossemens dans l'intérieur de la terre... «, dans Journal de Physique, an 9, 1801, 52, p. 266-267.

22 C'est nous qui soulignons dans les deux citations, pour attirer l'attention sur l'importance que Cuvier attache alors aux implications de cette «question principale».

23 Cet appel fut répercuté en Allemagne par le Magazin für die gesammte Mineralogie, Geognosie und mineralogische Erdbeschreibung..., herausgegeben von Karl Ernst Adolph von HOFF, 1801, I Bandes, 4 Heft, Leipzig, 449-469: «Über die Arten der Sâugethiere, von welchen man Knochen im Innern der Erde findet. Eine Aufforderung des Br. Geo. CuVIER an die Gelehrten und Freunde der Wissenschaften». 
elle pas peut-être plus inconcevable que toutes les autres parties du phénomène?» ${ }^{24}$, qu'il préfère visiblement laisser sans réponse.

\section{Lamarck 1801}

Lamarck publie l'ouvrage qu'il avait projeté sur les Invertébrés: le Système des Animaux sans vertèbres. Il introduit les espèces fossiles dans la classification qu'il propose de l'ensemble des êtres de ce sous-règne. En effet, il n'en fait pas des êtres à part, et il refuse les suffixes en ites que les naturalistes précédents leur accolaient pour mieux les séparer des êtres actuels. En les intégrant dans la grande famille animale, il fait faire un grand pas épistémologique à leur systématique, et à la manière de les appréhender dans la considération générale de la nature animale et de son histoire. Lamarck veut montrer, par ce traitement des fossiles, rangés dans les mêmes catégories que les êtres actuels, qu'il a entrepris l'étude des Invertébrés fossiles en même temps que celle des êtres actuels, et non pas dans des catégories séparées. Cette manière de classer les fossiles l'a amené à changer les anciennes classifications mal faites à cause de cette manière de les nommer: «L'usage généralement établi parmi les Lithologistes et les Oryctologistes, de terminer uniformément le nom de toutes les dépouilles des corps vivans qui sont dans l'état fossile, et dans ce cas de transformer le nom de peigne en pectinite, de turbo en turbinite, etc. m'a forcé de changer les dénominations de quelques genres parmi les mollusques testacés et les polypes coralligènes, parce qu'on avoit terminé mal-à-propos leurs noms, comme s'ils s'appliquoient à des objets connus seulement dans l'état fossile, ce qui n'étoit pas ainsi» ${ }^{25}$.

Lamarck donne le classement de plusieurs dizaines d'espèces fossiles de Mollusques, d'Echinodermes et même de Polypes. Il ne les utilise cependant pas encore pour confirmer sa théorie anticatastrophiste et transformiste.

Ce ne sera que dans l'«Appendice sur les fossiles», ajouté à la fin de l'ouvrage, et non dans le traitement systématique des fossiles eux-mêmes, comme il le fera plus tard dans l'Histoire naturelle des Animaux sans vertèbres, que Lamarck entreprendra de réfuter l'argumentation cuviérienne et développera sa théorie transformiste en s'appuyant concrètement sur les fossiles.

La réfutation que Lamarck en propose est un des plus beaux exemples du genre: elle est claire, rigoureuse, et définitive. «Plusieurs naturalistes», dit Lamarck —et c'est bien évidemment, entre autres, Cuvier qui est visé ici, aucun de ceux qui utilisèrent le Système des Animaux sans Vertèbres dans leurs propres travaux sur les Invertébrés ne pouvait l'ignorer - prétendent «que tous les fossiles appartiennent à des dépouilles d'animaux ou de végétaux dont les analogues vivans n'existent plus dans la nature» ${ }^{26}$.

24 Extrait d'un Ouvrage sur les Espèces de Quadrupèdes....», Journal de Physique, 1801, 52, p. 266.

25 Système des Animaux sans vertèbres, 1801, p. VI I-VIII.

26 Ibid., p. 407; c'est nous qui soulignons, comme nous l'avons déjà fait et comme nous le ferons systématiquement dans la suite des citations des textes de LAMARCK, pour montrer l' importance que 
Ayant proclamé que toutes les espèces fossiles sont des espèces différentes des espèces actuelles, ils en ont conclu, ajoute Lamarck, «que ce globe a subi un bouleversement universel, une catastrophe générale, et qu'il en est résulté qu'une multitude d'animaux et de végétaux divers se trouvent absolument perdues ou détruites» (ibid.). C'était bien ce que Cuvier avait soutenu, et Lamarck l'avait compris: le sens dans lequel il fallait entendre le terme d'espèces «perdues» était bien celui d'espèces «détruites».

«Il est très-vrai, reconnaît Lamarck, que sur la grande quantité de coquilles fossiles recueillies dans les diverses contrées de la terre, il n'y a encore qu'un fort petit nombre d'espèces dont les analogues vivans ou marins soient connus» (p. 407-408). C'est ce qu'il concède à Cuvier.

Cela étant dit, Lamarck expose sa propre méthodologie scientifique, celle qui désormais va être à la base de sa nouvelle doctrine anticatastrophiste et transformiste, et que nous aurons à garder à l'esprit tout au long de la lecture que nous allons faire de ses travaux paléontologiques: «Néanmoins, quoique ce nombre soit fort petit, dès qu'on ne sauroit le contester, il suffit pour que l'on soit forcé de supprimer l'universalité énoncée dans la proposition citée ci-dessus» (p. 408).

Son utilisation de l'analogie demande à être précisée, et c'est ce que Lamarck entreprend de faire: «ll est bon de remarquer que parmi les coquilles fossiles dont les analogues marins ou vivans ne sont pas connus, il en est beaucoup qui ont une forme très-rapprochée de coquilles des mêmes genres que l'on connoît dans l'état marin. Cependant elles diffèrent plus ou moins, et ne peuvent rigoureusement être regardées comme les mêmes espèces que celles que l'on connoît vivantes, puisqu'elles ne leur ressemblent pas parfaitement: ce sont là, nous dit-on, des espèces perdues» (p. 408).

Toutefois cette catégorie de fossiles a sa place opératoire dans la problématique anticatastrophiste et évolutionniste de Lamarck: «Je conviens qu'il est possible qu'on ne trouve jamais parmi les coquilles fraîches ou marines des coquilles parfaitement semblables aux coquilles fossiles dont je viens de parler. Je crois en savoir la raison; je vais l'indiquer succinctement, et j'espère qu'alors on sentira que quoique beaucoup de coquilles fossiles soient différentes de toutes les coquilles marines connues, cela ne prouve nullement que les espèces de ces coquilles soient anéanties, mais seulement que ces espèces ont changé à la suite des temps, et qu'actuellement elles ont des formes différentes de celles qu'avoient les individus dont nous retrouvons les dépouilles fossiles» (p. 408-409).

Lamarck fournit l'explication de ces changements, en introduisant le concept du temps dans l'histoire de la vie: «Tout, avec le temps, y subit des mutations diverses plus ou moins promptes, selon la nature des objets et des circonstances». En effet «si...la diversité des circonstances amène, pour les êtres vivans, une diversité d'habi-

prend désormais ce concept dans tout le reste de son oeuvre - importance qu'elle gardera d'ailleurs après lui, jusqu'à aujourd'hui, dans les relations de la paléontologie et de l'évolution. 
tudes, un mode différent d'exister, et par suite, des modifications ou des développemens dans leurs organes et dans la forme de leurs parties, on doit sentir qu'insensiblement tout être vivant quelconque doit varier dans son organisation et dans ses formes. On doit encore sentir que toutes les modifications qu'il éprouvera dans son organisation et dans ses formes, par suite des circonstances qui auront influé sur cet être, se propageront par la génération, et qu'après une longue suite de siècles, nonseulement il aura pu se former de nouvelles espèces, de nouveaux genres et même de nouveaux ordres, mais que chaque espèce aura même varié nécessairement dans son organisation et dans ses formes» (p. 409-410).

Voilà le problème, tel qu'il fut exposé, par Cuvier d'abord, et par Lamarck ensuite en réponse à l'appel lancé par Cuvier. Tout est dit de la problématique paléontologieévolution, et l'on n'a rien ajouté d'essentiel depuis. Les espèces analogues, c'est-àdire les espèces fossiles plus ou moins rapprochables des espèces vivantes actuelles: voilà désormais le maître mot de recherche de Lamarck dans l'étude des espèces fossiles d'Invertébrés. Cette expression devient l'instrument épistémologique qui lui permettra en même temps de réfuter le catastrophisme de Cuvier et de fonder sa doctrine de la transformation des espèces. Il est à remarquer dès l'abord que cette notion, introduite par Lamarck dans le domaine scientifique, n'en est pas sortie depuis, et qu'elle est restée la pierre fondamentale de tout l'édifice évolutionniste.

Ces textes sont fondamentaux pour comprendre la polémique Cuvier-Lamarck, et même toute l'histoire de la Biologie du début du XIXème siècle. C'est à partir de cette date que s'ouvre la polémique qui va opposer Cuvier et Lamarck durant la période que nous étudions.

Ces bases de raisonnement étant posées, Lamarck n'a aucune difficulté à montrer qu'il y a de nombreuses espèces qui se retrouvent des deux côtés de la prétendue Catastrophe imaginée par Cuvier. Il ne nous reste plus maintenant qu'à nous plonger dans les travaux scientifiques de Lamarck, et à énumérer toutes les «pièces justificatives» qu'il y a amassées en faveur de sa doctrine - énumération peut-être longue et fastidieuse, mais dont la lecture est indispensable si l'on veut faire l'effort nécessaire pour comprendre l'histoire des relations entre la paléontologie et l'évolution dans la naissance de la théorie actuelle de l'évolution.

\section{Hydrogéologie}

Lamarck, qui a donc entrepris d'étudier les fossiles d'invertébrés des environs de Paris, et qui se dispose à les utiliser pour la démonstration de sa doctrine transformiste, entend d'abord bien définir le terme de fossile, et lui donne ainsi le sens qu'il a conservé depuis dans les travaux des paléontologistes: «Tous les naturalistes, écrit-il, connaissent ces débris très-anciens d'animaux et de végétaux qu'on trouve dans le sein de la terre et à sa surface, et qui conservent encore leur véritable forme. C'est à ces dépouilles encore reconnaissables de corps organisés que j'ai donné particuliè- 
rement le nom de fossiles; nom que l'on ne doit pas étendre indistinctement, comme le font quelques naturalistes, à toutes les substances brutes et minérales qui composent la masse, et, d'une manière plus particulière, la croûte extérieure du globe» (p. 55-56).

\section{Mémoires sur les Fossiles des environs de Paris.}

Dans ses Mémoires sur les Fossiles des environs de Paris, que nous allons maintenant passer systématiquement en revue, et qui paraissent de 1802 à 1806 dans les Annales du Muséum national d'Histoire Naturelle de Paris, Lamarck s'attache à identifier les espèces analogues fossiles et vivantes, et même à préciser les degrés de ressemblance qu'il constate entre elles. Parmi les quelques 300 espèces fossiles dont il donne la description dans ces Annales, il en signale plus d'une trentaine dont le rapprochement avec les espèces actuellement vivantes s'impose.

En publiant cette étude des fossiles, dans le tome 1 des Annales, Lamarck, dans un mot d'introduction, annonce de nouveau clairement le sens qu'il donne à ces recherches dont il souligne l'importance pour la «théorie de notre globe».

«Depuis qu'on a pensé que les coquilles, les oursins et les différens polypiers pierreux (les madrépores, etc....) qu'on trouve dans presque toutes les parties sèches de la surface du globe dans l'état fossile, pouvoient être considérés comme des monumens qui attestent les révolutions que cette surface a éprouvées dans la suite des temps; la connoissance de ces débris fossiles d'animaux marins qui paroissent avoir vécu autrefois dans les lieux mêmes où maintenant on les rencontre, est devenue d'un grand intérêt pour le naturaliste. Cette connoissance a même acquis une importance de premier ordre depuis qu'on s'est aperçu qu'elle doit répandre des lumières, soit sur la véritable théorie de notre globe, soit sur les modifications que les espèces vivantes subissent avec l'état des lieux où elles habitent» (p. 299-300). Tout est dans ces quelques phrases du grand projet de Lamarck de lutter contre le catastrophisme, et de soutenir la transformation des espèces, contre la doctrine fixiste de Cuvier. Lamarck rappelle d'ailleurs en note que, depuis quelque temps, dans d'autres ouvrages, il enseigne ces vérités fondamentales: «Dans mes Recherches sur l'organisation des corps vivans, j'ai établi sur des faits que les corps vivans subissoient des modifications dans leur forme, et même dans leur organisation, à mesure qu'ils éprouvoient des changemens forcés dans leurs habitudes, leur manière de vivre et les impressions extérieures; et j'ai fait voir qu'ils sont assujétis à ces changemens, lorsque les circonstances de leur habitation se trouvent fortement changées. J'ai ensuite fait remarquer que, relativement à la chétive durée de notre existence, la lenteur des mutations essentielles que subissent les localités, entraînant une lenteur semblable dans les modifications des corps vivans, l'homme n'a pu observer lui-même une seule de ces mutations, mais seulement une portion de l'intervalle qui sépare chacune d'elles. Il n'a donc vu qu'un état stationnaire à son égard, qui le porte à se tromper sur la consé- 
quence de ses observations» (Ibid., note (1). L'importance de la longueur de temps que fournissent les fossiles apparaît donc déjà dans son enseignement sur les fossiles.

Un des points essentiels de leur étude réside dans le fait qu'il existe des ressemblances entre les fossiles et les êtres actuels: «Il paroît maintenant prouvé que les coquilles fossiles, que les vermiculaires testacées, pareillement fossiles; en un mot, que les oursins et les différentes espèces de polypiers qu'on trouve aussi dans l'état fossile, et qui sont enfouis avec tant de profusion dans le sol, ou semés à sa surface dans la plupart des parties découvertes du globe, même au milieu des continens et sur les plus hautes montagnes, sont les débris d'une multitude d'animaux marins qui ont vécu long-temps dans ces lieux, et parmi lesquels on en connoît maintenant plusieurs qui leur sont analogues et qui habitent encore les mers» (p. 300).

L'étude de cette masse de documents sert à démontrer plusieurs vérités importantes sur le passé de la terre et sur le passé de la vie.

Tout d'abord, que la face de la terre a changé dans sa répartition des eaux et des continents. «Comme la quantité de ces débris d'animaux marins qu'on trouve dans les parties sèches du globe est énorme, puisqu'on en connoît des masses rassemblées par le mouvement des eaux, qui forment des bancs qui ont plus de trente lieues (plus de treize myriamètres ${ }^{27}$ ) d'étendue; comme ensuite parmi ces débris, certaines coquilles d'une ténuité et d'une délicatesse extrêmes se trouvent encore dans leur état d'intégrité: ces considérations paroissent suffire pour nous convaincre que les animaux dont nous retrouvons ainsi les dépouilles fossiles, ont réellement vécu dans ces parties du globe, et conséquemment que la mer y a autrefois séjourné. Voyez mon Hydrogéologie, p. 54» (p. 300-301).

Mais l'étude de ces fossiles fragiles enseigne encore la lenteur des mouvements des eaux, et donc l'anticatastrophisme: «L'intérêt s'accroît à mesure que l'on examine ces objets importans, et que l'on recherche les causes qui peuvent y avoir donné lieu; car on s'aperçoit bientôt que la connoissance des fossiles ne se borne pas à nous apprendre que la mer a séjourné pendant long-temps sur les parties du globe qui sont maintenant élevées au-dessus du niveau de ses eaux: mais en joignant cette connoissance à d'autres faits qui attestent le déplacement des mers, on sent qu'elles ne se sont retirées des lieux où elles se trouvoient, qu'en obéissant à une cause lente et toujours active, et que, par la continuité d'action de cette cause, il est probable que les parties maintenant découvertes du globe redeviendront par la suite des temps le fonds même du bassin des mers, comme elles l'ont déjà été; en sorte que le bassin actuel des eaux marines se retrouvera un jour changé en partie sèche et découverte de la terre» (p. 301). Lamarck aura bien soin de montrer, au cours de ses descriptions de fossiles, comment elles appuient cette conclusion.

\footnotetext{
271 myriamètre égale $10 \mathrm{kms}$.
} 
Mais il n'y a pas que la distribution des eaux et des continents qui a changé. En même temps, celle des climats sur la surface du globe changeait aussi: «Ce n'est pas tout: la connoissance des fossiles par différens faits importans qu'elle présente, devient encore l'indice d'un changement continuel, quoiqu'infiniment lent, qui s'opère dans les climats, relativement à chaque point de la surface du globe. En effet, parmi les débris fossiles des corps vivans que l'on trouve en Europe, il y a des preuves évidentes que plusieurs de ces corps n'ont pu exister dans un climat dont la température seroit semblable à celle des lieux où maintenant l'on rencontre ces dépouilles fossiles» (p. 301).

Et Lamarck donne déjà quelques-uns des exemples qu'il développera dans la partie «technique» de ses articles: «On sait, par exemple: $1^{\circ}$. Que des coquilles dont les analogues ne vivent point dans nos mers, mais dans celles des pays chauds, font partie des fossiles que nous observons en France. Le nautilus pompilius trouvé à Courtagnon, et même dont les débris sont assez communs à Grignon, en est une preuve. Ce n'est pas la seule qui soit dans ce cas» (p. 302). Nous trouverons bien sûr cet exemple plus loin, et bien d'autres, comme l'annonce Lamarck. Par contre les autres exemples n'apparaitront pas dans la suite des Mémoires, car ce ne sont pas des fossiles d'invertébrés.

« $2^{\circ}$.», ajoute en effet Lamarck pour la même démonstration: «Que des débris de palmiers, qui ne sont point des végétaux naturels à nos climats, ont été trouvés en France dans le département de l'Oise et en d'autres endroits. $3^{\circ}$. Que des masses de succin, qui proviennent de résines différentes de celles de nos arbres conifères, ont été trouvées près de Soissons et dans d'autres parties de la France. $4^{\circ}$. Que des masses fossiles de gomme élastique, soit du caoutchou (sic), soit de quelque autre végétal des climats chauds qui en produisent, ont été trouvées dans le Derbyshire près de Castleton en Angleterre, dans d'assez gros volumes (Voy. dans ces Annales, $\mathrm{N}^{\circ} \mathrm{IV}$, un mémoire sur le Caoutchouc fossile $)^{28} .5^{\circ}$. Que des empreintes de fougères exotiques très-multipliées se rencontrent dans nos carrières de schistes et de charbon de terre».

Lamarck utilise même les travaux de Cuvier - mais pas seulement de Cuvier, du reste - dans le sens de sa propre thèse: $« 6^{\circ}$. Enfin, que des dépôts d'ossemens fossiles, appartenans à des animaux qui, comme l'éléphant et le crocodile, n'habitent point les climats froids, ont été trouvés dans différentes parties de l'Allemagne, de la France, etc..»

Aussi Lamarck peut en conclure: «Il y a donc eu des mutations dans le climat des lieux dont il s'agit» (p. 302). Et cette conclusion est très importante pour son explication anti-catastrophiste et pro-transformiste.

Car Lamarck ne vise pas seulement Cuvier et les catastrophistes. Il essaie aussi de répondre à ceux qui considèrent que le monde actuel est immuable. «Pour l'homme

28 Lamarck renvoie à un article de FAUJAS de SAINT-FOND dans ces Annales, p. 261-272. 
qui observe, et qui, à cet égard, ne juge que d'après les changemens qu'il aperçoit luimême, les intervalles de ces mutations sont des états stationnaires qui lui paroissent sans bornes, à cause de la brièveté d'existence des individus de son espèce. Aussi, comme les fastes de ses observations, et les notes des faits qu'il a pu consigner dans ses registres, ne s'étendent et ne remontent qu'à quelques milliers d'années (trois à cinq mille ans), ce qui est une durée infiniment petite, relativement à celles qui voient s'effectuer les grands changemens que subit la surface du globe; tout lui paroît stable dans la planète qu'il habite, et il est porté à repousser les indices que des monumens entassés autour de lui, ou enfouis dans le sol qu'il foule sous ses pieds, lui présentent de toutes parts» (p. 302-303).

Pour mieux atteindre son but, Lamarck ironise même sur le peu de perspective que possèdent ceux qui refusent l'existence de grandes durées: «ll me semble entendre ces petits insectes qui ne vivent qu'une année, qui habitent quelque coin d'un bâtiment, et que l'on supposeroit occupés à consulter parmi eux la tradition, pour prononcer sur la durée de l'édifice où ils se trouvent: remontant dans leur chétive histoire jusqu'à la vingt-cinquième génération, ils décideroient unanimement que le bâtiment qui leur sert d'asile est éternel et qu'il a toujours existé; car ils l'ont toujours vu le même, et ils n'ont jamais entendu dire qu'il ait eu un commencement» (p. 303).

Ayant présenté ses principes d'études dans ce préambule, Lamarck se consacre désormais à recueillir le plus grand nombre possible de documents fossiles qui, par leur rapprochement avec des espèces vivantes, pourront recevoir la qualification d'espèces analogues, et constitueront ce qu'il appelle les «pièces justificatives» de ses théories. Un premier exemple sera celui de l'Oliva canalifera: «Ses rapports avec l'Oliva hiatula de Gmelin sont tels qu'elle semble en être l'analogue fossile, à quelque différence près» ${ }^{29}$. La conclusion, qu'il n'explicite pas pour chaque exemple, mais qui, comme nous l'avons vu, sous-tend toutes ses études sur les fossiles, est cependant exprimée de temps en temps, comme un rappel. Ainsi pour le Voluta musicalis: «J'ai plusieurs fois soupçonné que cette coquille fossile étoit l'analogue du voluta musica de Linné, un peu changé par la suite du temps; elle lui ressemble en effet à beaucoup d'égards» (p. 477).

Même lorsqu'il ne trouve pas d'espèce analogue — ce qu'il fait remarquer, le cas échéant, montrant ainsi l'importance qu'il y attache - Lamarck attire l'attention sur les conclusions anti-catastrophistes que l'étude des fossiles permet. En étudiant le Terebellum convolutum, par exemple, il observe: «Cette tarrière fossile, dont l'analogue vivant n'est pas connu, est fort commune à Grignon. C'est une coquille mince, fragile, roulée en cornet cylindracé, et qui n'offre point de véritable spire. Malgré sa

29 «Suite des Mémoires sur les fossiles des environs de Paris», Annales du Muséum national d'Histoire naturelle, 1802, 1, 383-391; p. 391. 
grande fragilité, on en trouve beaucoup d'individus entiers et de tous les âges, ce qui ne pourroit être si l'énorme quantité de coquillages marins que l'on voit à Grignon n'avoient pas vécu dans cette région et y avoient été jetés par suite de quelque grande catastrophe» (p. 390).

La comparaison des fossiles de différents pays lui permet aussi, déjà, de proposer une histoire de la terre basée sur ce qu'on appellera plus tard la paléontologie stratigraphique. «En comparant les fossiles de Courtagnon, observe-t-il, avec ceux de Grignon, ainsi qu'avec ceux que Brander a recueillis dans le Hampshire en Angleterre, on est porté à croire que les fossiles dont il s'agit appartiennent au même banc; car, à quelques espèces près, les coquilles de ces trois endroits sont toutes entièrement les mêmes.

Ce banc, qui est encaissé dans le sol et qui paroît se diriger de l'est à l'ouest, se trouve à découvert à Courtagnon, à Grignon et dans quelques autres endroits; et comme il semble se propager jusqu'en Angleterre, ce qu'indiquent les coquilles fossiles du comté de Hampshire, il y a lieu de croire qu'il a été depuis sa formation coupé et séparé par la Manche. Cette considération, si elle est fondée, nous apprend que les coquilles et autres fossiles que renferme le banc dont il est question, sont d'une formation antérieure au dernier passage de la mer sur les contrées où il existe. Ce fait est bien intéressant à remarquer, et j'ai déjà cité dans mon Hydrogéologie (p. 85 et 86), d'autres indices de coquilles fossiles qui ne peuvent appartenir au dernier séjour de la mer sur la partie du globe où on les rencontre» ${ }^{30}$.

\section{Recherches sur l'organisation des corps vivans.}

Lamarck précise comment il voit, à partir de là, l'évolution de la vie, par une divergence ramifiante des espèces: «Outre qu'à la suite de beaucoup de temps, la totalité des individus de telle espèce change comme les circonstances qui agissent sur elle, ceux de ces individus qui, par des causes particulières, sont transportés dans des situations très-différentes de celles où se trouvent encore les autres, et y éprouvent constamment d'autres influences; ceux-là, dis-je, prennent de nouvelles formes par suite d'une longue habitude de cette autre manière d'être, et alors ils constituent une nouvelle espèce, qui comprend tous les individus qui se trouvent dans la même circonstance» (p. 148).

\section{Mémoires sur les fossiles (suite).}

Dans le tome 2 des Annales, Lamarck poursuit imperturbablement son travail de recherche des espèces analogues, base scientifique, rappelons-le encore, à la fois de sa démonstration anticatastrophiste et de sa construction transformiste. Ainsi, le Pur-

30 «Mémoires sur les fossiles des environs de Paris», Annales du Muséum national d'Histoire naturelle, 1802, 1, 299-310; p. 306. 
pura lapillus, le Pourpre des teinturiers: on le trouve dans «le banc fossile de Courtagnon, où il est commun. L'analogue vivant habite nos côtes de l'Océan et celles des mers du nord de l'Europe» (p. 64). Concernant le Murex tripterus (un Rocher), Lamarck note: «Son analogue vit actuellement dans la mer des Indes orientales, dans le voisinage de Batavia. Je possède dans mon cabinet, et des individus fossiles de Grignon, et des individus frais qui proviennent de la mer des Indes» (p. 223). Le Murex cingulatus fournit le même argument: «Ce rocher, assez commun à Courtagnon, a quelque chose du murex craticulatus de Linné, dans son aspect». Cependant, Lamarck a soin de fournir les raisons pour lesquelles il ne peut le réduire à l'identité: une espèce analogue n'est pas une espèce identique. Il y a en effet des nuances entre espèce identique, espèce analogue et espèce entièrement différente, dans le cas, signalé par Lamarck lui-même, où il n'a pas encore trouvé ou reconnu, d' «analogue vivant ou fossile». Ce murex cingulatus, assure-t-il en le comparant au murex craticulatus, «est moins grand, moins chargé de varices ou de bourrelets, et les interstices de ses rides ou cordelettes transverses sont écailleux; ce qui l'en distingue fortement», et justifie donc un nom spécifique différent (p. 224). Le Murex cancellinus, un «rocher fossile, est l'analogue bien remarquable de la Grimace blanche, qu'on a regardée comme une variété du murex anus de Linné; mais cette Grimace blanche est une espèce très distincte, qui vit actuellement dans l'Océan austral» (p. 225). Le Murex pyraster, quant à lui, «se rapproche beaucoup, par ses rapports, du murex pyrum de Linné; mais outre qu'il est plus petit, il en paroît assez distinct» (p. 225).

\section{Mémoires sur les fossiles (suite).}

L'année 1804 est particulièrement riche en échanges entre les deux paléontologistes du Muséum. Elle apporte à Lamarck un grand nombre de documents fossiles à l'appui de ses théories de continuité de la vie et de transformation successive des espèces. Les Cérites, en particulier, dont il va étudier une soixantaine d'espèces fossiles dans le tome 3 des Annales, sont des documents précieux, dont il signale l'importance: «L'étude des espèces de ce genre est d'autant plus intéressante, que parmi les fossiles dont notre continent se trouve en différens lieux si abondamment rempli, un grand nombre de ces fossiles nous présente une suite considérable de cérites qu'il importe de connoître, non-seulement pour l'avancement de l'histoire naturelle, mais encore pour celui de la théorie des mutations qu'a éprouvé (sic) la surface de notre globe» (p. 270). Ainsi le Cerithium serratum: «Cette belle coquille, qui est assez commune dans l'état fossile à Courtagnon, Grignon et ailleurs, habite maintenant dans la mer du Sud, car son analogue vivant ou dans l'état marin a été découvert à l'île des Amis, pendant le voyage du capitaine Coock» (sic) (p. 271). Le Cerithium petricolum «a de si grands rapports avec le cérite cordonné Brug. dict. $\mathrm{n}^{\circ} 14$ (murex torulosa L.), qu'on pourroit soupçonner qu'elle en est un analogue trèsancien...». Cependant Lamarck l'en sépare par différents caractères (p. 351). 
Après avoir donc décrit une soixantaine d'espèces fossiles de cérites, Lamarck observe qu' «on doit être extrêmement étonné de voir dans un seul genre tant d'espèces fossiles presque toutes inconnues aux naturalistes» (et ne présentant donc pas d'espèces analogues), «et la plupart recueillies dans le même lieu. Je me suis cependant attaché dans mon travail à resserrer le nombre des espèces, en n'admettant, comme telles, que celles qui m'ont offert des distinctions très-notables. D'après cette considération, on est en quelque sorte autorisé à penser que les débris des corps marins, et sur-tout que les coquillages marins fossiles qu'on trouve sur les continens, y sont plus abondans encore que les coquillages qui vivent maintenant dans nos mers. Combien n'importe-t-il pas de considérer ces faits pour l'avancement de nos connoissances sur les révolutions lentes et successives des parties de la surface de notre globe! Voyez mon Hydrogéologie» (p. 441).

\section{Cuvier 1804}

Les deux paléontologistes suivaient évidemment de près leurs travaux réciproques sur les fossiles, d'autant plus naturellement qu'ils paraissaient dans les mêmes revues. Cette même année 1804, en effet, dans le tome 3 des Annales, à l'occasion d'une étude sur les Tapirs, Cuvier part en guerre contre les faiseurs d'hypothèses. Si l'attaque est dirigée contre Faujas de Saint-Fond — qui est souvent la cible de Cuvier à cette époque - il est clair que d'autres, et en particulier Lamarck, pouvaient se sentir visés. «Voici, écrit Cuvier, un animal fossile qui, s'il existe encore vivant aujourd'hui, ne peut être que dans l'Amérique méridionale. Il est clair que toutes les hypothèses fondées sur l'origine asiatique de nos fossiles» (c'était l'hypothèse de Faujas) «sont détruites par là; et je crois que dans l'état actuel de la géologie, ce qu'on peut faire de plus utile pour elle, est de porter ainsi la pierre de touche sur les systèmes de ceux qui croyent avoir tout expliqué, lorsqu'ils n'ont fait simplement qu'oublier la plupart des faits qui demandoient une explication; c'est à ceux qui n'expliquent rien qu'on peut s'en fier, pour rappeler aux autres toute l'étendue de leur tâche» ${ }^{31}$ »

\section{Lamarck 1804 Mémoires sur les fossiles (suite)}

Dans le tome 4 des Annales de la même année 1804, Lamarck fournit encore d'autres exemples d'espèces analogues actuelles et fossiles, et par conséquent d'autres «pièces justificatives» de sa doctrine anticatastrophiste et évolutionniste. Ainsi le Trochus crenularis, qui permet un rapprochement significatif entre deux espèces, l'une vivante, l'autre fossile: «Il a de si grands rapports avec le trochus mauritianus de Gmelin... que je crois qu'il n'en est qu'une variété de l'analogue dans l'état fossi-

\footnotetext{
31 «Sur quelques dents et os trouvés en France qui paroissent avoir appartenu à des animaux du genre du Tapir», Annales du Muséum national d'Histoire naturelle, 1804, 3, 132-143; p. 138. Conseil sage et savoureux !...
} 
le» (p. 48). Il en est de même pour le Trochus agglutinans: «Cette coquille est nonseulement une véritable fripière fossile, mais ce n'est même réellement qu'une médiocre variété de la fripière ordinaire, c'est-à-dire, du trochus conchyliophorus de Borne.... qui vit actuellement dans les mers de l'Amérique méridionale» (p. 51). Le Turbo helicinoïdes, de son côté, «ressemble tellement au trochus vestiarius de Linné par son aspect, qu'on pourroit soupçonner qu'elle n'est qu'une variété de son analogue dans l'état fossile» (p. 107). Le Turbo denticulatus «se rapproche un peu du turbo rugosus de Linné» (p. 107). Dans le cas du Turitella imbricataria, Lamarck trouve qu' «il y a beaucoup d'apparence que c'est l'analogue fossile du turbo imbricatus de Linné (la vis marbrée) qui vit maintenant dans les mers des Antilles. Cependant j'ai changé la terminaison de son nom spécifique, parce que comme ses stries sont plus marquées que celle du turbo imbricatus, je n'ose assurer que ce soit parfaitement la même espèce» (p. 216). Le Bulla striatella «a de si grands rapports avec la bulle de Ceylan de Bruguière, que je soupçonne qu'elle en est l'analogue fossile» (p. 221).

En ce qui concerne les Bulimes, parmi «les espèces fossiles ou qui paroissent l'être», Lamarck a reçu un «individu fossile... communiqué par M. de Thury; j'en possède d'autres dans l'état frais et qui paroissent en être les analogues» (p. 291).

Les genres qui ne fournissent que peu d'espèces fossiles anciennes ne semblent pas passionner Lamarck, pas plus qu'elles ne semblaient intéresser Cuvier... «On ne connoît dans l'état fossile que très-peu de lymnées. Ces fossiles ne présentent d'ailleurs qu'un médiocre intérêt, parce qu'on ne peut les considérer comme des monumens des révolutions du globe, ni même comme des restes bien anciens des animaux qui les ont formés» (p. 298).

\section{Cuvier 1804}

Dans le tome suivant, le tome 5 des Annales, Cuvier poursuit de son côté sa recherche d'espèces non-analogues. En conclusion de son étude sur le petit hippopotame fossile, par exemple, il écrit: «Voilà donc encore une espèce bien évidemment distincte de toutes celles que l'on connoît à la surface du globe; on pourroit m'objecter ici, comme pour plusieurs autres, que je compose peut-être un édifice dont les parties n'étoient point destinées par la nature à être rapprochées; que c'est des os de plusieurs animaux mêlés confusément dans ces blocs que je forme un animal imaginaire; mais ma réponse est toujours prête. Je ne m'arrêterai point à montrer les rapports naturels de ces divers os, ni à prouver que leur ensemble s'accorde parfaitement avec les lois qui président à l'organisation des animaux; je m'en tiens à cet argument invincible: c'est que chaque os, considéré séparément, diffère de ceux de tous les animaux connus; que ce n'est point sur leurs combinaisons que j'établis mes caractè- 
res, et que si par hasard on pensoit que j'en ai réuni d'espèces différentes, on ne feroit qu'augmenter le nombre des espèces fossiles qui ne se retrouvent pas vivantes $»^{32}$.

\section{Lamarck 1804 Mémoires sur les fossiles (suite)}

Dans le même tome 5 des Annales de 1804, Lamarck est au contraire très heureux de présenter un cas exemplaire d'espèce «analogue». Un Céphalopode actuel et fossile bien connu, le Nautilus pompilius, fournit un argument très probant de sa théorie: «Cette espèce, que l'on trouve en France dans l'état fossile, conservant encore parfaitement sa nacre avec de belles couleurs irisées, est véritablement la même que celle qui vit actuellement dans les mers des Indes, et qui depuis long-temps est connue des naturalistes $»^{33}$. Lamarck fait remarquer l'intérêt de tels rapprochements: «Ce fait, parmi beaucoup d'autres semblables, est extrêmement important pour la géologie», ne manque-t-il pas en effet de souligner. (Ibid.). Lamarck va redonner cette remarque dans son dernier volume de l'Histoire naturelle des Animaux sans vertèbres, en 1822, t.7, p. 634, pour bien montrer l'importance qu'il y attache.

Dans toutes les considérations que Lamarck fera sur les rapprochements à opérer entre les espèces, et les dénominations spécifiques à leur attribuer, il sera nécessaire de garder en mémoire l'avertissement qu'il formule dans un autre article en 1804: «Au reste, à l'égard des productions naturelles que nous observons, ce que nous pouvons établir de positif, ce sont les différences plus ou moins grandes qui les distinguent; mais quant à nos déterminations soit d'espèces, soit de variétés par rapport à elles, il devient tous les jours de plus en plus évident qu'elles sont parfaitement arbitraires» ${ }^{34}$.

\section{Cuvier 1804}

Dans ce même tome 5 des Annales de 1804, où Lamarck avait présenté le cas qu'il trouvait si exemplaire du Nautilus pompilius, Cuvier raconte, dans un Mémoire célèbre, comment il a mis au jour un animal fossile du genre des sarigues qui n' a pas d'analogue vivant. Il redit son hostilité aux théories que Lamarck venait de développer quelques pages plus haut: «Je ne m'étendrai point, proclame Cuvier, sur les conséquences géologiques de ce Mémoire: il est évident pour tous ceux qui sont un peu au fait des systèmes relatifs à la théorie de la terre, qu'il les renverse presque tous dans ce qui concerne les animaux fossiles... Dans la persuasion où je suis de la futilité de tous ces systèmes, je me trouve heureux chaque fois qu'un fait bien constaté

32 «Sur les ossemens fossiles d'hippopotame», Annales du Muséum national d'Histoire naturelle, 1804, 5,99-122; p. 122.

33 «Suite des Mémoires sur les fossiles des environs de Paris», Annales du Muséum national d'Histoire naturelle, 1804, 5, 179-188; p. 181.

34 «Mémoire sur deux espèces nouvelles de Volutes des mers de la Nouvelle-Hollande», Annales du Muséum national d'Histoire naturelle, 1804, 5, 154-160; p. 160. 
vient en détruire quelqu'un; le plus grand service qu'on puisse rendre à la science est d'y faire place nette avant d'y rien construire, de commencer par raser tous ces édifices fantastiques qui en hérissent les avenues, et qui empêchent de s'y engager tous ceux à qui les sciences exactes ont donné l'heureuse habitude de ne se rendre qu'à l'évidence; ou du moins de classer les propositions d'après le degré de leur probabilité: avec cette dernière précaution, il n'est aucune science qui ne puisse devenir presque géométrique: les chimistes l'ont prouvé dans ces derniers temps pour la leur; et j'espère que le temps n'est pas éloigné où l'on en dira autant des anatomistes» ${ }^{35}$.

La même année encore, 1804, Cuvier, dans un des rares articles qu'il ait écrits sur des Invertébrés fossiles, assurait, en étudiant un fossile de Nummulaire (un Foraminifère): «Au reste, il en est de ce fossile comme de tous ceux qui l'égalent en antiquité: heureux quand on en retrouve le genre dans la nature actuelle, l'espèce ne se retrouve jamais $»^{36}$.

\section{Lamarck 1805}

Malgré les attaques de Cuvier, Lamarck continue encore en 1805, dans le tome 6 des Annales, à rechercher des appuis fossiles pour rendre sa théorie de plus en plus solide et riche en arguments paléontologiques. Les récoltes faites par Péron dans les mers australes lui fournissent le sujet d'une nouvelle intervention pour prouver que les mers et les climats ont changé au cours des âges, et qu'ils ont donc pu entraîner des modifications dans les espèces d'invertébrés. «Parmi les coquilles marines fossiles que l'on trouve si abondamment en France, fait-il remarquer de nouveau, déjà un grand nombre d'entre elles sont reconnues pour les analogues (c'est toujours nous qui soulignons, pour montrer la continuité et la prégnance du raisonnement) des coquilles qui vivent actuellement dans les pays chauds, et qu'on ne peut rencontrer que là, parce que ces coquillages vivans ne sauroient plus habiter dans nos mers» ${ }^{37}$. Et Lamarck cite de nouveau les exemples de fossiles qui lui sont chers: «N'est-il pas remarquable de trouver, parmi les fossiles de la France le nautilus pompilius Lin., qui ne vit actuellement que dans la mer des Indes et dans celle qui baigne les Moluques? De rencontrer en abondance aux environs de Bordeaux, parmi les fossiles, le murex spirillus Lin., qui vit maintenant sur la côte de Tranquebar? D'observer aux environs de Paris, dans l'état fossile, le cerithium hexagonum, Brug. dict. $\mathrm{n}^{\circ} 31$, et le cerithium

35 «Sur le squelette presque entier d'un petit quadrupède du genre des Sarigues, trouvé dans la pierre à plâtre des environs de Paris», Annales du Muséum national d'Histoire naturelle, 1804, 5, 277-292; p. 292.

36 «Sur les animaux auxquels appartenoient les pierres dites Nummulaires ou Lenticulaires, et sur ceux des cornes d'Ammon», Bulletin des Sciences par la Société philomatique, Vendémiaire an 13 (septembre-octobre 1804), 3, 237-238; p. 237.

37 «Considérations sur quelques faits applicables à la théorie du globe, observés par M. Péron dans son voyage aux Terres australes, et sur quelques questions géologiques qui naissent de la connoissance de ces faits», Annales du Muséum national d'Histoire naturelle, 1805, 6, 26-52, p. 46. 
serratum, Brug. dict. $\mathrm{n}^{\circ} 15$; les mêmes espèces que le capitaine Cook, dans ses voyages, a rencontrées vivantes dans la mer du Sud, à l'île des Amis? De trouver trèsabondant, parmi les fossiles de Bordeaux, le trochus conchyliophorus qu'on nous apporte vivant ou dans l'état frais, des mers de l'Amérique australe? De voir le murex tripterus, fossile si commun à Grignon près Paris, et qui nous arrive dans l'état frais de la mer des Indes? Enfin, d'en rencontrer bien d'autres dans le même cas, que les bornes de cet écrit ne me permettent pas de citer?» (p. 46-47).

Alors, s'exclame Lamarck, «Si ces faits ne sont pas décisifs sur la question relative à l'instabilité des climats; si les observations qui prouvent que les animaux dont je viens de parler ne peuvent subsister que dans des mers plus chaudes que ne le sont actuellement les nôtres, et que cependant ils ont long-temps vécu dans une mer qui couvroit autrefois le pays que nous habitons aujourd'hui: si ces observations ne mettent pas en évidence les changemens qu'a subis notre climat, j'oserai assurer qu'il n'y a rien de prouvé dans les sciences physiques» (p. 47).

De plus, et ceci directement contre Cuvier: «Quant aux masses madréporiques observées dans diverses parties de la France, elles attestent que la présence de la mer dans les lieux où nous les rencontrons, n'y a pas eu lieu par l'effet violent et passager d'une catastrophe universelle; une pareille cause ne pouvant donner à ses effets la durée nécessaire à la production des masses madréporiques dont il s'agit. Enfin leur adhérence et leur enchâssement dans les roches dont elles constituent souvent la principale partie, prouvent que ces polypiers ne se trouvent pas en France par les suites d'un transport violent ou d'un bouleversement quelconque» (p. 47-48).

\section{Mémoires sur les fossiles (suite)}

Ayant rappelé à ses lecteurs le sens de ses études sur les fossiles, Lamarck peut continuer de nouveau à leur exposer, dans ce tome 6 des Annales, le résultat de ses recherches, qui sont, rappelons-le de nouveau et toujours, les «pièces justificatives» des implications qu'il en tire. Le Mytilus rimosus est une «moule fossile» qui «ressemble presqu'entièrement par sa forme et son aspect au mytilus ungulatus de Linné» (p. 120). La même sorte d'observation peut se faire pour le Modiola subcarinata: «Cette modiole fossile a tellement l'aspect et les principaux caractères du mytilus modiolus de Linné, qu'on peut penser qu'elle en est véritablement l'analogue» (p. 123). De même pour le Nucula margaritacea: «cette nucule, qu'on trouve en France dans l'état fossile, est parfaitement la même que l'espèce connue que Linné a nommée arca nucleus, qui vit dans les mers du Nord, et que l'on trouve aussi sur les côtes de l'île de Saint-Domingue. Elle est peut-être du nombre de ces productions de la nature qui sont en quelque sorte orbicoles» (p. 125). L'arca barbatula, «arche fossile, fort commune à Grignon, semble être le type de l'arca barbata de Linné, que le temps et les circonstances d'habitation auroient un peu changée» (p. 220). Comme on le voit, Lamarck prend soin de rappeler de temps en temps la manière dont il conçoit 
les attributions d'analogie qu'il confère aux espèces qu'il étudie. «La détermination des caractères, insiste-t-il, soit génériques, soit spécifiques, des animaux dont on trouve des débris fossiles dans presque toutes les parties sèches des continens et des grandes îles de notre globe, seroit, sous plusieurs rapports, une chose extrêmement utile au progrès de l'histoire naturelle. D'abord, plus cette détermination sera avancée, plus elle concourra à compléter nos connoissances à l'égard des espèces qui existent dans la nature et de celles qui y ont existé, s'il est vrai qu'il y en ait de perdues comme on est fondé à le croire, au moins relativement aux grands animaux. Ensuite cette même détermination sera singulièrement avantageuse à l'avancement de la géologie; car les débris fossiles dont il est ici question peuvent être considérés, par leur nature, leur état et leur situation, comme des monumens authentiques des révolutions qu'a subi (sic) la surface de notre globe, et ils peuvent nous éclairer solidement sur l'espèce et le caractère de ces révolutions» (p. 222).

Le Cuculloea crassatina fournit encore un autre exemple: «Cette cucullée fossile ressemble beaucoup par sa forme générale et sa grosseur à la cucullée auriculifère, qui est l'espèce que l'on connoît vivante; mais la fossile est beaucoup plus épaisse» (p. 338).

Lamarck intègre même tellement les espèces fossiles aux espèces actuelles qu'il n'hésite pas à prendre une espèce fossile comme «type» d'un genre contenant aussi des espèces actuelles. Ainsi en ce qui concerne le Crassatella tumida: «C'est d'après cette belle crassatelle que j'ai établi le caractère du genre. Elle n'est pas rare à Grignon». Ce genre renferme donc des espèces vivantes, parmi lesquelles Lamarck observe des espèces analogues justement à cette Crassatella tumida: «Cette coquille de Grignon ressemble tellement à la Crassatella kingicola que l'on pourroit regarder celle-ci comme en étant l'analogue vivant»; ou encore la Crassatella sulcata: cette «crassatelle sillonnée, rapportée par M. Péron des mers voisines de la NouvelleHollande, ressemble, par tous ses caractères, aux individus fossiles que je viens de mentionner; mais elle est plus grande, sa longueur étant de 5 centimètres et sa largeur de 6: en sorte que la coquille citée de M. Péron me paroît entièrement l'analogue vivant des individus fossiles de la même espèce que l'on trouve près de Beauvais» (p. 408-409).

\section{Cuvier 1805}

La même année 1805, dans son Cours au Collège de France, Cuvier ne manque pas de mettre en garde ses étudiants — ce sont pour un certain nombre les mêmes que ceux qui suivent les cours de Lamarck - contre ceux qu'il appelle, comme nous l'avons vu, les «faiseurs de systèmes»: «ces systèmes, assure-t-il, ne sont appuyés sur rien», et il ne les rapporte «que pour effrayer et dégoûter ses auditeurs de l'esprit de système». «Toutes les recherches sur l'origine du globe, ajoute-t-il, sont des questions purement oiseuses qui ne peuvent produire que des conjectures». Il entend inculquer 
à ses auditeurs son propre point de vue sur l'histoire de la terre: «Toutes les causes lentes sont insuffisantes pour expliquer la formation des couches». Leur état actuel «annonce des changements subits qu'on peut même considérer comme séparés de ceux de leur première formation» ${ }^{38}$.

\section{6}

Profitant d'une étude sur des rhinocéros fossiles, Cuvier rappelle de nouveau ses objectifs: montrer qu'il n' y a pas d'espèces analogues fossiles et actuelles, et qu'il n'y a pas de transformation des êtres: «Une grande espèce de quadrupède, inconnue aujourd'hui, se trouve donc ensevelie dans une infinité d'endroits de l'Europe et de l'Asie; et ce qui est bien remarquable, elle n'y a pas été apportée de loin, et ce n'est pas par des changemens lents et insensibles, mais par une révolution subite, qu'elle a cessé d'y vivre» ${ }^{39}$.

\section{Lamarck 1806 Mémoires sur les fossiles (suite).}

Lamarck poursuit aussi, en 1806, dans le tome 7 des Annales, ses travaux dans le même esprit que celui qui présidait à ses recherches. La Cytheroea nitidula est une «coquille fossile (qui) a les plus grands rapports avec la venus loeta de Linneus» ${ }^{40}$. La Cytheroea elegans en a avec une autre que l'on trouve près de Bordeaux: «l'une et l'autre semblent n'être que des variétés de la venus erycina de Linné, qui vit dans l'Inde» (p. 135). La Tellina patellaris est une «belle et assez grande espèce, qui se rapproche beaucoup par ses rapports de la tellina remies de Linné, mais qui s'en distingue... Néanmoins elle n'en est peut-être qu'une variété» (p. 232). On voit que Lamarck observe consciencieusement chaque coquille actuelle et fossile, hésitant parfois à se prononcer nettement sur la qualité et le degré de l'analogie. Ainsi pour la Tellina sinuata: «La telline lacuneuse figurée dans l'Encyclopédie (voyez Mollusques testacés, planche 290, f. 14), est plus grande, à sinus du côté antérieur plus profond, et à stries transversales plus grossières. Notre coquille fossile en est-elle suffisamment distincte?» (p. 233). Ou encore: «On trouve aux environs de Dax une jolie telline fossile qui semble n'être qu'une variété de la tellina virgata: néanmoins comme elle est plus aplatie et qu'elle présente quelques autres différences, je l'en distinguerai, et en traiterai ailleurs sous le nom de tellina zonaria» (p. 235). Il est évident cependant qu'elle rentre dans la catégorie des espèces analogues. Le cas de la Lucina

\footnotetext{
38 GRANCHAMP Ph. (1994), «Deux exposés des doctrines de CUVIER antérieurs au «Discours préliminaire»: les cours de Géologie professés au Collège de France en 1805 et 1808», Travaux du Comité français d'Histoire de la Géologie, 3ème série, VIII, 13-26; p. 16.

39 «Sur les rhinocéros fossiles», Annales du Muséum national d'Histoire naturelle, 1806, 7, 19-52; p. 50 .

40 «Suite des Mémoires sur les fossiles des environs de Paris», Annales du Muséum national d'Histoire naturelle, 1806, 7, 130-140; p. 134.
} 
divaricata est par contre beaucoup moins problématique: «Cette lucine fossile est incontestablement l'analogue de l'espèce actuellement vivante que Linné a nommée tellina divaricata, mais qui ne peut être une telline» (p. 239). Il n'y a pas non plus de problème pour le Solen vagina: «Le solen fossile dont il s'agit est en tout exactement l'analogue de l'espèce vivant actuellement et que Linné a nommée solen vagina. La seule remarque que l'on puisse faire à cet égard, c'est que les individus fossiles les plus grands n'avoient pas plus de 3 pouces de longueur. On sait que le solen vagina vivant se trouve dans les mers de l'Europe..., mais on le trouve aussi dans la mer des Indes» (p. 423-424). Le cas du Solen fragilis est un peu plus douteux: «Il est possible que ce solen fossile soit l'analogue du solen cultellus de Linné, que l'on connoît dans l'état vivant, et qui se trouve dans la mer de l'Inde et des Moluques» (p. 424). Par contre le cas du Solen strigilatus se règle sans trop d'hésitations: «Ce solen fossile que l'on trouve près de Paris et aux environs de Bordeaux, est l'analogue du solen strigilatus de Linné, qui vit actuellement au Sénégal, au Brésil et dans la Méditerranée; c'est au moins l'analogue d'une des variétés de cette espèce» (p. 424).

La même année 1806, Lamarck continue à faire paraître ses recherches dans le tome 8 des Annales. L'Ostrea bellovacina présente des caractères d'analogie, mais avec un certain éloignement: «Cette huître paroît très-voisine de l' ostrea edulis, et l'on pourroit croire au premier aspect qu'elle n'en est qu'une variété». Cependant certains caractères l'en écartent un peu ${ }^{41}$. La Lima bulloides par contre a de plus grands rapports avec son analogue vivante: «Cette petite lime (de Grignon) n'a que 7 à 8 millimètres de longueur, et malgré sa petitesse, ses rapports avec la lime bullée sont si nombreux, qu'on peut soupçonner qu'elle en est l'analogue, ou au moins une variété particulière» (p. 463). Il en est de même pour la Lima obliqua, qui se trouve aussi à Grignon et qui la suit dans la classification: «Cette lime n'est pas beaucoup plus grande que celle qui précède; mais, en petit, elle ressemble tellement à notre lima inflata, qui est l'ostrea hians de Gmelin, qu'on peut penser qu'elle en est l'analogue fossile très-jeune» (p. 464). Le gisement de Grignon fournit ainsi beaucoup d'exemples de fossiles analogues à des espèces actuelles vivant dans des mers très éloignées de cet endroit. Ainsi encore pour la Lima fragilis: «Je possède une lime recueillie dans l'état frais ou vivant, par M. de Labillardière, dans les mers voisines de la Nouvelle-Hollande, et qui me paroît ressembler entièrement au pecten fragilis de Chemnitz (Conch., vol.7, p. 349). La lime fossile dont il s'agit ici, et que j'ai trouvée à Grignon, est en tout semblable à celle que j'ai reçue de $\mathrm{M}$. de Labillardière, mais elle est beaucoup plus petite. Ainsi voilà parmi les fossiles de Grignon encore l'analogue d'une espèce qui vit actuellement dans la mer des Indes et près de la Nouvelle-Hollande» (p. 464).

41 «Suite des Mémoires sur les fossiles des environs de Paris», Annales du Muséum national d'Histoire naturelle, 1806, 8, 156-166; p. 159. 
Comme on l'a vu, dans les comparaisons que Lamarck opère entre les espèces, la qualification d'analogues convient parfaitement pour un certain nombre d'entre elles, dans la mesure où elles présentent, à côté de grandes ressemblances, un certain nombre de caractères distincts. L'analogie conduit là bien près de l'identité, mais sans qu'on puisse l'établir véritablement.

Il y a d'autres espèces que Lamarck range, non parmi les «analogues» proprement dites, mais parmi les «variétés» des espèces actuelles (ou inversement), voulant marquer, à travers une parenté certaine, un certain éloignement des formes qui va parfois au-delà des limites de l'espèce.

Il existe aussi de nombreux cas où l'analogie se confond visiblement avec l'identité dans l'esprit de Lamarck, bien que le recouvrement des deux concepts n'apparaisse pas toujours dans son vocabulaire. Il existe, en effet, des espèces fossiles et actuelles que l'on ne peut pratiquement pas distinguer les unes des autres. Si Lamarck nuance parfois son jugement, et définit certaines espèces, nous l'avons vu, non pas comme plus ou moins, ou tout à fait, analogues, mais comme des variétés de l'espèce vivante, cependant, en définitive, c'est bien un lien direct entre les espèces qu'il entend affirmer quand il souligne leur analogie.

Le vocabulaire n'était pas encore bien défini à son époque, et il ne le sera qu'avec Defrance, en 1824: «On est forcé, écrit ce dernier, de reconnoître l'identité de certaines espèces fossiles avec les vivantes. Dans d'autres cas, on ne trouve que de l'analogie; enfin il en est où ces rapports sont encore plus éloignés. Pour exprimer ces trois circonstances, je me suis servi des mots identique, analogue et subanalogue dans les observations consignées dans le tableau qui termine ce travail...» ${ }^{42}$. L'année suivante, de Blainville, traitant du même sujet des rapprochements des espèces vivantes et fossiles - après avoir remarqué qu'il y avait encore beaucoup de confusion dans le vocabulaire employé- consacre cette définition et propose la même distinction, toute naturelle apparemment, d'espèces identiques et d'espèces analogues, et même subanalogues ${ }^{43}$.

Ce concept d'espèces analogues, qui devient si important entre les mains de Lamarck, n'est d'ailleurs pas un concept nouveau. Il avait été perçu au XVlllème siècle, comme bien d'autres concepts, du reste —que l'on pense seulement à celui de Transformisme- mais c'est Lamarck qui le rend opératoire, et c'est aussi à ce moment que l'on se rend compte de son existence. Le Dictionnaire des Sciences Naturelles (1816), par exemple, l'ignore, et il n'apparaît que dans le Dictionnaire Classique d'Histoire Naturelle, où Constant Prévost, en 1822, en souligne nettement l'existence et l'intérêt ${ }^{44}$. Le concept d'espèce analogue prend alors la signification d'espèce non-

\footnotetext{
42 Defrance, J. (1824), Tableau des Corps organisés fossiles, Paris, p. 63.

43 Blainville H. de (1825), Manuel de Malacologie et de Conchyliologie, Paris, p. 242-243.

44 PrÉvost, C. (1822), Art. «Analogues», dans op. cit., t.1, p. 316.
} 
perdue, et, par ce fait, signifie que tout l'édifice qui a été bâti sur l'existence des espèces perdues, le Catastrophisme, est un édifice menacé dans sa base.

\section{Cuvier 1806}

Cuvier répond à Lamarck dans le même tome 8 des Annales de 1806. Dans une étude sur les éléphants fossiles, il réaffirme la réalité des catastrophes destructrices et l'impossibilité des mutations d'espèces: «Tout paroît donc annoncer que la cause qui les a enfouis est l'une des plus récentes qui aient contribué à changer la surface du globe. C'est néanmoins une cause physique et générale... ${ }^{45}$.

«Ils n'ont pu donc y disparoître que par une révolution qui a fait périr tous les individus existans alors, ou par un changement de climat qui les a empêché de s'y propager. Mais quelle qu'ait été cette cause, elle a dû être subite.... Ainsi toutes les hypothèses d'un refroidissement graduel de la terre ou d'une variation lente, soit dans l'inclinaison, soit dans la position de l'axe du globe, tombent d'elles-mêmes. Si les éléphans actuels des Indes étoient les descendans de ces anciens éléphans qui se seroient réfugiés dans leur climat d'aujourd'hui, lors de la catastrophe qui les détruisit dans les autres, il seroit impossible d'expliquer pourquoi leur espèce a été détruite en Amérique, où l'on trouve encore des débris qui prouvent qu'ils y ont existé autrefois... Les divers mastodontes, le tapir gigantesque et le rhinocéros fossile vivoient dans les mêmes pays, dans les mêmes cantons que les éléphans fossiles, puisqu'on trouve leurs os dans les mêmes couches et dans le même état. On ne peut imaginer une cause qui auroit fait périr les uns en épargnant les autres. Cependant ces premiers animaux n'existent bien certainement plus, et il ne peut y avoir à leur égard aucune contestation, ainsi que nous le montrons à leurs chapitres. Tout se réunit donc pour faire penser que l'éléphant fossile est, comme eux, d'une espèce éteinte, quoiqu'il ressemble, plus qu'eux à l'une des espèces aujourd'hui existantes « (p. 268-269).

Cuvier le rappelle encore dans son article sur le grand mastodonte: «Nonseulement c'est ici le plus grand de tous les animaux fossiles; c'est encore le premier qui ait convaincu les naturalistes qu'il pouvoit y avoir des espèces détruites».

«De toute cette description il résulte:....que...il n'y a pas la moindre preuve, le moindre témoignage, propre à faire croire qu'il y en ait encore, ni en Amérique, ni ailleurs, aucun individu vivant» ${ }^{46}$.

Et, dans le «Résumé général de l'Histoire des ossemens fossiles de pachydermes des terrains meubles et d'alluvion», Cuvier met pour ainsi dire les points sur les i, et affirme de nouveau sa théorie des catastrophes dévastatrices: «Quant au résultat géologique, il consiste principalement dans les remarques suivantes... Il est donc proba-

45 «Suite du Mémoire sur les Eléphans vivans et fossiles», Annales du Muséum national d'Histoire naturelle, 1806, 8, 249-269; p. 265-266.

46 «Sur le grand mastodonte», Annales du Muséum national d'Histoire naturelle, 1806, 8, 270-312; p. $270 ; 311-312$. 
ble que ces ossemens ont été enveloppés par la dernière ou l'une des dernières catastrophes du globe.... La catastrophe qui les a recouverts étoit donc une grande inondation marine, mais passagère.... Avant cette catastrophe, ces animaux vivoient donc dans les climats où l'on déterre aujourd'hui leurs os; c'est cette catastrophe qui les y a détruits, et comme on ne les retrouve plus ailleurs, il faut bien qu'elle en ait anéanti les espèces.

Néanmoins, rien n'autorise à croire que les espèces de la zone torride descendent de ces anciens animaux du Nord qui se seroient graduellement ou subitement transportés vers l'équateur. Elles ne sont pas les mêmes; et nous verrons, par l'examen des plus anciennes momies, qu'aucun fait constaté n'autorise à croire à des changemens aussi grands que ceux qu'il faudroit supposer pour une semblable transformation, surtout dans des animaux sauvages ${ }^{47}$.

Le débat est donc lancé, dans les années 1801 à 1806, entre Lamarck et Cuvier, sur les deux points du catastrophisme et du transformisme, et désormais les arguments vont continuer à se répondre. Cuvier ne se laisse pas impressionner par les arguments de Lamarck tirés des invertébrés fossiles. Il leur oppose les fossiles de vertébrés, beaucoup plus probants à ses yeux. Ses travaux ultérieurs sont marqués par sa volonté de donner une base de plus en plus solide à ses affirmations, et de ruiner celles de Lamarck. Lamarck, du reste, manifeste aussi la même volonté face à celui qui est devenu maintenant son principal adversaire.

En 1806, Lamarck rassemble ses articles paléontologiques dans un ouvrage unique: Mémoires sur les fossiles des environs de Paris, qui est en fait, comme le soulignera le paléontologiste américain Packard, «le premier ouvrage véritablement scientifique de paléontologie à paraitre» ${ }^{48}$, Cuvier, imitant Lamarck, ne devant réunir ses articles déjà parus sur les fossiles de Vertébrés qu'en 1812, dans ses Recherches sur les Ossemens fossiles de Quadrupèdes. Lamarck continue bien sûr à travailler sur les invertébrés fossiles, mais, à part quelques articles, l'essentiel de ses travaux ne paraîtra que dans son grand ouvrage Histoire naturelle des Animaux sans vertèbres, en 7 tomes, de 1815 à 1822.

\section{Cuvier 1807}

Cuvier poursuit par contre, dans le tome 9 des Annales, ses livraisons d'études sur les fossiles, avec les mêmes réflexions qu'il continue à rappeler, par exemple à propos des Oiseaux: «C'est bien assez d'avoir montré l'existence de la classe des oiseaux parmi les fossiles, et d'avoir prouvé par-là qu'à cette époque reculée où les espèces étoient si différentes de celles que nous voyons maintenant, les lois générales de co-

\footnotetext{
47 «Résumé général de l'Histoire des ossemens fossiles de pachydermes des terrains meubles et d'alluvion», Annales du Muséum national d'Histoire naturelle, 1806, 8, 420-424; p. 422-424.

48 PACKARD, A.S. (1901), Lamarck, the Founder of Evolution, London, p. 134-135.
} 
existence, de structure, enfin tout ce qui s'élève au-dessus des simples rapports spécifiques, tout ce qui tient à la nature même des organes et à leurs fonctions essentielles, étoient les mêmes (que) de nos jours.

On voit en effet que dès-lors les proportions des parties, la longueur des ailes, celle des pieds, les articulations des doigts, les formes et le nombre des vertèbres, dans les oiseaux comme dans les quadrupèdes, et chez ceux-ci le nombre, la forme, la position respective des dents, étoient soumises (sic) aux grandes règles tellement établies par la nature des choses, que nous les déduisons presque autant du raisonnement que de l'observation. Rien n'a été allongé, raccourci, modifié, ni par les causes extérieures, ni par la volonté intérieure; ce qui a changé a changé subitement, et n'a laissé que ses débris pour traces de son ancien état» ${ }^{49}$.

Dans le tome 10 des Annales de la même année, dans un premier article sur les crocodiles, il rappelle son principe de séparation des espèces: «Nous voilà loin, assure-t-il, de l'époque où les plus grands naturalistes n'admettoient qu'une seule espèce de crocodile; il faudra en inscrire maintenant douze et peut-être quinze dans le catalogue des reptiles» ${ }^{50}$.

\section{8}

Cuvier, dans le tome 12 des Annales, poursuit son étude sur les crocodiles, fossiles cette fois. «Maintenant j'espère, avertit-il, que ceux qui auront eu la patience de lire cette longue description, ne penseront plus que l'on puisse expliquer les différences extraordinaires qui distinguent ces deux sortes d'os de ceux du gavial, par l'influence de l'âge, de la nourriture, du climat ou du passage à l'état de pétrification, ainsi que l'avoit voulu M. Faujas dans le passage cité au commencement de ce chapitre. Toutes ces causes réunies auroient-elles pu mettre en avant la convexité que les autres crocodiles ont en arrière de leurs vertèbres? auroient-elles pu changer l'origine des apophyses transverses, aplatir les bords des orbites, diminuer le nombre des dents, etc.? Autant vaudroit dire que toutes nos espèces vivantes viennent les unes des autres» ${ }^{51}$.

Continuant son étude des espèces fossiles de cette classe, Cuvier souligne encore à nouveau combien ses principes sont cohérents. «Mais ce qui est surtout important à remarquer, insiste-t-il, c'est cette constance admirable des lois zoologiques qui ne se dément dans aucune classe, dans aucune famille. Je n'avois examiné ni les vertèbres, ni les membres, quand je me suis occupé des dents et des mâchoires, et une

\footnotetext{
49 «Mémoire sur les ossemens d'Oiseaux qui se trouvent dans les carrières de pierre à plâtre des environs de Paris», Annales du Muséum national d'Histoire naturelle, 1807, 9, 336-356; p. 356.

50 «Sur les différentes espèces de crocodiles vivans», Annales du Muséum national d'Histoire naturelle, 1807, 10, 8-66; p. 63.

51 «Sur les ossemens fossiles de Crocodiles», Annales du Muséum national d'Histoire naturelle, 1808, 12, 73-110; p. 100-101.
} 
seule dent m'a, pour ainsi dire, tout annoncé; une fois le genre déterminé par elle, tout le reste du squelette est en quelque sorte venu s'arranger de soi-même, sans peine de ma part, comme sans hésitation. Je ne peux trop insister sur ces lois générales, bases et principes de méthodes, de découvertes, qui, dans cette science comme dans toutes les autres, ont un intérêt bien supérieur à celui de toutes les découvertes particulières, quelque piquantes qu'elles soient $»^{52}$.

Dans le Rapport sur les progrès des sciences naturelles, de la même année 1808, qu'il adresse à l'empereur Napoléon, Cuvier revenait sur son choix des fossiles, et assurait que celui qu'il avait fait était le bon: «Parmi ces étonnans monumens des révolutions du globe, il n'y en avoit point qui dussent faire espérer des renseignemens plus lumineux, que les débris des quadrupèdes, parce qu'il étoit plus aisé de s'assurer de leurs espèces, et des ressemblances ou des différences qu'elles peuvent avoir avec celles qui subsistent aujourd'hui» ${ }^{53}$.

Dans sa «Seconde partie du Cours d'histoire naturelle donné en 1808 au Collège de France - Principes de géologie», Cuvier développe à nouveau ses considérations sur la manière d'aborder cette étude, et sur les résultats qu'il en obtient. Il insiste sur l'importance de ses propres recherches: «Mr Cuvier, note à nouveau son élève d'Omalius d'Halloy, a démontré la nécessité de connaître les fossiles que recèlent les couches pour pouvoir établir les systèmes (de géologie), et il va passer à l'examen des plus intéressans de ces fossiles, c'est-à-dire de ceux qui appartiennent à la classe des quadrupèdes». Il fait connaître à ses étudiants les fossiles qu'il a étudiés, en les distinguant dans la mesure du possible des espèces vivantes actuelles: le mammouth, l'hippopotame, le tapir, l'hyène, le cheval, le lamantin, etc. Considérant les quadrupèdes fossiles, il affirme qu'ils «ont tous été anéantis et sont circonscrits à une même formation tandis qu'on en trouve en-dessus et en-dessous de ces terreins les mêmes coquilles. Toutes ces variations prouvent qu'il y a eu successivement des productions et des destructions de corps organisés». A propos des mammouths, il précise à nouveau: «on pourrait objecter que les espèces ont éprouvé des changemens, ce qui est...une hypothèse en faveur de laquelle il n'y a aucune preuve», et, à propos des crocodiles fossiles qui présentent des différences dans leurs vertèbres avec les espèces vivantes: «ce n'est certainement pas la température, le climat, ni le temps qui peuvent produire de tels changemens dans une espèce et retourner ainsi les vertèbres d'un animal».

Il n'hésite pas à donner des leçons à ceux qui s'occupent des coquilles fossiles dont tous ses étudiants savaient qu'il s'agissait avant tout de Lamarck. «En général, affirme-t-il, on ne s'est point occupé de cette étude de la manière qui aurait été la plus

52 «Sur le grand animal fossile des Carrières de Maestricht», Annales du Muséum national d'Histoire naturelle, 1808, 12, 145-176; p. 176.

53 Rapport historique sur les Progrès des Sciences Naturelles depuis 1789, et sur leur état actuel (1808), 1810, p. 193-194. 
avantageuse. Les zoologistes ne se sont occupés que de connaître les espèces sans rechercher leurs positions respectives dans le sein de la terre, et les géologistes, surtout ceux de l'école de Werner, n'ont pas pris garde aux coquilles que recèlent les couches. Cependant leur histoire étudiée sous ce double rapport serait de la plus grande importance». Et il ajoute: «ll serait extrêmement intéressant de comparer les madrépores de la Mer du Sud avec les espèces fossiles. Rien ne pourrait mieux nous apprendre si réellement notre pays a existé sous un climat analogue à celui de la zone torride» ${ }^{54}$.

Cuvier était cependant conscient des problèmes que posaient les analogies que l'on ne pouvait nier entre certaines espèces fossiles et certaines espèces vivantes. Le cas était particulièrement net avec les Ruminants. Aussi Cuvier consacra à ce problème, en 1808, une étude assez longue dans le tome 12 des Annales $^{55}$, qu'il devait reproduire en 1809 dans le Journal de Physique ${ }^{56}$. Les espèces de ruminants, reconnaît-il, «sont le plus difficiles à discerner les unes des autres... Mais les difficultés que les ruminans offrent en géologie sont plus grandes encore, s'il est possible, que celles qui concernent la distinction de leurs os.

Jusqu'à présent nous n'avons trouvé dans les terrains meubles que des pachydermes différens par l'espèce de ceux d'aujourd'hui. Les carnassiers qui les accompagnent sont au moins d'espèces fort étrangères: les cavernes elles-mêmes ne nous offrent guère que des carnassiers inconnus ou étrangers; mais, parmi les ruminans, presque toutes les espèces que nous trouvons fossiles, soit dans les terrains meubles, soit dans les fentes de rochers remplies de stalactites, ne paroissent différer en rien d'essentiel de celles de notre pays et de notre temps.... Le genre des chevaux partage, avec les ruminans, cette ressemblance des os fossiles avec ceux des espèces vivantes».

Le problème était sérieux pour Cuvier, car il remettait en question son catastrophisme, et, en particulier «la dernière révolution» que Cuvier plaçait à « cinq ou six mille ans» en arrière de la période actuelle ${ }^{57}$. Il était normal, par conséquent, que Cuvier examinât le problème, et il était normal aussi qu'il fît plusieurs considérations à ce sujet, sous forme de questions qui n'étaient effectivement pas faciles à résoudre: «Ces os appartenoient-ils à des races dont quelques individus, en se retirant sur les montagnes, ont échappé à la catastrophe qui a enfoui les éléphans et les rhinocéros dans nos plaines?» C'était déjà une concession.

54 GRANDCHAMP, Ph. (1994), «Deux exposés des doctrines de CUVIER antérieurs au «Discours préliminaire»: les cours de Géologie professés au Collège de France en 1805 et 1808», Travaux du Comité français d'Histoire de la Géologie, 3ème série, VIII, 13-26; p. 19-22.

55 «Sur les Os fossiles de Ruminans, trouvés dans les terrains meubles», Annales du Muséum national d'Histoire naturelle, 1808, 12, p. 333-398.

56 «Sur les Os fossiles de Ruminans, trouvés dans les terrains meubles», Journal de Physique, 1809, 68 , p. $358-377$

57 Recherches sur les Ossemens fossiles de Quadrupèdes, t.1, 1812, Discours préliminaire, p. 110. 
«Ou les terrains dans lesquels on les trouve pêle-mêle avec des races perdues, ontils été remués postérieurement à la destruction de celles-ci?» La question pouvait en effet être envisagée, comme pouvait l'être la suivante: «Ou bien ces espèces de ruminans se distinguoient-elles de celles d'aujourd'hui par des caractères extérieurs que l'on ne peut plus retrouver dans le squelette, comme le zèbre diffère de l'âne, par exemple, et le couagga, du cheval? Ou bien enfin seroit-il arrivé que l'on n'auroit recueilli avec des os d'éléphans et autres semblables, que des portions non caractéristiques, qui étoient les mêmes dans les espèces perdues et les vivantes, tandis que les crânes et autres parties distinctives, semblables à celles des espèces vivantes, n'auroient été retirées que de terrains modernes?».

Cuvier était, après ces habiles questions, justifié à répondre avec prudence et sans conclure: «Ces quatre cas sont possibles. Lequel a eu lieu? Je n'ose encore le décider; peut-être la suite de nos recherches nous donnera-t-elle des motifs d'être plus hardis; en attendant, poursuivons-en le cours, et cherchons à en remplir l'objet essentiel, qui est la détermination des $0{ }^{\prime} »^{58}$.

En tout cas, Cuvier peut se permettre d'affirmer que «tout semble donc s'accorder pour faire de l'élan fossile d'Irlande un animal perdu, comme le rhinocéros à tête prolongée, comme le petit hippopotame, comme l'éléphant à longs alvéoles, comme le tapir gigantesque, enfin comme tant d'autres espèces décrites dans cet ouvrage, et qui, pour appartenir à des genres connus, n'en sont pas moins inconnues comme espèces à la surface actuelle de la terre» (p. 354).

A la fin de son article, Cuvier ajoute encore un autre argument pour faire admettre qu'il y a des ruminans fossiles qui n'ont pas d'analogues vivans, en établissant une distinction entre les espèces connues et les espèces inconnues de ruminans fossiles: «Les faits recueillis jusqu'à ce jour, semblent donc annoncer, autant du moins que des documens aussi incomplets peuvent le faire, que les deux sortes de ruminans fossiles appartiennent à deux ordres de terrains, et par conséquent à deux époques géologiques différentes; que les uns ont été ensevelis, et le sont encore journellement dans la période où nous vivons, tandis que les autres ont été victimes de la même révolution qui a détruit les autres fossiles des terrains meubles, tels que les mammouths, les mastodontes et tous les pachydermes dont les genres ne vivent plus aujourd'hui que dans la zone torride» (p. 398).

\section{9}

Discutant, dans le tome 14 des Annales, du cas des chevaux fossiles, dont nous avons vu qu'il considérait qu'ils posaient autant de problèmes que les ruminants, Cuvier écrit qu' «ils sont aussi communs dans les couches meubles que ceux d'aucune

58 «Sur les Os fossiles de Ruminans, trouvés dans les terrains meubles», Annales du Muséum national d'Histoire naturelle, 1808, 12, 333-398; p. 333-335. 
autre grande espèce, et cependant l'on en a peu fait mention dans les ouvrages sur les fossiles... 11 y a des preuves nombreuses de ce dernier motif, qui paroîtroit bien extraordinaire, si l'on ne savoit quelle légèreté a toujours été mise dans la détermination des fossiles et des pétrifications».

En effet «c'est dans les alluvions récentes que l'on en trouve le plus, comme l'on devoit s'y attendre...Ceux-là nous intéressent peu, puisqu'ils ont été déposés depuis que nos continens ont pris leur forme actuelle; mais les premiers, ceux qui accompagnent les éléphans et les tigres, sont d'un ordre de choses antérieur. Les chevaux qui les ont fournis ressembloient-ils en tout à nos chevaux d'aujourd'hui? J'avoue que l'Anatomie comparée est hors d' état de répondre à cette question».

Et s'il est vrai que «les os fossiles de chevaux ne peuvent se discerner des os de chevaux vivans,... cependant on les trouve certainement dans les mêmes couches qui recèlent des animaux inconnus».

Cuvier termine sur une assertion dubitative: «On peut donc assurer qu'une espèce du genre du cheval servoit de compagnon fidèle aux éléphans ou mammouths et aux autres animaux de la même époque, dont les débris remplissent nos grandes couches meubles; mais il est impossible de dire jusqu'à quel point elle ressembloit à l'une ou l'autre des espèces aujourd'hui vivantes ${ }^{59}$.

L'étude des sangliers fossiles pose les mêmes difficultés que celle des chevaux, car «...les géologistes ont rarement pris des soins qu'ils jugeoient trop minutieux, et aimoient mieux réserver leur temps pour des systèmes que de l'employer à des recherches précises...» (ibid., p. 40).

Les deux Paléontologistes, qui étaient déjà les deux plus grands naturalistes du siècle, s'affrontaient ainsi très nettement sur un point précis - et capital. Ce n'était pas un hasard: ils appartenaient à deux mondes intellectuels différents. Zoologistes et paléontologistes tous les deux, ils élaboraient, parallèlement, deux «systèmes» zoologiques et paléontologiques irréductibles, dont le problème des «révolutions» avait été un révélateur du conflit profond qui les opposait sur le point bien plus important de l'origine et du devenir des espèces, dans l'affrontement du Fixisme et du Transformisme.

Mais nous sommes arrivés en $\mathbf{1 8 0 9}$, et le débat va rebondir avec la parution de la Philosophie zoologique de Lamarck, et s'amplifier avec la suite de leurs travaux: d'une part les Recherches sur les Ossemens fossiles de Quadrupèdes, de Cuvier, avec son fameux «Discours préliminaire» (qui deviendra le Discours sur les Révolutions de la surface du globe ), et d'autre part la monumentale Histoire naturelle des Animaux sans vertèbres de Lamarck.

59 «Des os fossiles de chevaux et de sangliers», Annales du Muséum national d'Histoire naturelle, 1809, 14, 33-42; p. 33, 36, 33-34, 36-37. On sait qu'en 1821 CUVIER prendra ses distances avec ces doutes (voir plus loin, p. 189). 


\section{Lamarck}

\section{9: La Philosophie zoologique}

La Philosophie zoologique ne comporte pas d'études proprement paléontologiques, mais il est nécessaire de rappeler quelques passages, dans la mesure où ils représentent une réaffirmation des principes anticatastrophistes et évolutionnistes de Lamarck, et une réponse aux prises de position opposées de Cuvier.

Ainsi, en ce qui concerne le catastrophisme: «Si l'on considère, d'une part, que dans tout ce que la nature opère, elle ne fait rien brusquement, et que partout elle agit avec lenteur et par degrés successifs, et de l'autre part, que les causes particulières ou locales des désordres, des bouleversemens, des déplacemens, etc., peuvent rendre raison de tout ce que l'on observe à la surface de notre globe, et sont néanmoins assujetties à ses lois et à sa marche générale, on reconnoîtra qu'il n'est nullement nécessaire de supposer qu'une catastrophe universelle est venue tout culbuter et détruire une grande partie des opérations mêmes de la nature». (t.1, p. 80-81).

L'influence du temps et des circonstances dans le changement des espèces, et dans la montée progressive de la vie, est réaffirmée elle aussi: «Comparativement aux durées que nous regardons comme grandes dans nos calculs ordinaires, il a fallu, sans doute, un temps énorme et une variation considérable dans les circonstances qui se sont succédées $(\mathrm{sic})$, pour que la nature ait pu amener l'organisation des animaux au degré de complication et de développement où nous la voyons dans ceux qui sont les plus parfaits. Aussi est-on autorisé à penser que si la considération des couches diverses et nombreuses qui composent la croûte extérieure du globe, est un témoignage irrécusable de sa grande antiquité; que si celle du déplacement très-lent, mais continuel, du bassin des mers, attesté par les nombreux monumens qu'elle a laissés partout de ses passages, confirme encore la prodigieuse antiquité du globe terrestre; la considération du degré de perfectionnement où est parvenue l'organisation des animaux les plus parfaits, concourt, de son côté, à mettre cette vérité dans son plus grand degré d'évidence» (p. 89).

Et enfin la différence des deux «philosophies» est nettement exposée: «Voici maintenant à quoi se réduit le point de la discussion. Le fait est que les divers animaux ont chacun, suivant leur genre et leur espèce, des habitudes particulières, et toujours une organisation qui se trouve parfaitement en rapport avec ces habitudes. De la considération de ce fait, il semble qu'on soit libre d'admettre, soit l'une, soit l'autre des deux conclusions suivantes, et qu'aucune d'elles ne puisse être prouvée ${ }^{60}$.

Conclusion admise jusqu'à ce jour: la nature (ou son Auteur), en créant les animaux, a prévu toutes les sortes possibles de circonstances dans lesquelles ils auroient à vivre, et a donné à chaque espèce une organisation constante, ainsi qu'une forme

60 Cette remarque montre que LAMARCK avait bien conscience que l'évolution était une théorie, et non un fait. 
déterminée et invariable dans ses parties, qui forcent chaque espèce à vivre dans les lieux et les climats où on la trouve, et à y conserver les habitudes qu'on lui connoît.

Ma conclusion particulière: la nature, en produisant successivement toutes les espèces d'animaux, et commençant par les plus imparfaits ou les plus simples, pour terminer son ouvrage par les plus parfaits, a compliqué graduellement leur organisation; et ces animaux se répandant généralement dans toutes les régions habitables du globe, chaque espèce a reçu de l'influence des circonstances dans lesquelles elle s'est rencontrée, les habitudes que nous lui connoissons et les modifications dans ses parties que l'observation nous montre en elle.

La première de ces deux conclusions est celle qu'on a tirée jusqu'à présent, c'est-àdire, que c'est à peu près celle de tout le monde: elle suppose, dans chaque animal, une organisation constante, et des parties qui n'ont jamais varié et qui ne varient jamais; elle suppose encore que les circonstances des lieux qu'habite chaque espèce d'animal ne varient jamais dans ces lieux; car si elles varioient, les mêmes animaux n'y pourroient plus vivre, et la possibilité d'en retrouver ailleurs de semblables, et de s'y transporter, pourroit leur être interdite.

La seconde conclusion est la mienne propre: elle suppose que, par l'influence des circonstances sur les habitudes, et qu'ensuite par celle des habitudes sur l'état des parties, et même sur celui de l'organisation, chaque animal peut recevoir dans ses parties et son organisation, des modifications susceptibles de devenir très considérables, et d'avoir donné lieu à l'état où nous trouvons tous les animaux.

Pour établir que cette seconde conclusion est sans fondement, il faut d'abord prouver que chaque point de la surface du globe ne varie jamais dans sa nature, son exposition, sa situation élevée ou enfoncée, son climat, etc., etc.; et prouver ensuite qu'aucune partie des animaux ne subit, même à la suite de beaucoup de temps, aucune modification par le changement des circonstances, et par la nécessité qui les contraint à un autre genre de vie et d'action que celui qui leur étoit habituel.

Or, si un seul fait constate qu'un animal depuis long-temps en domesticité, diffère de l'espèce sauvage dont il est provenu, et si, parmi telle espèce en domesticité, l'on trouve une grande différence de conformation entre les individus que l'on a soumis à telle habitude, et ceux que l'on a contraints à des habitudes différentes, alors il sera certain que la première conclusion n'est point conforme aux lois de la nature, et qu'au contraire, la seconde est parfaitement d'accord avec elles.

Tout concourt donc à prouver mon assertion; savoir: que ce n'est point la forme, soit du corps, soit de ses parties, qui donne lieu aux habitudes et à la manière de vivre des animaux; mais que ce sont, au contraire, les habitudes, la manière de vivre, et toutes les autres circonstances influentes qui ont, avec le temps, constitué la forme du corps et des parties des animaux. Avec de nouvelles formes, de nouvelles facultés ont été acquises, et peu à peu la nature est parvenue à former les animaux tels que nous les voyons actuellement» (p. 265-268). 
Il n'y a plus de compromis, ni de malentendu, possible entre les deux positions adverses.

\section{1}

Lamarck, qui a entrepris ses études sur les Conchifères, expose quelques-uns de ses résultats dans le tome $\mathbf{1 7}$ des Annales du Muséum, et relève, selon sa méthode, les espèces analogues. Ainsi, par exemple, en étudiant la Volute noyau, Voluta nucleus, «acquise avec d'autres venant de la mer du Sud», il remarque: «Elle a de si grands rapports avec le $V$. harpula qui se trouve en abondance fossile à Grignon, qu'on pourroit la regarder comme en étant l'analogue vivant, quoique sa spire soit un peu plus raccourcie» ${ }^{61}$. Lamarck met, comme nous l'avons déjà signalé, autant d'attention à faire remarquer, pour les espèces fossiles, ici Voluta harpa et Voluta spina, qu'on ne leur connaît pas d' «analogue vivant» (ibid., p. 74). Ces études ne sont du reste qu'une préparation de l'immense ouvrage qu'il fera paraître quelques années plus tard, et où il en reparlera.

A propos de ce genre, Lamarck laisse apparaître un aspect de sa personnalité qui révèle sa sensibilité esthétique (mais ce n'est pas la seule fois): «ce genre (des volutes), assure-t-il, comprend encore un grand nombre d'espèces, parmi lesquelles quantité sont très-précieuses par leur rareté, par la beauté, la vivacité et la diversité de leurs couleurs. On peut dire que c'est un des plus beaux genres de la conchyliologie, et qu'il forme un des plus riches ornemens des collections» (ibid., p. 55-56).

Des disciples commencent déjà d'ailleurs à marcher sur ses traces, et nous en aurons d'autres témoignages à la fin de cet exposé. En effet, dans le même numéro où Lamarck parlait des volutes, un autre savant — connu pour d'autres travaux - Ménard de la Groye, était tout heureux d'annoncer qu'il avait découvert «un petit Coquillage de la Méditerranée qui est analogue à des fossiles des environs de Paris et de Bordeaux». «Je les (les coquilles) ai examinées, proclame-t-il, avec d'autant plus d'intérêt que j'ai cru voir en elles les analogues vivans de deux autres coquilles qui se trouvent fossiles, l'une à Grignon près de Paris, l'autre dans les environs de Bordeaux», coquilles fossiles qui, fait-il remarquer, «ont été décrites par M. de Lamarck». Et il poursuit sur le même ton de profonde satisfaction: «Voilà une coquille vivante de plus à rapprocher des coquilles fossiles auxquelles on ne connoissoit point encore d'analogue. Le fait est d'autant plus remarquable que cette coquille vit dans la Méditerranée, et que le nombre de celles qu'on a trouvées dans ce cas ne s'élève pas à vingt». Et la conclusion qu'il donne à sa communication montre qu'il a bien compris

61 «Suite de la détermination des Mollusques Testacés», Annales du Muséum national d'Histoire naturelle, 1811, 17, 54-80; p. 73. 
l'enjeu de cette recherche des espèces analogues: «L'objet de cette note est minutieux en apparence, s'excuse-t-il, mais il intéresse et la conchyliologie et la géologie» ${ }^{62}$.

\section{Cuvier, Recherches sur les Ossemens fossiles de Quadrupèdes.}

\section{2, t. 1.}

Cuvier, de son côté, dans son grand ouvrage Recherches sur les Ossemens fossiles de Quadrupèdes, en 4 grands volumes, maintient et même renforce la perspective pro-catastrophiste, dans laquelle, à son avis, ses travaux paléontologiques prennent tout leur sens. Il ne le fait pas, à vrai dire, dans les travaux paléontologiques qu'il y présente, qui ne sont, comme il en avertit lui-même, que la reproduction des articles qu'il a fait paraître les années précédentes, dans les Annales du Muséum, et que nous avons déjà cités à leurs dates respectives. Il y décrit «soixante et dix-huit espèces, dont quarante neuf sont bien certainement aujourd'hui inconnues des naturalistes, et dont seize ou dix-huit sont encore douteuses. Les autres os trouvés dans des terrains récens paraissent appartenir à des animaux connus» ${ }^{63}$.

C'est dans le fameux «Discours préliminaire» à ces Recherches sur les Ossemens fossiles de Quadrupèdes qu'il expose longuement ses principes et ses conclusions: «C'est, avertit-il, le plan et le résultat de mes travaux sur les os fossiles que je me propose surtout de présenter dans ce discours. Ce que je donne aujourd'hui ne forme qu'une bien petite partie des faits dont cette antique histoire devra se composer; mais ces faits sont importans: plusieurs d'entre eux sont décisifs, et j'espère que la manière rigoureuse dont j'ai procédé à leur détermination permettra de les regarder comme des points définitivement fixés, dont il ne sera plus permis de s'écarter» (p. 3).

Et les résultats annoncés sont nettement exprimés: «Comme la différence entre ces espèces et celles d'aujourd'hui ne va pas au-delà de certaines limites, je montrerai que ces limites dépassent de beaucoup celles qui distinguent aujourd'hui les variétés d'une même espèce: je ferai donc connoître jusqu'où ces variétés peuvent aller, soit par l'influence du temps, soit par celle du climat, soit enfin par celle de la civilisation. Je me mettrai par là en état de conclure qu'il a fallu de grands événemens pour amener ces différences majeures que j'ai reconnues; je développerai donc les modifications particulières que mon ouvrage doit introduire dans les opinions reçues jusqu'à ce jour sur l'histoire primitive du globe» (p. 4).

La raison principale du rejet de la continuité chez Cuvier est bien, par conséquent, le Catastrophisme -- et son nom est resté à juste titre attaché à cette théorie. Si deux espèces semblables appartenant à deux époques successives, ne peuvent être réunies

62 Menard de la Groye, F. (1811), Annales du Muséum national d'Histoire naturelle, 17, 331332; p. 331-332.

63 CUVIER, G. (1816), «Analyse des travaux de la Classe des Sciences mathématiques et physiques de l'Institut pendant l'année 1812, Partie physique», Mémoires de la Classe des Sciences mathématiques et physiques de l'Institut national de France, année 1812, 2ème partie, LXXXI-CXXXII; p. XCIX. 
génétiquement, c'est qu'il existe une impossibilité radícale de descendance directe, due à une coupure absolue entre les deux périodes envisagées, à une «catastrophe» anéantissant toute vie sur la surface du globe: «le fil des opérations est rompu; la marche de la nature est changée» (p. 17).

Il n'y a pas de doute, en effet, que Cuvier ait soutenu un catastrophisme généralisé. Il a envisagé de nombreuses catastrophes universelles, où si «l'irruption» des mers «a été générale..., elle a pu faire périr la classe entière» des quadrupèdes. (p. 38).

Ces «révolutions» qui ont ravagé la terre ne sont pas, en effet, de simples déplacements de la mer; ce sont des invasions terribles et brutales.

«Ces irruptions, ces retraites répétées, n'ont point été lentes, ne se sont point faites par degrés», assure-t-il, «la plupart des catastrophes qui les ont amenées ont été subites» (p. 10). Cuvier en donne pour preuves «la dernière de toutes», sa référence habituelle: l'on a trouvé «dans les pays du Nord, des cadavres de grands quadrupèdes que la glace a saisis, et qui se sont conservés jusqu'à nos jours avec leur peau, leur poil, et leur chair. S'ils n'eussent été gelés aussitôt que tués, la putréfaction les auroit décomposés. Or cette gelée éternelle n'a pu s'emparer des lieux où ces animaux vivoient que par la même cause qui les a détruits: cette cause a donc été subite comme son effet» (p. 11). Il cite des exemples qui le confirment: «Les deux phénomènes de ce genre les plus remarquables, et qui détruisent pour toujours toute idée de révolution lente, sont le rhinocéros découvert en 1771, sur les bords du Vilhouï, et l'éléphant que M. Adams vient d'observer vers l'embouchure de la Léna. Celui-ci avoit encore sa peau, ses chairs, et son poil de deux espèces...Ses chairs étoient si bien conservées, qu'elles ont été mangées par les chiens» (p. 11, note 1).

Après avoir décrit, en de nombreuses pages dramatiques, les «événemens effroyables» qui ont marqué la surtace du globe, Cuvier conclut: «Telles sont les conséquences où conduisent nécessairement les objets que nous rencontrons à chaque pas, que nous pouvons vérifier à chaque instant dans presque tous les pays. Ces grands et terribles événemens sont clairement empreints partout pour l'oeil qui sait en lire l'histoire dans leurs monumens» (p. 12). Les causes actuelles sont impuissantes à en rendre compte. Aussi, lorsque pour expliquer un phénomène géologique donné, il est impossible de suivre «l'hypothèse qui paroît la plus simple et la plus naturelle», parce qu'elle est «sujette à des objections jusqu'à présent insolubles», il faut avoir recours à des causes d'une autre nature ${ }^{64}$. «Vraies ou non, peu importe», les causes actuelles «n'expliquent ríen, puisque aucune cause lente ne peut avoir produit des effets subits». Et c'est bien pour cette raison que l'on se trouve devant la «nécessité» de chercher «des causes différentes de celles que nous voyons agir aujourd'hui» ${ }^{65}$.

64 Essai sur la Géographie minéralogique des environs de París, 1812, p. 253.

65 Recherches sur les Ossemens fossiles de Quadrupèdes, 1812, t. 1, Discours préliminaire, p. 24-25. 
C'est dans l'embranchement des Vertébrés, et, plus particulièrement, dans la classe des Mammifères, que Cuvier trouve les arguments solides pour prouver sa thèse, et nous avons vu qu'il les choisit soigneusement. Il répète que c'est un choix délibéré qu'il a fait dans ses études, parce que les «quadrupèdes» fossiles procuraient un élément facile de vérification à la thèse de leur disparition. $\mathrm{Si}$ «aucune des grandes espèces de quadrupèdes aujourd'hui enfouies dans des couches pierreuses régulières, ne s'est trouvée semblable aux espèces vivantes que l'on connoît, ce n'est pas, assurait Cuvier, l'effet d'un simple hasard». L'on doit au contraire «regarder ce phénomène comme tenant à des causes générales» (p. 56). Ces causes générales, ce sont les cataclysmes universels, auxquels il n'y a pas de raisons que les petites espèces puissent échapper plus facilement que les grandes.

A partir de tous les documents sur les quadrupèdes fossiles qu'il possédait ou qu'il s'était fait communiquer, Cuvier se faisait donc toujours fort d'établir la réalité de la «dernière catastrophe», dont tout le monde savait qu'il s'agissait de celle admise par les croyants. Bien que la vision de destruction totale des êtres ne correspondît pas aux données de la Genèse, Cuvier se présentait comme un défenseur du Déluge biblique. «Je pense, assure-t-il, avec MM. Deluc et Dolomieu, que, s'il y a quelque chose de constaté en géologie, c'est que la surface de notre globe a été victime d'une grande et subite révolution, dont la date ne peut remonter beaucoup au-delà de cinq ou six mille ans; que cette révolution a enfoncé et fait disparoître les pays qu'habitoient auparavant les hommes et les espèces d'animaux aujourd'hui les plus connus; qu'elle a, au contraire, mis à sec le fond de la dernière mer, et en a formé les pays aujourd'hui habités; que c'est depuis cette révolution que le petit nombre des individus épargnés par elle se sont répandus et propagés sur les terrains nouvellement mis à sec» (p. 110).

\section{2, t. 2.}

Dans la reproduction de ses articles sur les espèces fossiles, Cuvier reprend donc les affirmations catastrophistes et antitransformistes qu'il avait énoncées dans ses contributions aux Annales du Muséum. Ainsi, en ce qui concerne les éléphants fossiles (140 p., cit. p. 139-140), ou le grand mastodonte (43 p., cit. p. 1, 42-43), ou les rhinocéros fossiles (33 p., cit. p. 32). Il en est de même dans le cas des chevaux (10 p., cit. p. 1-4), ainsi que dans celui des oiseaux (24 p.).

Dans son Résumé général de la première partie, $(4$ p.), Cuvier réitère les conclusions qu'il avait déjà formulées en 1806 dans les Annales du Muséum.

\section{2, t. 3.}

Sur la sarigue fossile (16 p.), Cuvier redonne aussi soigneusement le même texte que dans le tome 5 de 1804 des Annales du Muséum. 


\section{2, t. 4.}

Dans ses «Observations sur l'Ostéologie des Paresseux», (27 p.), Cuvier remarque de nouveau combien ces êtres sont étranges et semblent appartenir à «un autre ordre de choses»: «On leur trouve si peu de rapports avec les animaux ordinaires; les lois générales des organisations aujourd'hui existantes s'appliquent si peu à la leur; les différentes parties de leur corps semblent tellement en contradiction avec les règles de coexistence que nous trouvons établies dans tout le règne animal, que l'on pourroit réellement croire qu'ils sont les restes d'un autre ordre de choses.» (p. 3);

«Le seul aspect du squelette de l' aï indique des proportions en quelque sorte manquées» (p. 4);

«Les ongles des paresseux sont d'une longueur monstrueuse; et l'arme redoutable qu'ils fournissent est sans doute le moyen par lequel ces animaux se défendent avec assez de succès pour compenser tout le désavantage du reste de leur organisation» (p. 10).

Ni dans le présent ni dans le passé il ne peut être question pour Cuvier d'espèces analogues.

\section{Lamarck, 1815.}

Lamarck, lui non plus, qui avait entrepris de réfuter les théories de Cuvier, ne s'arrête pas dans ses recherches paléontologiques et ses démonstrations. Continuant ses travaux de classification, et étendant ses investigations à des fossiles d'autres classes d'Invertébrés provenant de différents pays de l'Europe, il prouve, dans l'Histoire Naturelle des Animaux sans Vertèbres, que le même phénomène se retrouve partout: des espèces identiques ou analogues à celles d'aujourd'hui ont vécu dans les temps anciens, et ont traversé par dizaines la limite que l'on prétendait infranchissable entre le passé et le présent.

\section{mars 1815: Histoire naturelle des Animaux sans vertèbres, t.1.}

En mars 1815, Lamarck publie le premier volume de ce qui devait devenir son ouvrage fondamental, base de tous les travaux qui devaient se faire sur les Invertébrés dans la suite du XIXè siècle: l'Histoire naturelle des Animaux sans vertèbres. Le tome premier est consacré en grande partie à rappeler les principes fondamentaux de sa théorie transformiste, qu'il avait déjà exposés à plusieurs reprises, et que nous n'allons pas reprendre ici. Nous retiendrons simplement, dans la perspective paléontologique qui est celle de notre étude, l'exposé de la manière dont il conçoit l'histoire de la vie:

«La nature, dans toutes ses opérations, ne pouvant procéder que graduellement, n'a pu produire tous les animaux à-la-fois: elle n'a d'abord formé que les plus simples; et passant de ceux-ci jusques aux plus composés, elle a établi successivement en eux différens systèmes d'organes particuliers, les a multipliés, en a augmenté de plus 
en plus l'énergie, et, les cumulant dans les plus parfaits, elle a fait exister tous les animaux connus avec l'organisation et les facultés que nous leur observons». Et Lamarck termine cette déclaration en y insistant: «Or, elle n'a rien fait absolument, ou elle a fait ainsi» (p. 123). Il marquait par là son opposition radicale aux vues de $\mathrm{Cu}$ vier sur l'histoire du passé.

A partir des documents, de fossiles entre autres, qu'il possède, et qu'il a minutieusement étudiés, Lamarck aboutit à un schéma d'histoire de la vie, qu'il propose à ses lecteurs, p. 456-457: «Ainsi, je soumets à la méditation des zoologistes, l'ordre présumé de la formation des animaux, tel que je l'exprime dans le tableau suivant»:

ORDRE présumé de la formation des Animaux, offrant 2 séries séparées, subrameuses.

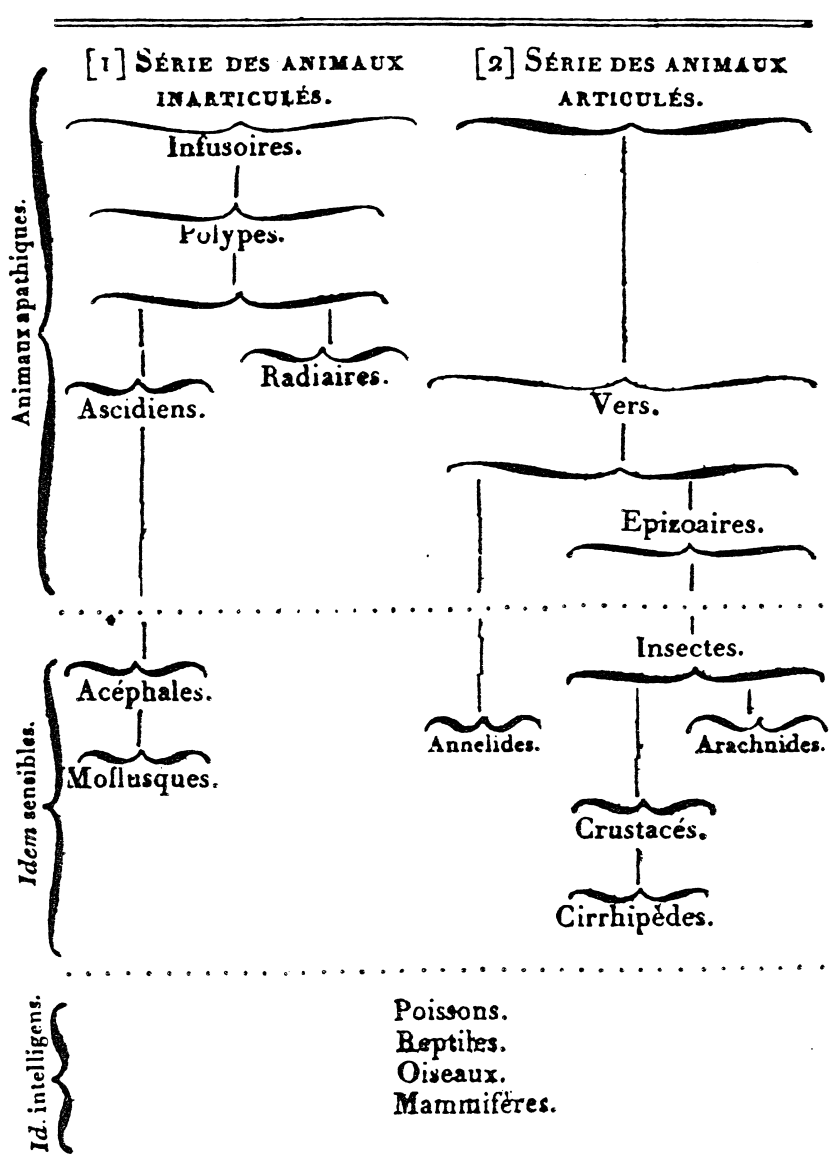


Ce tableau est, dans l'histoire de l'Evolution, le premier exemple, documenté, et non abstrait, d'arbre phylogénétique. 11 sera évidemment modifié au fur et à mesure des nouvelles découvertes paléontologiques - mais ils le sont encore tous aujourd'hui, et pour les mêmes raisons.

Les tomes suivants - il y en aura sept en tout- sont destinés, comme Lamarck en avertit lui-même, à fournir les «pièces justificatives» de sa théorie de la transformation des espèces (ibid., Avertissement, p. II).

\section{Cuvier, 1815.}

Cuvier, curieusement - mais ce ne sera pas la dernière fois! - semble donner le change, en employant un vocabulaire que Lamarck n'aurait pas désavoué, mais on sait qu'il restera sur ses positions. Étudiant les Anatifes et les Balanes, il écrit: «Nous voici arrivés à des animaux bien différens de tous les mollusques dont nous avons parlé jusqu'à présent; des membres cornés, articulés en quelque sorte, nombreux, susceptibles de mouvemens variés, une bouche garnie de lèvres et de mâchoires, un système nerveux formé d'une suite de ganglions, tout annonce que la nature va nous conduire à l'embranchement des animaux articulés» ${ }^{66}$.

\section{Lamarck,}

\section{mars 1816, Histoire naturelle des Animaux sans vertèbres, t.2.}

Lamarck continue ses études des Invertébrés actuels et fossiles selon sa méthode de rapprochement des espèces. Il n'hésite pas, par exemple, à placer, dans le tableau des espèces de Rétépores, le Retepora frustulata, «fossile des environs d'Angers», entre deux rétépores actuels, pour bien signaler les ressemblances que cette espèce présente avec des Polypiers vivants du même genre, en particulier avec la suivante, le Retepora ambigua (p. 184). Le Sarcinula organum est une espèce qui «habite dans la Mer rouge», mais «on la trouve fossile sur les côtes de la mer Baltique» (p. 223). Il en est de même du Caryophyllia fasciculata, qui «habite l'océan des Gr. Indes», et qu'on «trouve fossile en Europe» (p. 226-227), ou du Caryophyllia musicalis, qui «habite l'océan indien», et que l'on « trouve fossile sur les côtes de l'Irlande» (p. 227). L'Astrea favosa habite aussi «l'Océan des Grandes-Indes», et se trouve «fossile en France, près de Givet» (p. 263). Quand on sait le parti que Lamarck tire de ces analogies ou de ces identités d'espèces pour combattre le catastrophisme de Cuvier, on comprend qu'il les relève soigneusement, comme le feront d'ailleurs les innombrables invertébristes qui prendront la même voie, à sa suite, et en utilisant ses méthodes.

66 «Mémoire sur les Animaux des Anatifes et des Balanes Lam. (Lepas Lin.), et sur leur Anatomie», Mémoires du Muséum,1815, 2, 85-101; p. 85. 


\section{août 1816, Histoire naturelle des Animaux sans vertèbres, t.3.}

Les Echinides présentent aussi des cas du même genre. Ainsi le Clypeaster oviformis «habite les mers australes», mais une variété «se trouve fossile dans les vignes aux environs du Mans» (p. 15). Lamarck fait la réflexion, à propos des ananchites, que toutes celles qui sont connues «sont dans l'état fossile», ce qui, assure-t-il, «est assez remarquable»; et que ce n'est pas le cas «parmi les spatangues», car «on en connaît beaucoup dans l'état frais ou vivant, et beaucoup d'autres dans l'état fossile» (p. 24). Il présente le Cidarites pulvinata, qui est une espèce actuelle, qui «habite probablement les mers de l'Asie», comme étant «moyenne» entre le Cidarites pseudo-diadema, qui est fossile, et le Cidarites radiata, qui est actuelle, et qui «habite les côtes de l'Asie» (p. 59).

\section{Cuvier 1817 Le Règne animal}

Dans cet ouvrage, Cuvier, comme il fallait s'y attendre, traite surtout des animaux vertébrés, qui sont, assure-t-il, «plus intéressans sous tous les rapports» (t.1, Préface, p. Xl). Il se contente d'une brève description de leurs fossiles, et renvoie à son ouvrage sur les Ossemens fossiles de Quadrupèdes. Il s'explique par ailleurs sur la manière un peu rapide dont il traite les invertébrés (surtout leur paléontologie): «Parmi les non vertébrés, j'ai dû étudier plus particulièrement les mollusques nus et les grands zoophytes; mais les innombrables variations des formes extérieures des coquilles et des coraux, les animaux microscopiques, et les autres familles qui ne jouent pas dans la nature un rôle très apparent, ou dont l'organisation offre peu de prise au scalpel, ne demandaient pas d'être traitées avec le même détail». Ces raisons peuvent sembler assez spécieuses, mais la véritable raison était sans doute la suivante: «Je pouvais d'ailleurs, pour la partie des coquilles et des coraux, m'en rapporter à l'ouvrage que $M$. de Lamarck publie en ce moment, et où l'on trouvera tout ce que le plus ardent désir de savoir peut exiger» (p. Xl-XII), et il confie les Insectes à Latreille. Sur un total d'environ 2000 pages consacrées au Règne animal, Cuvier n'a écrit personnellement que 276 pages sur les Invertébrés (à comparer avec le travail de Lamarck, qui, dans l'ouvrage à peu près contemporain, l'Histoire Naturelle des Animaux sans Vertèbres, y a consacré plus de 4000 pages!).

Cuvier ne cite que rarement l'existence d'espèces fossiles, même chez les Mollusques, alors que Lamarck en fournissait des dizaines, et il ne tente jamais de faire le rapprochement des formes anciennes avec les formes actuelles. Ainsi, pour les Cérites, où Lamarck avait étudiés et décrits une soixantaine de fossiles, et leur avait consacré une bonne douzaine de pages, Cuvier se contente de cette courte phrase: «On en trouve beaucoup parmi les fossiles», avec, en note, la mention de quelques huit fossiles et un renvoi aux travaux de Lamarck, mais sans jugement sur l'utilisation qu'il en faisait (t.2, 1817, p. 438). 


\section{Lamarck 1817 Nouveau Dictionnaire d'Histoire naturelle, t.7.}

Lamarck, en réponse en quelque sorte à Cuvier, a soin de recommander expressément au naturaliste de bien étudier la nature des fossiles qu'il découvre, pour pouvoir connaître «l'ordre de formation» des couches qui les contiennent: «Comme les coquilles fossiles sont des monumens essentiels à consulter pour connoître les révolutions lentes qui s'exécutent sans cesse à la surface de notre globe, et l'ordre de formation des couches qui composent sa croûte externe, ainsi que la nature de chacune de ces couches, rien n'est plus utile à l'avancement de nos études géologiques, que la détermination des caractères qui peuvent indiquer si telle coquille que l'on examine est terrestre, ou fluviatile, ou marine» (art. «Coquillage», p. 553).

En réponse aussi pour ainsi dire aux affirmations de Cuvier, qui soutenait que c'était par l'étude des fossiles de vertébrés que l'on pouvait découvrir la véritable histoire du passé, Lamarck soutient au contraire l'importance de l'étude des «coquilles», et l'on sait que l'avenir lui donnera très rapidement raison, grâce au grand nombre de naturalistes qui se lanceront à sa suite, et ses ouvrages à la main, dans cette étude: «C'est donc uniquement à l'étude approfondie des coquilles, etc., qu'est réservée la possibilité de jeter un véritable jour sur ces grandes questions d'histoire naturelle; enfin, ce ne pourra être qu'à la connoissance bien précise des coquilles, qu'on devra l'avantage d'avoir une opinion solide sur ces objets importans» (art. Conchyliologie, p. 417).

Lamarck va même plus loin, et plus directement, et même en maniant l'ironie, dans la contradiction apportée à Cuvier: «Au lieu de ces catastrophes générales qui sont si commodes, parce qu'elles dispensent d'étudier, dans le sujet dont il s'agit, la marche constante de la nature, et qu'on a supposées pour tâcher d'expliquer l'importante considération des débris de corps marins entassés et si abondans dans toutes les parties sèches de notre globe; quel est le naturaliste observateur qui n'aperçoit pas au contraire les changemens, très-lents sans doute, mais continuels, qu'éprouve la surface du globe que nous habitons?... Des catastrophes partielles ou locales, comme des éruptions volcaniques, des tremblemens de terre, de grandes invasions d'eau dans les lieux bas, ces eaux ayant miné et franchi les barrières qui les retenoient, sont maintenant assez connues; celles-ci suffisent à l'intelligence de beaucoup de faits observés. Mais ces prétendues catastrophes générales du globe, sur quelles bases les appuie-ton? Si nous observons, par places, des bancs considérables de coquilles fossiles amassées, les courans qui existent dans les mers n'ont-ils pu donner lieu à ces amas locaux et à d'autres semblables, et se trouve-t-on forcé d'avoir recours à des suppositions que rien ne prouve, pas même les mélanges dans les amas cités?» (p. 416-417).

\section{Cuvier 1817}

Cette même année 1817, Cuvier publie ses Mémoires pour servir à l'histoire et à l'anatomie des Mollusques. Il avertit que la plupart de ces Mémoires ont déjà été 
publiés séparément dans les Annales du Muséum d'Histoire naturelle, et que par conséquent cet ouvrage ne contient rien de bien nouveau sur le sujet. Il est à remarquer cependant que Cuvier choisit de le publier pendant que Lamarck est en train de livrer au public son Histoire naturelle des Animaux sans vertèbres, dont il n'a fait paraître qu'une petite partie. Deux passages de Cuvier, écrits pour cette nouvelle édition de ses mémoires sur les Mollusques, ne pouvaient échapper ni à Lamarck ni à ses lecteurs. Tout d'abord, Cuvier écrit dans son «Avertissement» du début de l'ouvrage (p. V-VI): «L'Auteur» (c'est-à-dire Cuvier lui-même), «en les (ses mémoires déjà publiés) rassemblant et en les complétant par quelques Mémoires nouveaux, se proposait d'abord de faire précéder cette collection d'un Discours préliminaire sur les rapports des animaux sans vertèbres, et sur leur véritable classification». Quand on sait le sens et la portée qu'il avait donnés à son Discours préliminaire aux Recherches sur les Ossemens fossiles de Quadrupèdes, il n'est pas difficile de penser que ce discours n'aurait évidemment pas été dans le même sens que celui que Lamarck avait donné, en 1815, à son Introduction à l'Histoire naturelle des Animaux sans vertèbres. L'allusion à la «véritable classification» qu'il en proposait ne pouvait non plus être comprise dans un sens favorable à la classification que proposait Lamarck. Cuvier renonce cependant à ce discours préliminaire: «ll a pensé, assure-t-il, que les principes qu'il aurait pu développer dans ce Discours, sont devenus tellement vulgaires depuis quinze ans, soit par ses propres travaux, soit par ceux des naturalistes qui ont adopté ses idées, qu'il est presque superflu de les reproduire séparément». Cuvier ne va donc pas suivre la voie, tracée par Lamarck, de comparaison des espèces actuelles et fossiles. «Il se borne donc à offrir aux Amateurs de la science des descriptions et des figures propres à leur rendre très-sensible l'organisation compliquée de ces animaux». Cuvier choisit là encore d'ignorer la partie de l'histoire naturelle concernant les fossiles d'Invertébrés, alors qu'il en avait fait son domaine de prédilection quand il étudiait les Vertébrés.

Cependant Cuvier ne voulait pas laisser le champ libre à une interprétation transformiste de l'histoire de la vie à partir des Invertébrés, comme le faisait Lamarck dans le même moment. Profitant de son étude inédite sur les Céphalopodes, Cuvier attaque encore plus nettement la théorie de Lamarck. Concluant son article sur le Poulpe, il écrit: «Tels sont les principaux traits de l'organisation du poulpe, par lequel nous commençons cette histoire anatomique des animaux mollusques. Il n'est sans doute personne qui, à la lecture de cette courte description, et à la vue des figures qui l'accompagnent, ne soit frappé de cet appareil de parties organiques tout aussi développées et de même nature que dans les vertébrés, employées à la composition d'un être entièrement différent, quant au plan et à l'arrangement général, tant intérieur qu'extérieur. Ces fibres, cette matière médullaire, ces artères, ces veines, ces valvules, ce parenchyme, ces intestins, cet oeil, tout est semblable au fond, et tout est autrement entrelacé, autrement combiné. Si l'on excepte les organes de l'odorat, le système de la veine porte, les vaisseaux absorbans, le squelette et les organes relatifs à 
l'urine, qui même sont peut-étre remplacés par la bourse du noir, nous retrouvons àpeu-près ici toutes les fonctions qui s'exercent dans les poissons, et cependant il n'y a nulle ressemblance, nulle analogie de disposition. Même pour les imaginations les plus prévenues, les bras qui couronnent la tête ne deviendront point des nageoires; les cartilages qui renforcent le dos ne se changeront point en vertèbres; ces trois coeurs au fond de l'abdomen ne remonteront point vers la gorge pour se réunir en un seul. En vain chercherait-on à rapprocher ces mollusques de quelques poissons, dont le squelette a presque disparu; ceux-ci n'en sont pas moins des poissons par tous leurs autres organes, par la forme de ces organes, par leur position mutuelle, par l'ensemble de la configuration, et rien de tout cela n'existe de même dans nos céphalopodes.

En un mot, nous voyons ici, quoi qu'en aient dit Bonnet et ses sectateurs, la nature passer d'un plan à un autre, faire un saut, laisser entre ses productions un hiatus manifeste; les céphalopodes ne sont sur le passage de rien; ils ne sont pas résultés du développement d'autres animaux, et leur propre développement n'a rien produit de supérieur à eux; considérations qui leur donnent en histoire naturelle une importance capitale, attendu qu'elles renversent un grand nombre de vains systèmes. C'est ce qui nous a engagé depuis long-temps à donner à leur étude une attention particulière» ${ }^{67}$.

Lamarck allait attendre d'aborder l'étude des céphalopodes pour répondre à $\mathrm{Cu}$ vier, ce que nous verrons plus loin. En attendant, il continue ses études sur les Invertébrés, en suivant sa propre classification, qui le conduit aux Annélides.

juillet 1818. Histoire naturelle des Animaux sans vertèbres, t. 5 .

Les Annélides ne sont pas en effet en reste de fossiles «analogues». Le Dentalium entalis «habite l'Océan d'Europe et celui de l'Inde. La variété fossile se trouve à Dax et à Grignon, mais moins grande» (p. 345); le Dentalium eburneum «habite dans l'Inde, et se trouve fossile à Grignon» (p. 346); le Serpula protensa «habite les mers de l'Inde, de l'Amérique et dans la Méditerranée. On la trouve fossile en Italie» (p. 364); le Serpula minima «habite la Méditerranée, près de Civitta Vecchia. La variété b. (fossile) se trouve à Grignon»; le Serpula echinata «habite la Méditerranée. Les variétés $\mathrm{b}$. et $\mathrm{c}$. sont fossiles. Une troisième variété, non fossile, se trouve au port d'Ancône» (p. 366); le Serpula sulcata «habite les mers de la Nouvelle Hollande, etc. Se trouve fossile dans la Touraine»; le Serpula dentifera «habite les mers de l'Asie australe. La variété c. (fossile) se trouve en Italie» (p. 367).

Les Cirrhipèdes eux-mêmes fournissent à Lamarck des espèces actuelles et fossiles analogues: ainsi le Balanus sulcatus «habite les mers d'Europe... La variété fossile se trouve en Piémont et dans le Plaisantin»; le Balanus tintinnabulum «habite l'Océan

67 Mémoires pour servir à l'histoire et à l'anatomie des Mollusques, 1817, «Mémoire sur les Céphalopodes et leur anatomie», 54 pages (pagination à part); p. 42-43. 
d'Europe, d'Amérique et de l'Inde... On la trouve fossile en Italie» (p. 390-391); le Balanus cylindraceus «habite l'Océan d'Europe et d'Amérique», et une de ses variétés fossiles «se trouve près de Turin» (p. 391); le Balanus miser «habite les mers de l'Europe... La variété b. habite dans la Manche, et se trouve fossile en Italie» (p. 392); le Balanus amphimorphus, que l'on «trouve fossile en Italie», «tient de très près» au Balanus perforatus, qui «habite la Méditerranée, les côtes de Barbarie, cel-les du Sénégal, etc.» (p. 392-393). On sait que Darwin allait continuer cette étude, sans utiliser la problématique des espèces analogues, ni l'utiliser pour la démonstration de la transformation des espèces, ni, bien entendu, faire référence à ce qu'il devait à Lamarck.... ${ }^{68}$

Mais ce sont évidemment les Mollusques, que Lamarck divise en Conchifères et en Mollusques proprement dits, qui allaient lui fournir le plus grand nombre d'exemples d'espèces analogues actuelles et fossiles.

Le Solen vagina «habite l'Océan d'Europe, d'Amérique et de l'Inde...La variété B. se trouve fossile à Grignon». (p. 451); le Solen strigilatus «habite la Méditerranée, l'Océan atlantique... On le trouve fossile près de Bordeaux et à Dax» (p. 455); la Lutraria solenoides «habite l'Océan d'Europe... On la trouve fossile au Mont Marius, près de Rome». (p. 468); la Lutraria elliptica «habite l'Océan d'Europe, dans le sable des côtes... On la trouve fossile aux environs de Bordeaux» (p. 468-469); la Crassatella tumida, «Fossile de Grignon... Son analogue vivante paraît être la crassatelle sillonnée» (Crassatella sulcata), (qui) «habite les mers de la Nouvelle-Hollande, à la baie des chiens marins» (p. 484 et 481); la Lucina concentrica, un «fossile de Grignon... est presque l'analogue fossile de la 1. rotondaire» (p. 541); la Lucina lactea «habite la Méditerranée...» et se trouve «fossile dans les faluns de la Touraine» (p. 542-543); la Cyprina Islandica, «habite l'Océan boréal, à l'embouchure des fleuves... On la trouve fossile aux environs de Bordeaux et en Italie» (p. 557-558 - dans la deuxième pagination de ces pages); la Cytherea erycina, «habite l'Océan indien...On la trouve fossile aux environs de Bordeaux» (p. 564); la Venus plicata, «habite l'Océan indien... On la trouve fossile près de Turin» (p. 588); la Venericardia australis, «habite les mers de la Nouvelle Hollande... Je crois que c'est l'analogue vivant de la vénéricarde imbriquée («fossile de Grignon», et dont on trouve «une variété à Courtagnon»), dont je n'ai que des individus très-jeunes; elle lui ressemble en petit» (p. 610).

\section{février-juin 1819, tome 6,1 ère partie.}

Passant aux Bucardes dans le tome 6, Lamarck note que «les bucardes vivent ordinairement enfoncées dans le sable, à la proximité des côtes. On en trouve dans

68 Je remercie la direction d'Asclepio de me permettre de signaler ce fait. Dans une autre occasion, une revue (française!) m'avait demandé de supprimer cette remarque... 
toutes les mers connues, et on reconnaît, parmi les fossiles de l'Europe, quelques espèces qui ne vivent maintenant que dans les mers de l'Océan asiatique» (p. 3). Plusieurs exemples illustrent cette constatation. Le Cardium Burdigalium, «fossile des environs de Bordeaux...» est une «coquille voisine de notre cardium Indicum» (qui) «habite l'Océan des grandes Indes» (p. 18 et p. 4); le Cardium porulosum, «fossile de Grignon..., tient par ses rapports au card. Asiaticum» (qui) «habite l'Océan asiatique, aux îles de Nicobar» (p. 18 et p. 4); le Cardium sulcatinum, «fossile... semble avoisiner notre card. sulcatum par ses rapports, mais elle est moins grande et moins inéquilatérale»; cette espèce actuelle «habite la Méditerranée» (p. 18 et p. 10); le Cardium Telluris, «fossile de S.-Jean-d'Assé, département de la Sarthe... (se) trouve aussi près de Chauffour, à deux lieues du Mans». C'est une «coquille rapprochée du cardium cardissa et des espèces avoisinantes», (qui) «habite l'Océan indien» (p. 19 et 16); la Cardita intermedia, «habite les mers de la Nouvelle Hollande... et se trouve fossile en Italie, près de Sienne» (p. 23); la Cypricardia coralliophaga, «habite les mers de $\mathrm{S}$. Domingue, dans les masses madréporiques, les coraux... On la trouve fossile en Italie» (p. 28); l'Isocardia cor, «habite l'Océan d'Europe, la Méditerranée, etc... La variété fossile se trouve en Italie, près de Plaisance, et aux environs de Bordeaux» (p. 31); le Pectunculus pulvinatus, «fossile de Grignon, de Courtagnon, des environs de Beauvais, de la Touraine; le même, variété (2), est commun près de Bordeaux, de Dax, etc.; le même, variété (3), se trouve en Italie, dans le Piémont et à Sienne... Je le crois l'analogue du P. glycimeris» (qui) «habite la Méditerranée et l'Océan atlantique. La variété (b) se trouve dans la Manche...» (p. 54-55 et p. 49); le Pectunculus cor, est un «fossile des environs de Bordeaux... Je le crois l'analogue du P. pilosus», (qui) «habite la Méditerranée et l'Océan atlantique» (p. 55 et p. 49-50); le Pectunculus transversus, «fossile de Plaisance (qui) a quelque chose de la forme du P. glycimeris», (qui) «habite la Méditerranée et l'Océan atlantique..., mais il est plus transverse et en est distingué par ses stries». «La variété (b) se trouve dans la Manche» (p. 55 et p. 49); le Pectunculus nummiformis, est un «fossile de la Touraine; on le trouve aussi à Grignon... II semble l'analogue du pectunculus nummarius», (qui) «habite la Méditerranée», «mais il n'est pas auriculé, et varie beaucoup» ( p. 56 et p. 53); la Nucula rostrata «habite la mer Baltique, les côtes de la Norwège... On la connaît dans l'état fossile», sous la forme de la «Nucula rostralis, fossile de la Bourgogne», qui «paraît être l'analogue de la N. rostrée» ( p. 58-59-60); la Nucula margaritacea «habite l'Océan européen, à Cherbourg, sur les côtes d'Angleterre et dans la mer du Nord... On la trouve fossile en divers lieux de la France» (p. 59 ).

L'importance que Lamarck attache à la recherche des espèces analogues actuelles et fossiles pour la détermination des espèces se révèle par les réflexions qu'il fait à propos d'espèces isolées. Classant le Chama loevigata, espèce fossile, il remarque: «Je ne connais aucune came vivante qui puisse être l'analogue de cette coquille; ainsi c'est une espèce distincte» (p. 97). En revanche, le Chama gryphina, «fossile du Piémont, colline de Lastesan.. paraît tenir du Ch. Gryphoides», (qui) «habite la Méditerra- 
née, l'Océan américain?»; «néanmoins son grand crochet tourne de droite à gauche» (p. 97 et p. 94); le Chama unicornaria, «fossile des environs de Plaisance... est au moins une variété de la came unicorne», (qu') «on dit de la Méditerranée, des mers de l'Inde et d'Amérique» (p. 98 et p. 94).

Les modioles fournissent plusieurs exemples d'espèces analogues. La Modiola picta (Modiole arborisée), «habite l'Océan atlantique?... Dans une pierre des environs de Mayence, qui fait partie du cabinet de M. Faujas, et qui contient des individus d'une petite paludine, on aperçoit une modiole fossile que nous croyons être analogue à la modiole arborisée» (p. 112-113); la Modiola cinnamomea, «habite les mers de l'Isle de France... La variété (b) a été trouvée dans l'intérieur de polypiers pierreux. On la trouve fossile, près de Rome» (p. 114-115); la Modiola subcarinata est un «fossile de Grignon. On en trouve une variété près de Plaisance, en Italie. Elle se rapproche de la M. papuana» (qui) «habite l'Océan atlantique boréal, les côtes de l'Amérique septentrionale» (p. 116 et 111).

Les Mollusques conchifères présentent encore de nombreux cas d'espèces analogues. Le Mytilus margaritaceus, «fossile d'Angleterre, trouvé en creusant un canal de navigation dans le Devonshire... avoisine le mytilus exustus» (qui) «habite les mers d'Amérique» (p. 128 et 121); 1'Avicula phaloenacea, «fossile des environs de Bordeaux... paraît tenir de l'Av. papilionacée» (qui) «habite les mers de la Nouvelle Hollande» (p. 150 et 149); la Lima spathulata, «fossile de Grignon... tient de la lime étroite», (qui) «habite aux îles de Nicobar», «mais elle s'élargit plus supérieurement», (p. 158 et 157); la Lima vitrea, «fossile de Grignon... tient de très-près à la L. linguatule» (qui) «habite les mers de la terre de Diémen» (p. 158 et 157); le Pecten maximus, «habite les mers d'Europe... On le rencontre fossile dans quelques provinces de France» (p. 163); le Pecten medius, espèce actuelle, est «intermédiaire entre l'espèce précédente» (le Pecten maximus, fossile et actuel), «et celle qui suit» (le Pecten Jacoboeus, lui aussi fossile et actuel), (p. 163); le Pecten Jacoboeus, «habite les mers d'Europe... On la trouve fossile en Italie» (p. 163); le Pecten pleuronectes, «habite l'Océan indien... Elle se trouve fossile en France, à S.-Paul-Trois-Châteaux, département de la Drôme» (p. 165); le Pecten asperrimus, «habite les mers australes, à la Nouvelle Hollande, les côtes de Diémen... On le trouve fossile en Europe»(p. 174); le Pecten asper, "fossile des environs de la Ferté-Bernard, département de la Sarthe... semble être l'analogue fossile de notre $P$. asperrimus qui vit dans les mers de la Nouvelle Hollande» (p. 180 et 174); le Pecten benedictus, «fossile de France, près de Perpignan, et des environs de Doué, département de Maine-et-Loire... tient de trèsprès au $P$. ziczac» (qui) «habite l'Océan atlantique et américain». «On dit qu'on le trouve vivant dans la mer Rouge» (p. 180 et 164); le Pecten lepidolaris est un «fossile des environs de Boutonnet, près de Montpellier... Il tient du P. asper», fossile dont nous avons vu qu'il «semble être l'analogue fossile du pecten asperrimus», pecten actuel (p. 182 et 174); le Pecten scabrellus, «fossile d'Italie... a des rapports avec le P. pallium» (qui) «habite les mers de l'Inde» (p. 183 et 170); la Plicatula angulosa, 
«fossile... a des rapports avec la plicatule en crête» (qui) «habite les mers d'Amérique» (p. 185); la Plicatula rugosa est un fossile qui «fait un passage» des plicatules (actuelles et fossiles) aux spondyles (p. 186); le Spondylus crassi-squama, «habite les mers de l'Inde... On le trouve fossile à Carthagène d'Amérique» (p. 191); le Spondylus crassi-costa, «fossile des environs de Turin,... parait avoir de l'analogie avec notre Sp. grosses-écailles (Sp. crassi-squama)» (p. 193 et 191).

Les podopsides, autre genre de mollusques, «que l'on ne connaît que dans l'état fossile, avoisinent les gryphées par leurs rapports... Ces coquilles tiennent encore aux pectinides... Elles semblent avoir des rapports avec les plagiostomes...»(p. 194-195).

Les huitres présentent aussi beaucoup de cas de ce genre. Un des plus remarquables est celui de l'Ostrea erucella, espèce qui «habite l'Océan indien», et qui est «curieuse en ce qu'elle indique le chaînon auquel appartiennent quelques espèces singulières que l'on trouve fossiles en Europe» (p. 211). L'Ostrea Virginica «habite les côtes de Virginie... On la trouve fossile en France, près de Bordeaux»(p. 207); 1'Ostrea flabelloides est une huître fossile qui «est presque l'analogue de l'huître crête-decoq» (qui) «habite l'Océan indien» (p. 215 et 213); l'Ostrea crassissima «fossile... tient... de l'O. Virginica» (qui) «habite les côtes de Virginie» (p. 217 et 207); l'Ostrea edulina, «fossile des environs de Paris, de Longjumeaux, de Normandie, du Piémont. Ici se rapportent les variations d'une huître fossile qui paraît appartenir à l'ostrea edulis» (qui) est l'huître comestible des mers d'Europe (p. 218 et 203).

Autres exemples de conchifères analogues: la Placuna papyracea, qui «habite l'Océan indien, la mer Rouge, et se trouve à Sienne en Egypte, presque fossile» (p. 224); la Terebratula ampulla, «fossile d'Italie, rapportée de Plaisance par M. Cuvier.. Cette espèce a les plus grands rapports par sa forme avec l'espèce vivante que j'ai décrite, $\mathrm{n}^{\circ} 5$, sous le nom de terebratula rotundata» (p. 251 et 246).

En ce qui concerne les Lingules, Lamarck ne retient que la lingule actuelle, Lingula anatina, qui «habite l'Océan des Moluques»(p. 258). Mais il a remarqué que «l'animal de la térébratule est fort rapproché de celui de la lingule par ses rapports» (p. 244). Le genre Térébratule compte d'ailleurs de très nombreuses espèces fossiles. Lamarck en cite 47, avec noms et descriptions, ainsi que 12 vivantes. Il est intéressant de comparer de nouveau sa «méthode» de traitement des fossiles d'invertébrés avec celle de Cuvier dans ce cas précis: «On trouve, dit Cuvier, une quantité innombrable de térébratules à l'état fossile ou pétrifié, dans certaines couches secondaires d'anciennes formations. Les espèces sont moins nombreuses dans la mer actuelle». (Le Règne animal distribué d'après son organisation, 1817, t.2, p. 503). Il donne en note les noms d'une douzaine d'espèces vivantes, et renvoie pour les espèces fossiles à l'Encyclopédie méthodique, sans indication de rapprochements: il est vrai que ce n'était pas sa «méthode» à lui, même pas dans l'étude des «quadrupèdes», comme nous l'avons vu. 
Les Mollusques conchifères apportent ainsi à Lamarck un lot important de «pièces justificatives» dans la démonstration de son anticatastrophisme et de son transformisme. 11 faut retenir cependant ses aveux de limitation dans son travail que lui impose son handicap. Il avait déjà averti à propos des Térébratules: «Etant actuellement tout-à-fait privé de la vue par des cataractes qui sont hors d'état de subir avec succès les opérations qui pourraient me rendre la lumière, $\mathrm{M}$. Valenciennes a bien voulu se charger de la détermination des espèces de ce genre qu'il a pu voir dans les collections de Paris» (p. 244).

Lamarck répète le même avertissement à propos de l'étude qu'il fait des Mollusques proprement dits. Ainsi en qui concerne les Oscabrions: «Ce genre est fort nombreux en espèces... Malheureusement, privé de la vue, et hors d'état de constater nous-mêmes les caractères des espèces, nous n'en citerons qu'un petit nombre parmi celles que nous possédons» (p. 320). Ensuite en ce qui concerne les Patelles: «Ce que je viens d'exposer, d'après ma seule collection, que je n'ai pas même épuisée, est probablement très-peu de chose auprès de ce qu'eût été mon travail, si j'eusse fait l'examen des patelles du Muséum; mais ma cécité m'oblige de me borner aux seules espèces que j'ai citées en exemple. J'espère pouvoir reprendre un jour ce travail, et le donner dans un supplément à la fin de mon ouvrage» (p. 335). On sait que Lamarck n'a pas pu remplir sa promesse...

\section{Système analytique des connaissances positives de l'Homme}

Lamarck, devenu aveugle, rappelle combien il a été laborieux et minutieux dans ses études, quand il était en pleine possession des ses moyens: «Je me suis livré constamment à l'observation des faits, et me suis ensuite efforcé de rassembler tous ceux qui avaient été constatés par d'autres observateurs... J'ai long-temps examiné tous les faits parvenus à ma connaissance» (p. 2). Personne, du reste, de son temps, n'aurait osé mettre en doute la valeur scientifique de son travail.

Lamarck se félicite d'avoir ainsi fait faire des «progrès...aux sciences naturelles..., particulièrement en instituant l'ordre le plus naturel que l'on puisse établir parmi les animaux sans vertèbres, et en montrant que cet ordre prend sa source dans la production successive de ces animaux» (p. 34) ${ }^{69}$.

69 DARWIN allait exprimer la même idée en 1859: «Toutes les règles, toutes les difficultés, tous les moyens de classification qui précèdent, s'expliquent, à moins que je ne me trompe étrangement, en admettant que le système naturel a pour base la descendance avec modification, et que les caractères regardés par les naturalistes comme indiquant des affinités réelles entre deux ou plusieurs espèces sont ceux qu'elles doivent par hérédité à un parent commun. Toute classification vraie est donc généalogique; la communauté de descendance est le lien caché que les naturalistes ont, sans en avoir conscience, toujours recherché, sous le prétexte de découvrir, soit quelque plan inconnu de création, soit d'énoncer des propositions générales, ou de réunir des choses semblables et de séparer des choses différentes». De l'Origine des Espèces, (1859), traduction TORT, P. (1989), Dictionnaire du Darwwinisme et de l'Évolution, p. 463. 


\section{Cuvier}

1821 Nouvelle Édition des Recherches sur les Ossemens fossiles. (1ère édition: 1812)

1821, t.1. Cuvier n'avait plus fait paraître beaucoup d'études sur les fossiles depuis l'édition de 1812 des Recherches, et cependant, comme il le fait remarquer, «la science des fossiles a fait de grands progrès en Europe depuis l'époque de cette première édition» (Avertissement, p. 1). Comme nous venons de le voir aussi, Lamarck avait pratiquement occupé le terrain à lui tout seul pendant ces années, avec l'édition rapprochée des tomes successifs de son immense Histoire naturelle des Animaux sans vertèbres, dont nous savons qu'elle était devenue l'instrument de travail indispensable des invertébristes, en particulier dans leur étude des fossiles. Cuvier n'était évidemment pas resté inactif: «l'auteur, avertit-il, depuis huit ans, n'a pas cessé de revoir, de compléter et de coordonner son travail» (p. 5). Grâce à ses travaux, et de ceux de ses collègues de tous pays, «beaucoup d'objets déjà connus ont pu être étudiés avec plus de soin, mais une infinité d'objets nouveaux se joignent à ceux que l'on connoissoit; dès ce moment, le nombre des hippopotames fossiles est porté à quatre; celui des rhinocéros également à quatre; celui des crocodiles à six ou sept, sans parler du nouveau genre des ichtyo-saurus. Autour de Paris seulement deux genres et peutêtre dix ou douze espèces nouvelles viendront augmenter le nombre des espèces perdues» (p. 2).

Cuvier est donc à même de présenter, non seulement une nouvelle édition, mais véritablement un ouvrage nouveau, beaucoup plus riche que le précédent. L'ouvrage sera en effet beaucoup mieux composé: «L'auteur s'est efforcé d'ailleurs de mettre tout l'ouvrage dans un meilleur ordre, et d'empêcher qu'il ne se ressente de la manière fragmentaire et successive dont avoient été rédigés les Mémoires qui composoient la première édition; chaque fait, chaque idée y sera à sa place, et on pourra le lire et l'étudier de suite, sans être obligé de revenir sur les premiers Mémoires, et de les rectifier au moyen des idées nouvelles et des supplémens contenus dans les Mémoires suivants» (p. 4).

La nouvelle édition des Recherches sur les Ossemens fossiles représente ainsi une véritable somme des travaux de Cuvier sur la paléontologie des vertébrés. Dans le Résumé général qu'il donne à la fin de l'ouvrage (t.5, 2, 1824, p. 527 à 536), Cuvier récapitule la liste «des Animaux dont les caractères ont été indiqués ou rectifiés, ou dont l'Ostéologie a été décrite dans cet ouvrage». Cette liste contient non seulement les animaux fossiles qu'il a étudiés, mais aussi les animaux vivants qui leur ressemblaient le plus: «Il (l'auteur) y fera connoître tout ce qu'il a rassemblé et tout ce que d'autres auteurs ont décrit depuis 1812 de relatif soit aux os fossiles, soit à l'ostéologie des espèces vivantes voisines de celles d'où proviennent ces os» (p. 4). On voit que Cuvier garde la même perspective de démonstration de la non-analogie des 
espèces vivantes et fossiles, car c'était sur elle, comme nous le savons, et comme il le répétait, qu'il fondait son catastrophisme et son anti-transformisme.

Cuvier distribue ses études entre les différentes classes de Mammifères (p. 527534), de Reptiles, dans lesquels il classe les Batraciens (p. 535-542). On y trouve aussi les Oiseaux, mais pas les Invertébrés, ni l'Homme.

Dans ses articles sur les espèces fossiles, beaucoup plus nombreuses dans cet ouvrage, comme nous l'avons vu, Cuvier reprend les affirmations catastrophistes et antitransformistes qu'il avait énoncées dans ses contributions aux Annales du Muséum, et dans la première édition des Recherches, en les complétant parfois (textes que nous reproduirons dans la mesure où ils sont significatifs). Si elle était plus abondante en faits, la nouvelle édition défendait en effet les mêmes idées que la première. Cuvier y redonnait le «Discours préliminaire» sous la forme d'un «Discours sur les Révolutions de la Surface du Globe, et sur les changemens qu'elles ont produits dans le Règne animal», beaucoup plus développé lui aussi. Et, pour qu'il n'y ait pas de confusion là-dessus, Cuvier en informait le lecteur dans l'Avertissement: «Tout s'accorde donc chaque jour davantage, assurait-il, pour démontrer la vérité d'une grande catastrophe qui a changé la face des continens, détruit des races vivantes, transporté à de grandes distances les foibles restes de celles qu'elle a épargnées, et pour nous faire suivre les traces de plusieurs catastrophes du même genre qui avoient précédé celle-là» (p. 4).

Dans la classe des Mammifères, qu'il considère comme étant «les derniers comme les plus parfaits produits de la puissance créatrice» ${ }^{70}$, Cuvier commence par les Pachydermes.

Il rappelle que c'est lui qui a caractérisé l'Eléphant: l' «Éléphant fossile ou Mammouth des Russes (El. primigenius)», t.1, 1821, p. 75-195 et 335; t.3, 1822, p. 371 et $405 ;$ t.4, 1823, p. 491, en les distinguant des éléphants vivants, dont il fait deux espèces elles-mêmes distinctes l'une de l'autre, l'éléphant d'Asie et l'éléphant d'Afrique: t.1, 1821, p. 12-72. Il en distingue aussi six espèces de Mastodontes: le «Grand Mastodonte (M. maximus)», t.1, 1821, p. 206-249; t.3, 1822, p. 376; le «Mastodonte à dents étroites (M. angustidens)», t.1, 1821, p. 250-265 et 335; t.4, 1823, p. 493; le «Mastodonte des Cordilières ( $M$. Andium)», le «Mastodonte humboldien (M. Humboldii)», le «Petit Mastodonte (M. minutus)», le «Mastodonte tapirö̈de (M. tapiroïdes)», t.1,1821, p. 266-268.

En ce qui concerne les éléphants, Cuvier rappelle ses déclarations catastrophistes précédentes, en les complétant: «Tout se réunit donc pour faire penser que l'éléphant fossile, est comme eux» (les autres fossiles du quaternaire) «d'une espèce éteinte, quoiqu'il ressemble plus qu'eux à l'une des espèces aujourd'hui existantes, et que son

70 1824, t.5, 2ème partie. Des Ossemens de Reptiles 542 p. + pl., Observations préliminaires, p. 8. 
extinction a été produite par une cause subite, par cette même grande catastrophe qui a détruit les espèces de la même époque et dont nous allons retrouver des preuves dans tous les chapitres suivants» (t.1, 1821, p. 204).

Cuvier a aussi étudié quatre Hippopotames fossiles, tous distincts de l'hippopotame actuel, t.1, 1821, p. 270-302. Ce sont le «Grand Hippopotame fossile (H. major)», t.1, 1821, p. 304-322, t.3, 1822, p. 380, t.4, 1823, p. 493; le «Petit Hippopotame fossile (H. minutus)», t.1, 1821, p. 322-331, t.3, 1822, p. 382; le «Moyen Hippopotame fossile (H. medius)», t.1,1821, p. 332-333; l' «Animal voisin des Hippopotames (H. dubius)», t.1, 1821, p. 333-334.

A leur propos, Cuvier rappelle: «Chacun peut voir maintenant que malgré la ressemblance générale de ces os avec ceux du vivant, ils offrent cependant tous assez de caractères pour faire admettre une différence d'espèce, et que le grand hippopotame fossile n'échappe point à la règle qui frappe et les éléphans et les rhinocéros et les autres pachydermes de nos couches meubles. Quant aux deux autres espèces d'hippopotames fossiles, cette règle s'y applique dans toute son étendue et même avec plus de force qu'aux éléphans.» ( t.1,1821, p. 322).

Les Rhinocéros fossiles sont au nombre de quatre. Le «Rhinocéros fossile à narines cloisonnées ( $R$. tichorhinus)», t.2, 1ère partie, 1822, p. 64, et t.4, 1823, p. 496, est différent du «Rhinocéros unicorne des Indes», t.2, 1ère partie, 1822, p. 5; le «Rhinocéros fossile à narines non cloisonnées et sans incisives ( $R$. leptorhinus)», t.2, 1ère partie, 1822, p. 71, est différent du «Rhinocéros unicorne de Java», t.2, 1ère partie, 1822 , p. 33, et t.3, 1822, p. 384; le «Rhinocéros fossile à narines non cloisonnées muni d'incisives (R. incisivus)», t.2, 1ère partie, 1822, p. 89, t.3, 1822, p. 390, et t.5, 2ème partie, 1824, p. 501, est différent du «Rhinocéros bicorne de Sumatra», t.3, 1822, p. 385; le «Petit Rhinocéros (R. minutus)», t.2, 2ème partie, 1822, p. 89, est différent du «Rhinocéros bicorne du Cap», t.2, 1ère partie, 1822, p. 29 et t.4, 1823, p. 493.

Cuvier fait aussi remarquer: «On peut donc affirmer, ainsi que nous en avions prévenu, qu'il existe des ossemens de rhinocéros à peu près dans autant de pays que des ossemens d'éléphans; que ces deux sortes d'os s'accompagnent, et qu'il se trouve avec eux des os d'autres grandes espèces; que presque toujours on les déterre dans les mêmes circonstances; que leur degré de conservation est semblable; et que les causes géologiques qui ont placé les uns où ils se trouvent, sont les mêmes que celles qui $\mathrm{y}$ ont placé les autres» (t.2, 1ère partie, 1822, p. 56).

Les pachydermes suivants n'ont aucun point de comparaison dans la nature actuelle. Ce sont les Palaeothériums: les «Palaeotherium magnum, Pal. medium, Pal. crassum, Pal. latum, Pal. curtum, Pal. minus, Pal. minimum», t.3, 1822, «passim et 
spécialement p. 250», et t.5, 2ème partie, 1824, p. 505; puis «Pal. aurelianense», t.3,1822, p. 254 et t. 4, 1823, p. 498-499, et «Pal. isselanum», t.3, 1822, p. 258.

Il en est de même pour les Anoplothériums: «Anoplotherium commune, Anopl. gracile, Anopl. leporinum, Anopl. murinum, Anopl. obliquum», t.3, 1822, «passim, et spécialement p. 250», et «Anoplotherium secundarium», ibid. et t.3, 1822, p. 396.

Et encore les Anthracothériums: l' «Anthracotherium magnum», t.3, 1822, p. 398; 1' «Anthr. minus», ibid., p. 403; l' «Anthr. minimum», ibid., p. 404; l' «Anthr. alsaticum», t. 4, 1823, p. 501; 1' «Anthr. velaunum», t.5, 2ème partie, 1824, p. 506.

Les autres pachydermes fossiles se présentent à l'unité: le «Choeropotamus parisiensis», t.3, 1822, p. 260; l' «Adapis parisiensis», t.3, 1822, p. 265, ainsi que l' «Élasmothérium», t.2, lère partie,1822, p. 95.

Viennent ensuite les exemples du Cheval: le «Cheval fossile», t.2, 1ère partie, 1822, p. 109, différent du Cheval actuel, t.2, 2ème partie, 1822, p. 99; du Cochon: le «Cochon fossile», t.2, 1ère partie, 1822, p. 125, différent du Cochon actuel, t.2, 2ème partie, 1822, p. 116; du Tapir: le «Tapir gigantesque», t.2, lère partie, 1822, p. 165, différent du «Tapir d'Amérique», t.2, 2ème partie, 1822, p. 145, et du «Tapir des Indes», t.2, 1ère partie, 1822, p. 156.

A propos du Cheval, Cuvier affirme maintenant: «On peut donc assurer qu'une espèce du genre du cheval servoit de compagnon fidèle aux éléphans et aux autres animaux de la même époque dont les débris remplissent nos grandes couches meubles; que cette espèce ne différoit pas beaucoup pour la taille de nos chevaux domestiques de grandeur moyenne; que ses os des membres n'offroient point de différences sensibles; mais on doit remarquer en même temps que ces rapports ne suffisent point pour faire affirmer que cette espèce fût l'une de celles qui vivent aujourd'hui plutôt qu'un des animaux dont la race a été détruite par les révolutions du globe» (t.2, 1ère partie, 1822, p. 113).

A propos du Tapir: «On a pu voir, par ce qui précède, que le daman, le tapir et le rhinocéros ont ensemble de grands rapports ostéologiques, et que l'on doit aussi rapprocher d'eux le cheval qui leur ressemble par la plupart des caractères de son squelette; mais ces animaux, bien qu'appartenant à la même famille naturelle, ne sont cependant pas tellement pareils que l'on ne puisse concevoir des genres intermédiaires qui les uniroient....Ces intervalles, ces sortes de hiatus laissés dans leur série, paroissent avoir été remplis autrefois par des genres dont nous ne connoissons plus que les débris fossiles, mais dont les dents, les pieds et les autres organes caractéristiques tiennent en partie de l'un en partie de I'autre, et qui diffèrent de tous par l'ensemble....ll paroît que ces tapirs gigantesques datent de la même époque que les mastodontes et les éléphans fossiles, qu'ils vivoient avec eux, et qu'ils ont été détruits par la même catastrophe, puisque leurs os se trouvent dans les mêmes couches, et quel- 
quefois, comme à Chevilly et à Avaray, pêle-mêle avec les leurs» (1822, t.2, lère partie, p. 163 et 175).

Pour terminer la série des «Pachydermes», viennent les Lophiodons, qui n'ont pas non plus d'espèces correspondantes actuelles. Ainsi le «Lophiodon moyen d'Issel», t.2, lère partie, 1822, p. 177; le «Petit Lophiodon d'Issel», p. 183; le «Grand Lophiodon d'Issel, d'Argenton et de Soissons», p. 184, 189 et 211; le «Lophiodon secondaire d'Argenton», p. 191; le «Petit Lophiodon d'Argenton», p. 193; le «Trèspetit Lophiodon d'Argenton», p. 194; le «Grand Lophiodon de Buchsweiler», p. 200 et 212; le «Lophiodon secondaire de Buchsweiler», p. 206; le «Très-grand Lophiodon de Montabusard près Orléans, et de Gannat», p. 214, et t.3, 1822, p. 394; le «Moindre Lophiodon de Montabusard», t.2, 1ère partie, 1822, p. 216; le «Lophiodon de Montpellier», p. 217; le «Lophiodon du Laonnais», p. 218; et le «Cinquième Lophiodon d'Argenton», t.4, 1823, p. 498.

A propos des Lophiodons, Cuvier rappelle ses vues générales sur l'histoire de la terre et de la vie: «Ce que ces animaux ont de plus important pour la théorie de la terre, c'est que tous ceux de leurs débris, dont il a été possible de constater le gisement, sont enveloppés de pierres ou de terres remplies exclusivement de coquilles d'eau douce, et qui, par conséquent, ont été déposées dans les eaux douces; que les animaux dont on trouve les débris avec les leurs sont, ou des animaux terrestres et inconnus comme eux, ou des crocodiles, des trionyx et des émides, par conséquent des animaux aquatiques dont les genres habitent aujourd'hui les eaux douces des pays chauds; enfin que dans plusieurs endroits bien déterminés ces couches sont recouvertes par des couches d'une origine certainement marine. Par conséquent le genre des lophiodons vient se joindre à ceux des palaeothériums et des anoplothériums, ainsi qu'à d'autres genres inconnus que je décrirai bientôt, pour démontrer la certitude d'un état antérieur, d'une création animale ${ }^{71}$ qui occupoit la surface de nos continens actuels, et nommément celle de la France, et qu'une irruption de la mer est venu détruire, pour en recouvrir les débris par des roches d'une nouvelle origine» ( t.2, lère partie, 1822, p. 222).

En donnant la description de l'élasmothérium, Cuvier affirme qu'on ne peut «douter qu'il n'ait été d'un genre particulier... Quel étonnant animal ne devoit-ce donc pas être que cet élasmothérium!» (t.2, 1ère partie, 1822, p. 97).

Dans ses considérations sur les Pachydermes, Cuvier remarque: «J'ai dit depuis long-temps que la famille des Pachydermes moins riche en genres, et dont les genres sont moins liés entre eux que dans aucune autre, semble avoir fait des pertes, auxquelles

71 Noter le sens du mot «création» dans le vocabulaire de CUVIER: il ne s'agit pas d'un acte, mais d'un état. 
seroient dus ces sortes de hiatus ou de vides qui interrompent sa série. C'est en effet à la famille des Pachydermes que l'étude des os fossiles a fourni le plus de formes nouvelles et singulières: les divers Mastodontes, le Rhinocéros à cloison osseuse, les Palaeotheriums et les Anoplotheriums, les Lophiodons, offrent déjà un nombre d'espèces perdues plus considérable que celui des espèces vivantes connues des naturalistes, et cependant ils n'épuisent pas, à beaucoup près, celles que nos couches recèlent encore... C'est une chose bien remarquable que cette abondance des Pachydermes parmi les fossiles, comparativement à leur proportion dans le nombre des animaux vivans. Aussi les nuances qui lient les genres entre eux, ces formes intermédiaires, ces passages d'un genre à l'autre si communs dans les autres familles, sembloient-ils manquer dans celle-là. Il étoit réservé à l'histoire des os fossiles de les retrouver dans les entrailles de la terre, parmi les races qui complétoient l'ensemble du grand système des êtres naturels, et dont la destruction y a produit ces lacunes si frappantes» $(1822, \text { t. } 3 \text {, p. } 260 \text { et } 265)^{72}$.

Dans le Résumé général de la première partie, ainsi que dans l'Avertissement précédant la 2ème partie du tome 2 , Cuvier réintroduit les principales bases de sa théorie:

«Quant au résultat géologique, il consiste principalement dans les remarques suivantes.... Il est donc probable que ces ossemens ont été enveloppés par la dernière ou l'une des dernières catastrophes du globe.... La catastrophe qui les a recouverts étoit donc une grande inondation marine, mais passagère.... Avant cette catastrophe, ces animaux vivoient donc dans les climats où l'on déterre aujourd'hui leurs os; cette catastrophe y a recouvert de nouvelles couches les os qu'elle a trouvés épars à la surface; elle a tué et enfoui les individus qu'elle a atteints vivans, et comme on n'en retrouve plus ailleurs des mêmes espèces, il faut bien qu'elle en ait anéanti entièrement les races.... Les parties septentrionales du globe nourrissoient donc autrefois des espèces appartenant aux genres de l'éléphant, de l' hippopotame, du rhinocéros, de l'élasmothérium et du tapir, ainsi qu'à celui du mastodonte, genres dont les uns n'ont plus aujourd'hui d'espèces que dans la zone torride, et dont les autres n'en ont nulle part». (p. 224-226).

Dans l' «Avertissement» par lequel il introduit la seconde partie du tome $2, \mathrm{Cu}-$ vier réaffirme ses idées générales: «Nous avons donné à nos résultats un nouveau degré de généralité, de certitude, et par conséquent d'importance pour l'histoire de la structure du globe....Nous avons cru donner plus d'intérêt à notre travail en faisant voir que les terrains que nous avons décrits n'étoient pas particuliers au bassin de Paris, et nous avons jugé que ce n'étoit pas lui associer des objets étrangers que d'y

72 Voir plus loin, p. 195, les mêmes réflexions faites par LAMARCK, mais dans une perspective transformiste. 
joindre l'indication et quelquefois même la description des terrains semblables aux nôtres qu'on a observés sur les différentes régions du globe». Dans le même «avertissement», il semble rendre hommage aux travaux de Lamarck, ce qui n'est pas tellement fréquent de sa part: «Quant aux coquilles du terrain de Paris, ce travail est fait depuis long-temps, au moins en grande partie, par M. de Lamarck, et nous avons continué de nous servir des noms qu'il a donnés aux coquilles fossiles de notre bassin» (Avertissement, p. I, II et III).

\section{2, t. 3}

Concernant les Oiseaux, Cuvier reproduit les textes de 1807 et 1812, en y ajoutant cependant une incise qui exprime une certain agacement (passage porté en gras par nous): «Qu'on ne vienne donc plus nous parler de ces variations produites par les habitudes. Rien n'a été allongé, raccourci, modifié, ni par les causes extérieures, ni par la volonté intérieure; ce qui a changé a changé subitement, et n'a laissé que ses débris pour traces de son ancien état» ( t.3, 1822, p. 328).

Dans les Additions de ce tome 3 de 1822, Cuvier semble cependant atténuer ses affirmations antérieures sur l'universalité des catastrophes: «M. Jean André Deluc.... ne pense pas que les éléphans occupassent en même temps tous ces pays, ni que l'irruption de la mer qui les fit périr fût générale, unique et momentanée...Ces hypothèses, qui, de l'aveu de l'auteur, sont un développement des vues de son oncle, ne me paraissent avoir rien de contraire aux idées générales que j'ai exprimées, soit dans mon chapitre des Éléphans, page 201 et suivantes de mon premier volume, soit dans le résumé de ma première partie, page 223 et suiv. de mon second volume, soit surtout aux pages LXIII et LXIV de mon Discours préliminaire» ${ }^{73}$. Le lecteur pourra juger, non seulement d'après ces pages, mais d'après toutes celles où Cuvier s'est exprimé sur ce sujet.

\section{Lamarck, avril 1822}

Histoire naturelle des Animaux sans vertèbres, t.6, 2ème partie.

Lamarck continue, dans la deuxième partie du tome 6 de l'Histoire naturelle, qui n'a paru qu'en 1822, à discuter de la parenté des espèces, et par conséquent de leur origine. Ainsi, étudiant les Calyptrées, il considère que «la lame, soit en cornet, soit en diaphragme spiral, qui se trouve dans la cavité de sa coquille, semble indiquer en lui un élément de forme qui paraîtrait conduire à celle des trochus». Et il se pose la question: «Serait-ce ici que les coquilles spirales à ouverture entière prendraient leur source et formeraient une série particulière en rameau latéral?» (p. 20-21).

\footnotetext{
73 Addition «Sur les causes qui ont enfoui les os d'Éléphans», p. 374-375.
} 


\section{Lamarck, août 1822, Histoire naturelle des Animaux sans vertèbres, t.7.}

Le souci que mettait Lamarck à trouver des espèces analogues se manifeste plus fortement que jamais dans ses études du septième et dernier tome de son grand ouvrage. Ainsi, à propos des Cadrans, il signale leurs rapports étroits avec les Troques et les Planorbes; pour ces derniers, «l'examen de certaines espèces fossiles nous montre qu'il est même assez difficile d'établir entre les cadrans et les planorbes des limites bien tranchées». Il n'empêche que Lamarck remarque qu'il y a parmi les Cadrans «quelques (espèces) dans l'état fossile, dont les analogues vivans n'ont pas encore été observés» (p. 2). Il en a trouvé par contre parmi les Troques. Ainsi le Trochus calyptroeformis, qui «habite les mers de la Nouvelle-Hollande»,...est une «coquille fort intéressante en ce qu'elle paraît être l'analogue vivant d'un fossile que l'on trouve à Grignon... et que j'avais nommé calyptroea trochiformis «(p. 12 et 558); le Trochus crenularis, «fossile de Grignon,... a de si grands rapports avec le Tr. Mauritianus» (qui) «habite les mers des îles de France et de Bourbon», «que je crois qu'il n'en est qu'une variété» (p. 21 et 555); le Trochus granulatus, que l'on «trouve fossile en Angleterre», a un «analogue vivant» (p. 26). La Turritella terebellata, «fossile de Chaumont», «se rapproche un peu par ses caractères» de la Turritella terebra, qui «habite les mers d'Afrique et de l'Inde»... (p. 56 et 563). La Turritella imbricataria, «fossile de Grignon, Chaumont et Courtagnon,... semble d'abord être l'analogue fossile de notre turritelle imbriquée» (la Turritella imbricata), (qui) «habite l'Océan des Antilles»; «néanmoins ses stries transverses, entremêlées de stries finement granuleuses, suffisent pour l'en distinguer» (p. 57 et 561). La Turritella terebralis, «fossile des environs de Bordeaux, où il est très-commun,... a des rapports avec le $T$. terebra; mais, outre son état fossile, elle en est très-distincte» (p. 59 et 56).

Parmi les Mollusques, les Cérites ont particulièrement attiré l'attention de Lamarck. «Leur genre est très-nombreux en espèces; et déjà l'on en connaît un très-grand nombre, soit fraîches ou marines, soit dans l'état fossile... J'ai déjà fait remarquer que plus nos collections s'enrichissent, plus la détermination des genres, et surtout des espèces, devient difficile, les lacunes que nous prenons pour des limites imposées par la nature, se trouvant proportionnellement remplies. Les embarras que j'ai éprouvés pour fixer le caractère de chaque espèce de cérites me permettent d'avancer que c'est principalement dans ce genre que cette vérité se montre avec le plus d'évidence, parce que nous sommes fort avancés dans la collection de ces coquillages.... L'étude des espèces de ce genre est d'autant plus intéressante, que parmi les fossiles dont notre continent se trouve en différens lieux si abondamment rempli, un grand nombre d'entre eux nous présente une suite considérable de cérites qu'il importe de connaître, non-seulement pour l'avancement de l'histoire naturelle, mais encore pour celui de la théorie des mutations qu'a éprouvées la surface de notre globe» (p. 64-65).

S'il n'y a pas cependant à retenir le cas de la Cérite géante, où il semble que Denys de Montfort ait abusé de la bonne foi de Lamarck en la lui vendant comme une 
espèce actuelle ${ }^{74}$, la conclusion est bien entendu valable pour tous les autres nombreux exemples non douteux. Après avoir souligné «l'importance du nouveau fait que présente cette belle coquille pour l'étude de la géologie», Lamarck conclut: «Cette cérite singulière, tant par sa taille que par sa forme, et qui se trouve fossile à Grignon, est d'autant plus intéressante à considérer, que c'est précisément la même espèce qui est actuellement vivante dans les mers de la Nouvelle-Hollande... Le fait trèsremarquable que présente cette espèce, dont les individus, dans deux états trèsdifférens, se trouvent maintenant dans des régions du globe si éloignées l'une de l'autre, sans offrir néanmoins dans leur forme aucune différence notable, prouve assurément selon nous que les divers climats de la terre ont nécessairement changé, et les preuves que nous fournit ce fait ne sont pas les seules que nous puissions citer: nous en offrirons d'autres dans le cours de cet ouvrage» (p. 65-66 et 89).

Les exemples d'espèces analogues ne manquent pas en effet dans les nombreux autres genres de Mollusques étudiés par Lamarck. Ainsi la Pyrula loevigata, «fossile de Grignon et Courtagnon,... a l'aspect, surtout dans les jeunes individus, de notre pyrula ficus» (qui) «habite l'Océan des grandes Indes et des Moluques» (p. 141 et 571). De même la Pyrula tricarinata, «fossile de Parnes.... Espèce rare et trèsremarquable, qui appartient à la division des pyrules dites figues...» (qui habitent) «l'Océan des grandes Indes et des Moluques» ( p. 141 et 571); la Pyrula clathrata, «fossile de Grignon,... a tout-à-fait la forme du bulla ficus de Linné, et peut être regardée comme l'analogue fossile de l'une des deux espèces vivantes dont les synonymes ont été confondus parmi ceux de la figue» (p. 572 et 141); le Murex tripteroides, «fossile de Grignon... Je le considérais comme l'analogue fossile du rocher triptère», (qui) «habite l'Océan des grandes Indes», «mais il est plus allongé, et offre des caractères différens» (p. 177 et 165); le Triton clathratum «habite les mers de l'Amérique méridionale», et est un «fossile de Grignon... Cette Coquille est l'analogue fossile bien remarquable de notre triton clathratum, nommé vulgairement la grimace blanche ou gauffrée, qui est une espèce très-distincte, vivant actuellement dans l'Océan austral, et que j'ai mentionnée dans son genre, p. 186» (p. 186 et 577); le Rostellaria fissurella, «fossile de Grignon et de Courtagnon..., vit dans les mers de l'Inde, selon Linné» (p. 194); le Cassidaria carinata, «fossile de Grignon,... semble avoir quelques rapports avec le C. echinophora» (qui) «habite les mers Méditerranée et Adriatique» ( p. 217 et 215-216); le Purpura imbricata «habite dans les mers d'Europe, où elle est aussi très commune...Cette coquille peut n'être qu'une variété de celle qui précède (le Purpura lapillus)»; car, fait de nouveau remarquer Lamarck, «à l'égard des produits de la nature, tous sont variétés les uns des autres, ce que constate partout l'observation des avoisinans»; elle est aussi un «fossile de Courtagnon, où il

74 Cf. Deshayes G. P. (1824), Description des Coquilles fossiles des environs de Paris, Paris, t.2, p. $300-301$ 
est commun. Son analogue vivant (voyez p. 244...) habite nos côtes de l'Océan et celles des mers du nord de l'Europe» (p. 244-245 et 577); le Buccinum clathratum présente le même cas: «On le dit vivant dans l'Océan des grandes Indes, et on le trouve dans l'état fossile en Italie, près de Sienne, et en France, à Courtagnon, etc. Je ne le possède que dans ce dernier état» (p. 279).

A propos des Mitres, Lamarck observe: «On en connaît un assez grand nombre d'espèces dans l'état fossile, et même dont les analogues vivans n'ont pas été observés» (p. 298).

Les Volutes actuels ont aussi des analogues fossiles. Ainsi le Voluta nucleus, déjà mentionné dans le tome 17 des Annales, et le Voluta musicalis, «fossile de Courtagnon et de Grignon,... très-belle espèce, qui avoisine par ses rapports le $V$. musica» (qui) «habite l'Océan des Antilles» (p. 349 et 339).

Dans les Ovules, Lamarck relève les cas de l'Ovula passerinalis, qui est un «fossile des environs de Fiorenzola, dans le Plaisantin,... dont l'analogue vivant n'est pas encore connu» (p. 371); et de l'Ovula birostris, «fossile des environs de Fiorenzola, dans le Plaisantin... Elle ressemble en tout à son analogue vivant, qui habite sur les côtes de Java» (p. 371 et p. 370).

Les Porcelaines sont les mollusques qui fournissent peut-être le plus grand nombre de «pièces justificatives» de sa doctrine transformiste. Le Cyproea mus, «fossile des environs de Fiorenzola, dans le Plaisantin,... est parfaitement l'analogue fossile de l'espèce vivante dont elle porte le nom», le Cyproea mus, (qui) «habite l'Océan américain et la Méditerranée» (p. 381 et 405); le Cyproea rufa, «fossile du Plaisantin,... ne diffère de l'analogue vivant déjà cité que par l'altération de ses couleurs», le Cyproea rufa (qui) «habite l'Océan africain, les côtes du Sénégal, la Méditerranée»(p. 388 et 406); le Cyproea adusta est une espèce actuelle qui «habite l'Océan asiatique» --- le Cyproea pyrula, «fossile des environs de Fiorenzola, dans le Plaisantin», présente une «forme très-rapprochée de celle du $C$. adusta»- le Cyproea utriculata, «fossile des environs de Fiorenzola, dans le Plaisantin,...se rapproche aussi beaucoup du C. adusta» (p. 389 et 405-406); le Cyproea inflata, «fossile de Grignon, (qui) se trouve aussi dans le Plaisantin», est une «coquille très-rapprochée par la forme et la taille du Cyproea turdus», qui est une porcelaine actuelle (p. 392 et 407); le Cyproea fabagina, «fossile des environs de Turin», présente une «forme rapprochée de celle du C. flaveola», qui est une porcelaine actuelle - le Cyproea flavicula, «fossile des environs de Fiorenzola, dans le Plaisantin» a aussi une forme «un peu rapprochée de celle du C. flaveola» (p. 394 et 406-407); le Cyproea columbaria, porcelaine fossile, «se rapproche entièrement par la forme et la taille du $C$. sanguinolenta», qui est une porcelaine actuelle (p. 395 et 407); le Cyproea ambigua, «fossile des environs de Bordeaux» est une «coquille se rapprochant par sa forme du C. staphyloea», porcelaine actuelle (p. 399 et 407); le Cyproea sphoericulata, «fossile des environs de Fiorenzola, dans le Plaisantin,...se rapproche du C. Oniscus par sa taille et son as- 
pect», (qui) «habite l'Océan américain»; (p. 402 et 408); le Cyproea pisolina, «fossile des environs d'Angers... Jolie petite porcelaine, très-distincte comme espèce, et dont l'analogue vivant n'est pas encore connu» (p. 408); le Cyproea pediculus, qui «habite l'Océan des Antilles,etc.», est aussi un «fossile de Grignon et des environs d' Angers» (p. 403 et 408); le Cyproea leporina est un «fossile des environs de Dax... Je ne reconnais dans aucune des espèces vivantes que j'ai décrites la forme précise de cette porcelaine fossile...» (p. 405); le Cyproea dactylosa, «fossile très-rare, qui paraît avoir été recueilli à Grignon...Très-belle espèce de porcelaine, éminemment distincte de toutes celles qui sont connues, et surtout de celles qui composent la division des sillonnées» (p. 407-408).

Dans les Tarrières, le Terebellum fusiforme est un «fossile dont la localité n'est pas bien connue... Cette espèce se rapproche beaucoup du T. subulatum (qui)... habite l'Océan indien... Cette belle espèce est la seule connue de ce genre comme vivant actuellement dans les mers» (p. 411).

Dans les Olives, Lamarck ne mentionne aussi que 1'Oliva plicaria, «fossile des environs de Bordeaux... Son ouverture est ample et lâche inférieurement, comme dans l'O. hiatula» (qui) «habite l'Océan américain austral et les côtes du Sénégal» (p. 439 et 435-436).

Les Cônes, en revanche, fournissent de très nombreux exemples d'espèces analogues: le Conus clavatus, «fossile des environs de Dax, dans la France méridionale... paraît être très-distinguée, par la forme de sa spire, de tous les cônes vivans connus. Elle se rapproche, par sa taille et son aspect général, du cône memnonite» (le Conus distans), qui «habite l'Océan Pacifique, les côtes de la NouvelleZélande»; «mais sa spire n'est point couronnée» (p. 459 et 527-528); le Conus antiquus, «fossile du Piémont,... approche par sa forme et sa taille du cône arabe» (le conus litteratus ), qui «habite l'Océan asiatique» (p. 462-463 et 527); le Conus avellana, «fossile du Piémont... Petit cône dont la forme et la taille approchent celles du cône réseau (Conus mercator )», qui «habite les côtes de l'Afrique et les mers des Indes» (p. 482-483 et 528); le Conus betulinoides, «fossile du Piémont... Très-beau Cône... qui, par la forme de sa spire, approche du cône tine $(C$. betulinus )», qui «habite les mers des grandes Indes, depuis Madagascar jusqu'en Chine» (p. 483-484 et 527); le Conus cancellatus «habite l'Océan pacifique, sur les côtes de l'île d'Owhyhée. Bruguières le regarde comme l'analogue vivant du cône perdu que l'on trouve en France dans l'état fossile»; ce Conus deperditus (cône perdu) est en effet un «fossile très-commun à Grignon, près de Versailles, et qui se trouve aussi à Courtagnon, dans les environs de Bordeaux, et même en Italie». Lamarck discute cependant du bien-fondé de ce rapprochement fait par son ami Bruguière: «On regarde ce cône comme l'analogue fossile du cône treillissé» (conus cancellatus) «qui vit dans l'Océan Pacifique. En effet, Bruguières, qui a comparé les deux coquilles, fut complètement de cette opinion. Il observe que le cône treillissé ne diffère du cône perdu que par la saillie un 
peu plus grande de ses stries circulaires. Mais je possède des individus du cône fossile dont les stries circulaires sont éminemment prononcées et saillantes. Ainsi ce cône est mal nommé» (p. 500-501 et 528-529); le Conus fusiformis «habite l'Océan Pacifique?... Ce cône, très-rare, paraît voisin du précédent» (le Conus cancellatus (actuel) «et semble tenir le milieu entre cette espèce ou le cône perdu et le cône antidiluvien», le Conus antidiluvianus, qui est un «fossile de Courtagnon, en Champagne... Cette espèce est rare, et avoisine évidemment le cône perdu, par ses rapports» (p. 501 et 529).

A ce moment de son exposé, Lamarck se rend compte qu'il n'a pas assez développé la partie paléontologique de ses études, et il rédige un «Supplément à divers genres de Gastéropodes et de Trachélipodes, comprenant l'indication des coquilles fossiles qui ne furent point citées sous leurs genres respectifs», qu'il fait précéder d' «Observations»: «Obligé de parler, en traitant des mollusques, des produits nombreux et extrêmement variés de ces animaux, produits qui sont le plus souvent les seuls objets que nous en connaissions, je m'étais borné d'abord à ne mentionner que ceux qui sont dans l'état frais et dont nos collections sont remplies. Mais, depuis, considérant l'importance de l'étude de la géologie, dont les naturalistes modernes s'occupent avec beaucoup de zèle, j'ai sentí la nécessité de faire connaître les coquilles fossiles de divers genres que je suis parvenu à me procurer ou à observer, et de contribuer, par leur exposition, à remplir le but intéressant que se proposent les géologistes. En conséquence, ayant déjà cité, à la suite de plusieurs des genres de mes gastéropodes et trachélipodes, des coquilles fossiles qui y appartiennent et que j'ai connues, tandis que dans beaucoup d'autres j'ai négligé cette citation, je me propose ici de réparer ces omissions, et de mentionner successivement toutes celles que j'ai décrites dans les Annales du Muséum, en suivant l'ordre de leurs genres respectifs, tel qu'il est indiqué dans cet ouvrage» (p. 531-532).

Ce supplément luí fournit l'occasion de mentionner un certain nombre d'autres espèces analogues, base essentielle, comme il faut le rappeler, de toute sa démonstration anticatastrophiste et pro-évolutionniste. Ainsi chez les Bulimes. Le Bulimus sextonus, «fossile de Villiers et Grignon..., ressemble beaucoup au B. lubricus» (qui) «habite dans l'Europe septentrionale; commun aux environs de París, dans le voisinage des eaux» (p. 535, et t.6,2, 1822, p. 126); le Bulimus nitidus, «fossile de Grignon et de Parnes..., se rapproche beaucoup de notre agathine aiguillette» (qui) «habite en France» (p. 535 et t.6,2, 1822, p. 133).

De même chez les Auricules. L'Auricula sulcata, «fossile de Grignon..., semble avoisiner notre tornatelle brocard» (Tornatella flammea, espèce de gastéropode actuelle), «mais sa spire est un peu plus élevée et aiguë» (p. 538 et t.6,2, 1822, p. 219220); l'Auricula ringens, «fossile de Grignon; se trouve aussi dans les environs de Bordeaux... Petite coquille fort singulière, qui est très-voisine par ses rapports de 
notre tornatelle piétin», (Tornatella pedipes), (qui) «habite les mers du Sénégal» (p. 539, et t.6, 2, 1822, p. 221).

Et encore chez les Lymnées. La Lymnoea palustris, «fossile de Grignon et de Nogent-l'Artault, dans la pierre calcaire tendre....., est réellement l'analogue fossile de l'espèce vívante ainsi nommée» (qui) «habite en France dans les marais, les eaux douces» (t.7, 1822, p. 543 et t.6,2, 1822, p. 160).

Puis chez les Rochers. Le Murex tubifer, «fossile de Grignon, où il n'est pas rare... Selon Bruguières, l'analogue marin de cette coquille singulière existe à Londres dans le cabinet du feu docteur Hunter» (t.7, 1822, p. 576).

Arrivé aux Céphalopodes, Lamarck commence son étude en se situant par rapport à Cuvier, qui, nous l'avons vu, s'en était nettement pris à ses théories transformistes. Lamarck admet que les céphalopodes, «ainsi nommés par M. Cuvier», dont il reprend en partie l'analyse, «sont même, de tous ceux (les mollusques) exposés jusqu'ici, les plus avancés en complication d'organes», et il reconnaît aussi qu'ils «ont une conformation si singulière, qu'elle ne paraît nullement devoir conduire à celle qui est propre aux poissons». Mais Lamarck n'abandonne pas pour autant sa vision évolutionniste: «Il est donc probable que les céphalopodes ne sont pas encore les mollusques qui avoisinent le plus les animaux vertébrés, et conséquemment qu'ils ne sont pas les derniers de la classe» (p. 580).

Lamarck verrait en effet les intermédiaires recherchés plutôt dans les hétéropodes. «D'après ceux qui nous sont connus, nous voyons sans doute que les céphalopodes sont les plus parfaits des mollusques, ceux qui ont l'organisation la plus compliquée et la plus développée, et qui l'emportent à cet égard sur les autres animaux sans vertèbres; cependant, ainsi que je viens de le dire, leur conformation est si particulière, qu'il est difficile de supposer qu'immédiatement après eux, la nature ait commencé dans les poissons le plan d'organisation des animaux vertébrés. 11 est probable au contraire qu'après les céphalopodes, elle a produit d'autres animaux encore sans vertèbres, dans lesquels elle s'est préparée à l'exécution de son nouveau plan. Or ces animaux, se trouvant dans une circonstance de changement qui exige en eux une grande diminution dans la consistance de leurs parties, doivent nous paraitre par-là moins avancés en perfectionnemens que les céphalopodes. C'est précisément ce qui a lieu dans les hétéropodes, qui sont les seuls mollusques en qui l'on commence à voir une conformation un peu rapprochée de celle des poissons» (p. 582).

C'est de leur côté qu'il faut chercher par conséquent les formes de passage entre les Invertébrés et les Vertébrés. «Si, dans la nature, les céphalopodes terminaient réellement les mollusques, il est évident qu'il y aurait entre ceux-ci et les poissons un hiatus considérable; ce qui n'est pas probable, d'après ce que l'on observe ailleurs. Or, puisque les hétéropodes avoisinent les céphalopodes par leurs rapports, que plusieurs ont une coquille qui se rapproche de celle de l'argonaute, qui ne sent qu'il convient de 
les ranger après eux plutôt qu'avant, en un mot, de les placer à la fin de la classe des mollusques !

Ainsi les hétéropodes peuvent être considérés comme les premiers vestiges d'une série d'animaux marins intermédiaires entre les céphalopodes et les poissons; animaux probablement nombreux et très-diversifiés, mais dont l'observation a été jusqu'à présent négligée. Je les regarde donc comme devant être rangés vers la limite supérieure des mollusques, et comme faisant partie de ceux de ces animaux qui forment une transition avec les poissons. Effectivement, ces mollusques, gélatineux et transparens, ont précisément la consistance la plus appropriée aux changemens que la nature a eu besoin d'exécuter dans l'organisation pour amener le nouveau plan des animaux vertébrés» (p. 670-671).

Parmi les Céphalopodes, Lamarck accorde une attention spéciale aux petits fossiles du genre Miliole. Nous avons déjà vu que Cuvier avait affirmé la supériorité des vertébrés sur les invertébrés dans leur signification pour l'étude de l'histoire de la terre, et que Lamarck avait mis en cause cette manière de voir. Il soutient de nouveau l'importance des fossiles d'invertébrés pour la véritable connaissance du passé. «Les milioles, assure-t-il, sont des coquilles des plus singulières par leur forme, et peutêtre des plus intéressantes à considérer, à cause de leur multiplicité dans la nature et de l'influence qu'elles ont sur l'état et la grandeur des masses qui sont à la surface du globe, ou qui composent sa croûte extérieure. Leur petitesse rend ces corps méprisables à nos yeux, en sorte qu'à peine daignons-nous les examiner; mais on cessera de penser ainsi, lorsque l'on considérera que c'est avec les plus petits objets que la nature produit partout les phénomènes les plus imposans et les plus remarquables. Or, c'est encore ici un de ces exemples nombreux qui attestent que, dans sa production des corps vivans, tout ce que la nature semble perdre du côté du volume, elle le regagne amplement par le nombre des individus, qu'elle multiplie à l'infini et avec une promptitude admirable. Aussi les dépouilles de ces très-petits corps vivans du règne animal influent-elles bien plus sur l'état des masses qui composent la surface de notre globe, que celles des grands animaux, comme les éléphans, les hippopotames, les baleines, les cachalots, etc., qui, quoique constituant des masses bien plus considérables, sont infiniment moins multipliés dans la nature» (p. 611). Comme espèce analogue, Lamarck ne cite que le Miliolites planulata, «fossile de Louvres, près Paris», qui présente une variété «que je possède dans l'état frais ou vivant» (p. 613).

Les Nautiles fournissent à Lamarck le dernier exemple, et un des plus significatifs, comme nous l'avons déjà vu, et comme il se plaît à le répéter. Lamarck a déjà cité le Nautilus pompilius, mais il n'hésite pas à le redonner. Il «habite l'Océan des grandes Indes et des Moluques... Nota. Le nautilus pompilius se trouve dans l'état fossile à Courtagnon, Grignon, Chaumont, aux environs de Dax et en beaucoup d'autres lieux en France. Il conserve encore, dans cet état, sa nacre avec de belles couleurs irisées. C'est véritablement la même espèce que celle qui vit actuellement dans les mers des Indes, et 
qui depuis longtemps est connue des naturalistes. Ce fait, parmi beaucoup d'autres semblables, est extrêmement important pour la géologie, puisqu'il atteste, comme les autres, les révolutions subies dans les climats des diverses parties de notre globe. (Voyez les Annales du Muséum, vol. 5, (1804) p. 179 et suiv.)» (p. 633-634).

Ce sont là - de 1822 à sa mort en 1829, à l'âge de 85 ans, Lamarck, aveugle et âgé, n'a plus rien écrit - les dernières contributions du grand paléontologiste au débat qui l'opposait à Cuvier, concernant la manière de concevoir les rapports entre la paléontologie et l'évolution. Le lecteur a peut-être ressenti une certaine lassitude à lire le détail de ses études d'espèces analogues, mais la lecture de ce catalogue, qui s'apparentait souvent à une sorte de répétitions, était nécessaire pour une prise de conscience de l'immensité et du poids des «pièces justificatives», véritables preuves scientifiques, accumulées par Lamarck en faveur de l'anticatastrophisme et de l'évolution. Une telle masse de documents est en effet trop importante pour pouvoir être rejetée, ou simplement ignorée, et l'historien des sciences rigoureux ne se verra plus infliger, il faut l'espérer, l'accablement de lire que Lamarck a construit sa théorie transformiste sans aucun fondement dans les faits. Nous savons comment Lamarck eut facilement gain de cause, dans ce domaine, sans que la contradiction fût possible — d'autant moins que ceux qui voulaient travailler dans ce domaine étaient obligés, pour leurs travaux,... de se référer à lui $!^{75}$

\section{Cuvier 1823-1824.}

Cuvier allait évidemment continuer à faire paraitre la suite (tomes 4 et 5) de sa nouvelle édition des Recherches sur les Ossemens fossiles.

Les Ruminants fossiles présentent de nombreuses espèces correspondantes vivantes, ce qui, nous l'avons vu, présentait une certaine difficulté pour la théorie de Cuvier, ce dont il s'est expliqué.

Les Boeufs fossiles: 1' «Aurochs fossile», t.4, 1823, p. 140; le «Boeuf fossile», t.4, 1823 , p. 150 et t.5, 2ème partie, 1824, p. 508; le «Bufle musqué fossile», t.4, 1823 , p. 155, sont différents entre eux et d'avec les espèces vivantes: le «Boeuf commun», t.4, 1823, p. 109; l' «Aurochs (B. urus L.)», ibid.; le «Buffalo (B. bison L.)», p. 117; le «Bufle (B. bubalus L.)», p. 122; le Bufle «à longues cornes (B. arni)», p. 127; le «Boeuf à queue de cheval (B. grunniens)», p. 129; le «Bufle du Cap (B. Caffer)», p. 132; le «Buffle musqué (B. moschatus)», p. 133; le «Boeuf des Jongles (B. frontalis)», p. 506.

Pour les Chevreuils: le «Chevreuil de Montabusard», t.4, 1823, p. 103 et le «Chevreuil des tourbières», p. 105, diffèrent du «Chevreuil», p. 47.

75 Cf. Laurent G. (1987), Paléontologie et Évolution en France,1800-1860, de Cuvier-Lamarck à Darwin, Éditions du CTHS, Paris. 
Pour les Rennes: le «Renne d'Etampes et de Breugue», t.4, 1823, p. 89, est différent du «Grand Cerf du Canada (C. canadensis )»,p. 26; le «Renne de Scanie», p. 96, et t.5, 2ème partie, 1824, p. 509, est différent du «Cerf de la Louisiane (C. virginianus)», t. 4,1823 , p. 33 .

Pour les Daims, le «Daim gigantesque», t.4, 1823, p. 94, est différent du «Daim (C. dama)», ibid., p. 29.

Pour les Antilopes: 1'«Antilope ou Mouton de Nice», t.4, 1823, p. 187, est aussi différent des espèces connues.

Pour les Cerfs: le «Cerf à bois gigantesques», t.4, 1823, p. 70, est distinct du «Cerf commun (C. Elaphus )», p. 24; les «Cerfs semblables au Cerf commun», p. 98, sont différents du C. paludosus, p. 38; les autres cerfs fossiles: le «Cerf des brèches osseuses de Gibraltar, etc.», le «1er Cerf de Nice, à collet saillant aux molaires», le « $2^{\text {e }}$ Cerf du même lieu», la «Petite espèce de Pise», t.4, 1823, de la page 168 à la page 226; le «Cerf des molasses de Suisse», t.5, 2ème partie, 1824, p. 508, sont aussi différents des espèces vivantes que Cuvier a étudiées: le «C. Axis», t.4, 1823, p. 38; le «C. Hippélaphe», p. 40; le «C. Mulet», p. 43; le «C. Cochon», p. 43 et 503; le «C. Rousso», p. 44; le «C. equinus», p. 45; le «C. des Marianes», p. 45; le «C. de Manille», p. 46; le «C. de Timor», p. 46; le «C. Muntjak», p. 48; le «C. subcornutus», p. 51; le «C. Campestris», p. 51-52; le «C. Guazouti», p51-52; le «C. Rufus», p. 52; le «C. Nemorivagus», p. 53; «le Renne», p. 57; «l'Elan», p. 64 et 506; le «C. Aristotelis», p. 503; le «C. Wallichü» et le «C. Duvaucelü», p. 505.

A propos des Cerfs, Cuvier est heureux de pouvoir faire remarquer combien ses convictions sortent renforcées de l'étude de l'un d'entre eux: «Ainsi, non-seulement ce petit cerf des antiques carrières de Montabusard, que l'on n'avoit jusqu'ici pu distinguer du chevreuil, n'est pas un chevreuil, mais il diffère de tous les cerfs connus par un caractère presque générique. Il m'est arrivé rarement de trouver une confirmation plus frappante de mes règles générales, et plus j'avance dans ces sortes de recherches, plus je me persuade que ces identités des espèces anciennes avec les vivantes, que moi-même je ne suis pas encore en état de réfuter, disparoîtront à mesure que l'on connoîtra les premières de ces espèces plus complètement» (t.4, 1823, p. 105). On se souvient que Cuvier utilise cet argument à propos des espèces de chevaux fossiles.

Passant aux Carnassiers, Cuvier distingue entre eux les Félidés fossiles: le «Grand Félis des Cavernes (Felis speloea)», t.4, 1823, p. 452; le «Petit Félis des cavernes (Felis antiqua)», ibid.; le «Grand Félis des brêches» et le «Petit Félis des brêches», ibid., p. 193; et les distingue aussi des Félidés vivants: les «Chats», t.4, 1823, p. 233 et 275; «le Lion», p. 408; «le Cougar», p. 411; «le Tigre», p. 414; «le Jaguar», p. 417; «le Jaguar noir», p. 421; «la Panthère», p. 425; «le Léopard», p. 426; «le Léopard noir», p. 427; «l'Once», p. 427 et t.5, 2ème partie, 1824, p. 517; «le Guépard», t.4, 1823, p. 430; «le Serval», p. 432; «le Chibigouazou» et «l'Ocelot», p. 
434; «le Chati», «le Margay», «le Chat de Java», et «le Chat de Sumatra», p. 436; «le Chat de Diard», «le Chat sauvage», et «le Chat du Cap», p. 437; «le Jagaurondi», p. 438; «le Caracal», p. 439; «le Chaus», p. 440; «le Lynx», p. 441; «le Lynx du Canada» et «le Chat-Cervier», p. 443.

L' «Hyène fossile», t.4, 1823, p. 392 et 507, se distingue des Hyènes vivantes: «les Hyènes», p. 236 et 276, «l'Hyène rayée d'orient» et «l'Hyène tachetée», p. 381 et suiv., et du «Ratel», p. 237.

Le Putois fossile, t.4, 1823, p. 467, se distingue des espèces vivantes: «Putois, Zorille, Marte», p. 239, 277; la «Belette fossile», p. 475, des espèces vivantes du «Zorille», p. 473, du «Grison», du «Taïra» et du «Glouton», p. 241 et 277.

Le Glouton fossile, t.4, 1823, p. 475, se distingue des espèces vívantes du «Glouton», p. 476, du «Ratel», p. 479; du «Grison», p. 481; du «Taïra», p. 481; des «Moufettes et Midaus», p. 241; du «Chinche», p. 471; de la «Moufette du Chili»; de la «Moufette de l'Amérique septentrionale», p. 472; du «Midaus», et du «Gulo orientalis de Horsfield», p. 474; des «Loutres» et des «Blaireaux», p. 244 et p. 277.

Les Canidés fossiles: le «Loup fossile», t.4, 1823, p. 458; le «Renard fossile», p. 461 et 508 ; le «Chien fossile gigantesque», p. 466, et le «Chien des plâtrières», t.3, 1822, p. 267, se distinguent aussi entre eux, et d'avec les espèces vivantes: les «Chiens», t.4, 1823, p. 246 et 267; les «Isatis», t.5, 2ème partie, 1824, p. 506; le «Renard tricolor», le «Corsac», le «Chacal», le «Chacal à dos noir» et le «Grand Loup rouge», t.4, 1823, p. 463; le «Loup du Mexique», le «Guaracha», le «Loup crabier», le «Loup des îles Malouines», les «Chiens sauvages» et les «Mégalotis», p. 464; le «Chien hyénoïde», p. 386. La «Genette des plâtrières», t.3, 1822, p. 272, se distingue des «Civettes, Mangoustes, Genettes, Paradoxures», t.4, 1823, p. 249 et 277; de la «Genette hyénoïde» p. 389, et du «Suricate», p. 251.

Le «Genre voisin des Coatis retiré des plâtrières», t.3, 1822, p. 269, se distingue des espèces vivantes des «Ratons et Coatis», t.4, 1823, p. 253 et 274.

Les Ours fossiles: $1^{\prime} \ll$ Ours des cavernes (U. speloeus)», t.4, 1823, p. 351, et t.5, 2ème partie, 1824 , p. 514 et 515; l' «Ours arctoïde (U. arctoïdeus)», t. 4, 1823, p. 356; l' «Ours intermédiaire (U. priscus Goldf.)», p. 357; l' «Ours à dents comprimées de Toscane (U. cultridens)», p. 378, 507, et t.5, 2ème partie, 1824, p. 516, sont différents entre eux et d'avec les Ours vivants: les «Ours», t.4, 1823, p. 255 et 273; l' «Ours brun», p. 314 et 332; l' «Ours gris», p. 319, et t.5, 2ème partie, 1824, p. 514; l' «Ours noir d'Europe», t.4, 1823, p. 316 et 333; l' «Ours noir d'Amérique», p. 318 et 333 ; l' «Ours blanc polaire», p. 327 et 332 ; l'«Ours paresseux et à larges lèvres $(U$. labiatus)», p. 322, 324, 334 et t.5, 2ème partie, 1824, p. 512; 1'«Ours malai (U. malayanus)», t.4, 1823, p. 324 et 334; l' «Ours du Thibet», p. 325; 1'«Ours des Cordilières», t.5, 2ème partie, 1824, p. 514.

La «Sarigue des plâtrières», t.3, 1822, p. 284, et le «Carnassier de Stonesfield, voisin des Sarigues», t.5, 2ème partie, 1824, p. 349, se distinguent des Insectivores 
actuels, t.4, 1823, p. 258. A leur propos, Cuvier avertit ici de nouveau qu'il «laisse cet article tel qu'il a paru d'abord dans les Annales du Muséum» (t.3, 1822, p. 284).

Les Phoques fossiles, (que Cuvier rattache, avec les Morses, à la catégorie des Carnassiers), t.5, 1ère partie, 1823, p. 232, et 2ème partie, 1824, p. 521, se distinguent des Phoques vivants: le «Phoque commun», t.5, 1ère partie, 1823, p. 200; le «Phoca groënlandica ou oceanica», t.5, 1ère partie, 1823, p. 203, et 2ème partie, 1824, p. 520; le «Phoca leporina», t.5, 1ère partie, 1823, p. 205; le «Phoca lagura», p. 206; le «Phoca leptonyx» et le «Phoca monacus», p. 208; le «Phoca cristata», p. 210, et 2ème partie, 1824, p. 520; le «Phoca proboscidea», t.5, 1ère partie, 1823, p. 212; le «Phoca barbata», ibid., p. 214 et 2ème partie, 1824, p. 520; le «Phoca hispida», t.5, lère partie, 1823, p. 215, et 2ème partie, 1824, p. 520; le «Phoca ursina?», t.5, 1ère partie,1823, p. 217; et le «Phoca leonina?», p. 211.

Le «Morse fossile», t.5, 1ère partie, 1823, p. 234, et 2ème partie, 1824, p. 521, se distingue du «Morse» actuel, t.5, 2ème partie, 1824, p. 522.

A la fin de son chapitre sur les «cavernes à ossemens», Cuvier réaffirme ses idées catastrophistes: «Mais comment tant d'êtres féroces qui peuploient nos forêts en ontils été extirpés? Toute la réponse que nous puissions faire, c'est qu'ils ont dû être détruits en même temps et par la même cause que les grands herbivores qui les peuploient comme eux, et dont on ne trouve pas plus de traces aujourd'hui» (t.4, 1823, p. 309).

D'une manière assez curieuse, et en quelque sorte paradoxale, Frédéric Cuvier, le frère du grand paléontologiste, à qui celui-ci avait confié une partie de l'étude des Chiens et des Ours, accompagne son travail d'observations qui iraient plutôt dans le sens des idées de Lamarck: «Des Chiens», t.4, 1823, p. 246: «Nous n'avons point interrompu la série des systèmes de dentition caractérisés par une seule molaire tuberculeuse à chaque mâchoire, parce qu'ils nous ont présenté d'une manière sensible la marche de la nature pour modifier graduellement les formes et changer les facultés, tout en conservant les caractères principaux des formes primitives. En effet, en plaçant les putois à la tête de cette série, nous sommes arrivés, par le développement successif de la tuberculeuse supérieure, de la partie interne de la carnassière qui la précède et de la partie postérieure de la carnassière d'en bas, nous sommes arrivés, dis-je, sans intervalle considérable, jusqu'aux blaireaux, en passant par les zorilles, les martes, les grisons, les gloutons, les moufettes et les loutres; c'est-à-dire, que d'animaux presque aussi carnassiers que les chats, nous sommes parvenus insensiblement à des animaux qui le sont presque aussi peu que des ours»; p. 252: «Avec une grande attention on retrouve bien à ces dents les formes que nous avons remarquées sur celles qui leur sont analogues chez les civettes; mais les modifications qu'elles ont éprouvées ne peuvent manquer d'être en rapport avec des changemens analogues dans les goûts, les penchans, les besoins des animaux; aussi les suricates, carnassiers très-peu connus, présentent-ils une physionomie qui ne peut être confondue avec celle d'aucun autre mammifère». 
«Des Ours», ibid., p. 255: «Nous voici arrivés au dernier point de modification connu du système de dentition des carnassiers en général. Nous ne pourrions même plus rattacher les ours à la famille des chiens ou des civettes que par les incisives et les canines, sans l'intermédiaire des ratons à l'aide desquels nous retrouvons encore dans ces animaux, presque exclusivement frugivores, les traces des molaires des animaux les plus carnassiers»; p. 257-258: «Après avoir donné la description du système de dentition des carnassiers, nous donnerons celle du système de dentition des insectivores, mais d'une manière sommaire seulement; et nous nous attacherons à montrer les rapports qui existent entre l'un et l'autre; car nous y retrouverons encore les traces de l'unité de plan que paroît avoir suivi la nature dans toutes les parties de l'organisation animale».

Les Rongeurs fossiles se distinguent aussi entre eux et d'avec les Rongeurs vivants. Les «Marmottes», t. 5, 1ère partie, 1823, p. 6 et 29, et les «Spermophyles», p. 2 et 29 , n'ont pas de correspondants fossiles. Les «Écureuils des plâtrières», t.5, 2ème partie, 1824, p. 506, sont différents des Écureuils actuels, t.5, 1ère partie, 1823, p. 9 et 28 . Le «Castor des tourbières», t.5, 1ère partie, 1823, p. 55, et 2ème partie, 1824, p. 518, et le «Trogonthérium», t.5, 1ère partie, 1823, p. 59, sont différents des «Castors» actuels, p. 10, 37 et 49, des «Oryctères», p. 12 et 31, et des «Géoriques», p. 32.

Les Campagnols fossiles: le «Campagnol des schistes de Bohême», t.5, lère partie, 1823, p. 59; les «Campagnols des cavernes» et le «Petit Campagnol des cavernes», p. 54, sont différents des Campagnols actuels, p. 13 et 42.

Les Rats fossiles: le «Rat des cavernes», t.5, lère partie, 1823, p. 55, se distingue des Rats actuels, p. 14 et 30, et des «Hamsters», p. 15 et 31.

Les Loirs fossiles: le «Loir des plâtrières», t.3, 1822, p. 297, et le «Second Loir des plâtrières», p. 300, sont différents des espèces vivantes: les «Loirs», t.5, lère partie, 1823 , p. 15 et 30; les «Hydromys», p. 15 et 31; les «Spalax», p. 16 et 32; les «Gerboises», p. 16 et 33; les «Gerbilles», p. 32; les «Merions», p. 34; les «Hélamys», p. 17 et 43 ; les «Echimys», p. 18 et 34 ; les «Saccomys», p. 36.

Le «Porc-épic fossile», t.5, 2ème partie, 1824, p. 517, est différent des espèces vivantes: les «Porc-épics», t. 5, 1ère partie, 1823, p. 18 et 39; le «Couïa», p. 20; les «Agoutis», p. 20 et 40; le «Paca», p. 21 et 37. Le «Rongeur des schistes calcaires d'Oeningen, voisin des Cochons d'Inde», t.5, lère partie, 1823, p. 60, est différent de l' «Anoema ou Cochon d'Inde», p. 22 et 41, et des «Kerodontes», p. 42.

Le «Lièvre des cavernes», t.5, 1ère partie, 1823, p. 55, est différent du «Cabiai», p. 23 et 40; du «Lièvre», p. 24 et 43; du «Lagomys» et de l' «Aye-aye», p. 26.

A propos des Rongeurs, Cuvier avait réaffirmé ses idées anti-transformistes, c'est-à-dire anti-lamarckiennes: «Le règne animal à ces époques reculées étoit composé d'après les mêmes lois; il comprenait les mêmes classes, les mêmes familles que de nos jours; et en effet, parmi les divers systèmes sur l'origine des êtres organisés, il n'en est pas de moins vraisemblable que celui qui en fait naître successivement les 
différens genres par des développemens ou des métamorphoses graduelles. Qui ne voit que chaque genre, chaque espèce en particulier, est nécessaire à l'harmonie, à l'équilibre de l'ensemble?» ( t.3, 1822, p. 297-298).

Les Édentés fossiles: le «Mégalonyx», t.5, 1ère partie, 1823, p. 160; le «Mégathérium», p. 174, et t.5, 2ème partie, 1824, p. 519, et le «Pangolin gigantesque», t.5, 1ère partie, 1823, p. 193, diffèrent aussi entre eux et d'avec les espèces vivantes: les «Paresseux», t.5, 1ère partie, 1823, p. 71 et suiv.; les «Fourmiliers et Pangolins», p. 97 et suiv.; les «Tatous et Oryctérops», p. 117 et suiv., l' «Ornithorynque et l'Echidné», p. 143 et suivants.

Ces Édentés fournissent à Cuvier l'occasion de réaffirmer ses idées: «une phalange onguéale fossile... annonce à elle seule un Édenté inconnu, probablement du genre des Pangolins, et de taille gigantesque.... A lui seul ce morceau prouveroit qu'il a existé autrefois des animaux aujourd'hui inconnus, qu'une catastrophe quelconque a fait disparoître des pays qu'ils habitoient, et a probablement anéantis sur toute la surface du globe». (t.5, 1ère partie, 1823, p. 193).

Les Cétacés fossiles fournissent aussi un grand nombre de fossiles nonanalogues.

Le «Lamantin fossile», t.5, lère partie, 1823, p. 266, est différent des Lamantins vivants; le «Lamantin», p. 235; le «Lamantin d'Amérique», p. 242; le «Lamantin du Sénégal», p. 254; le «Rytina», p. 256 et le «Dugong», p. 259.

Les Dauphins fossiles: l' «Epaulard fossile», t.5, lère partie,1823, p. 309; le «Dauphin fossile de Sort, département des Landes, à longue symphyse», p. 312; le «Dauphin fossile de Sort, voisin du commun», p. 316; le «Dauphin à long museau du département de l'Orne», p. 317, sont aussi différents des espèces vivantes: le «Dauphin», p. 273 et 290; le «Dauphin commun», p. 275; le «Delphius dubius», p. 295; le «Dauphin souffleur ou tursio», p. 277 et 296; le «Delph. frontatus», p. 278; le «Delph. acuminatus», p. 296, 298 et 400; le «Dauphin couronné», ibid.; le «Dauphin du Gange», p. 279 et 298; le «Dauphin marsouin», p. 280 et 296; le «Dauphin épaulard», p. 281 et 297; le « Dauphin bélier ou D. griseus», p. 284 et 297; le «Dauphin globiceps», p. 285 et 297; le «Dauphin beluga», p. 287 et 297, et le «Dauphin leucoramphe», p. 288 et 297.

Pour les autres Cétacés fossiles, Cuvier note que le «Narval fossile», t.5, 1ère partie, 1823, p. 349, est différent du «Narval», p. 319; que le «Genre Ziphius» et le «Ziphius cavirostris», p. 352, le «Ziphius planirostris», p. 356, le «Ziphius longirostris», p. 357, le «Rorqual fossile», p. 390 et la «Baleine fossile», p. 393, sont différents de l' «Hyperoodon», p. 324, des «Cachalots», p. 328, des «Baleines», p. 359, de la «Baleine franche et Baleine du Cap», p. 362 et 373, et des «Rorquals», p. 363 et 372. 
Les Ziphius donnent à Cuvier une nouvelle occasion de renforcer ses théories catastrophistes et anti-transformistes: « Les Ziphius, comme on l'a vu, ne sont ni tout-àfait des baleines, ni tout-à-fait des cachalots, ni tout-à-fait des hypéroodons. Ils tiennent dans l'ordre des cétacés une place analogue à celle qu'occupent dans l'ordre des pachydermes nos mastodontes, nos palaeotheriums, nos anoplotheriums et nos lophiodons, et dans celui des édentés, notre mégathérium et notre mégalonyx. Ce sont probablement aussi des restes d'une nature détruite, et dont nous chercherions en vain aujourd'hui les originaux à l'état de vie. Par là se confirme de plus en plus la proposition à laquelle l'examen des coquilles fossiles avoit déjà conduit; c'est que ce ne sont pas seulement les productions de la terre qui ont changé lors des révolutions du globe, mais que la mer elle-même, agent principal de la plupart de ces révolutions, n'a pas conservé les mêmes habitans; que lorsqu'elle formoit dans nos environs ces immenses couches calcaires peuplées de coquilles aujourd'hui presque toutes inconnues, les grands mammifères qu'elle nourrissoit n'étoient pas ceux qui la peuplent aujourd'hui, et que, malgré les forces que sembloit leur donner l'énormité de leur taille, ils n'ont pas mieux résisté aux catastrophes qui ont bouleversé leur élément que n'y ont résisté sur terre les éléphans, les rhinocéros, les hippopotames et tous ces autres quadrupèdes si robustes, qu'à défaut des arts de l'homme une révolution générale de la nature pouvoit seule extirper leurs races» (t.5, 1ère partie, 1823, p. 399).

Cuvier a aussi étudié un grand nombre de Reptiles: il leur consacre 487 pages, presque un volume entier (tome 5, 2ème partie, 1824). Dans les Crocodiles fossiles, il a établi que le «Gavial de Monheim et de Boll (Crocodilus priscus)», t.5, 2ème partie, 1824, p. 120, le «Gavial de Caen», p. 127, le «Gavial de Honfleur» et le «2ème Gavial de Honfleur», p. 143 et 525, sont bien différents entre eux et différents des «Gavials», p. 30 et 59, du «Grand Gavial», p. 60, et du «Petit Gavial», p. 62. Il en est de même ensuite de toute la série des Crocodiles proprement dits: le «Crocodile de Meudon» et le «Crocodile de Sussex», p. 161; le «Crocodile d'Auteuil», p. 163; le «Crocodile de Provence», p. 164; le «Crocodile de Sheppey», p. 165; le «Crocodile des plâtrières», p. 166, et t.3, 1822, p. 335; le «Crocodile des marnières d'Argenton», t.5, 2ème partie, 1824, p. 166; le «Crocodile des graviers de Castelnaudary», p. 168; le «Crocodile de Blaye», le «Crocodile de Brentfort» et le «Crocodile du Mans», p. 169, sont des fossiles tous bien distincts des espèces vivantes des «Crocodiles», p. 14; des «Caïmans», p. 30 et 32; du «Caïman à museau de brochet», p. 32; du «Caïman à lunettes», p. 35; du «Caïman à paupières osseuses», p. 38; des «Crocodiles proprement dits», p. 30 et $42 ;$ du «Crocodile vulgaire», p. $42 ;$ du «Crocodile à deux arêtes», p. 49; du «Crocodile à lozange», p. 51; du «Crocodile à casque», p. 52; du «Crocodile à deux plaques», p. 53; du «Crocodile à museau effilé», p. 55 et du «Crocodile à nuque cuirassée», p. 58.

Les Chéloniens fournissent aussi un bon nombre d'espèces fossiles: les «Trionyx fossiles», t.5, 2ème partie, 1824, p. 221; le «Trionyx des plâtrières de Paris», p. 222; 
le «Trionyx des plâtrières d'Aix», p. 223; le «Trionyx des molasses de la Gironde», p. 224; le «Trionyx des graviers de Lot-et-Garonne» et le «Trionyx des graviers de Castelnaudary», p. 226; le «Trionyx des sables d'Avaray», les «Emydes ou Tortues d'eau douce fossiles», les «Emydes du Jura», p. 227; les «Emydes de Sussex», les «Emydes des molasses de la Dordogne et de la Suisse», p. 232; les «Emydes de Sheppey», p. 234; les «Emydes de Bruxelles», p. 236; les «Emydes des sables d'Asti», p. 238; les «Chélonées ou Tortues de mer fossiles» et la «Chélonée de Maestricht», p. 239; la «Chélonée de Glaris», p. 243; la «Chélonée de Lunéville», p. 525; les «Tortues terrestres fossiles» et les «Tortues des environs d'Aix», p. 244, et les «Tortues de l'lle de France», p. 248: toutes sont différentes entre elles et différentes des espèces vivantes de «Tortues», p. 175; de «Tortues de terre», p. 176; de «Tortues d'eau douce», p. 184; de «Tortues molles ou Trionyx», p. 186; de «Tortues de mer», p. 187 et des «Chélydes», p. 200.

Les Sauriens fossiles sont aussi parmi les plus célèbres animaux du passé «ressuscités» par Cuvier: le «Monitor fossile de Thuringe», t.5, 2ème partie, 1824, p. 300; le «Grand Saurien des carrières de Maestricht ou Mosasaurus», p. 310; le «Grand Saurien de Monheim (Lacerta gigantea Soemmerring»), p. 338; le «Mégalosaurus», p. 343; le «Grand Saurien de Honfleur», p. 353; le «Saurien gigantesque des carrières de Caen», p. 354; le «Saurien des environs de Lunéville», p. 355; le «Ptérodactyle à long museau», p. 358; le «Ptérodactyle à museau court», p. 376, et le «Grand Ptérodactyle», p. 380, que Cuvier distingue entre eux et distingue des espèces vivantes des «Lézards», p. 251; des «Monitors», p. 255; des «Sauvegardes», p. 261; des «Lézards proprement dits», p. 263; des «Cordyles» et des «Tellions», p. 264; des «Dragons», des «Agames», des «Marbrés», des «Anolis», du «Basilic» et de l' «Iguane», p. 266; du «Gecko», p. 267; du «Caméléon», p. 268; des «Scinques» et des «Ophisaures», p. 270.

Dans les Batraciens, Cuvier place, comme l'on sait, la «Salamandre gigantesque d'Oeningen, ou prétendu homme fossile», t.5, 2ème partie, 1824, p. 431, à distinguer bien sûr des espèces vivantes de «Grenouilles», p. 386; de «Rainettes» et de «Crapauds», p. 392; de «Pipa», p. 393; de «Salamandres», p. 406, de l' «Axolotl», p. 415; de la «Sirène», p. 417, et du «Proteus», p. 426.

Et pour couronner le tout: l' «Ichtyosaurus», t.5, 2ème partie, 1824, p. 447 et le «Plésiosaurus», p. 475, sont aussi, bien entendu, des espèces perdues.

Cuvier s'appuie sur ces études des crocodiles pour souligner à nouveau qu'il n'y a pas d'espèces fossiles analogues aux espèces actuelles. Sa méthode est vraiment de distinguer et non de réunir les espèces. «L'ostéologie du crocodile, affirme-t-il, étoit avant moi à peu près aussi imparfaitement connue que celle de la plupart des grands quadrupèdes vivipares». («Des Ossemens de Reptiles», t.5, 2ème partie, 1824, p. 67), et dans le «Résumé du chapitre sur les crocodiles», il insiste encore: 
«On voit que si les crocodiles encore existans sont plus nombreux qu'on ne l'avoit cru, les espèces fossiles de ce genre présentent aussi une assez grande variété; nous pouvons en compter au moins six de parfaitement distinctes, et qui ne diffèrent pas moins des crocodiles vivans qu'elles diffèrent entre elles....Telles qu'elles sont, nos connoissances sur ce genre ne laissent pas que d'avoir un grand intérêt, puisqu'elles nous prouvent que les crocodiles ont subi la même loi que les mammifères, et que leurs espèces n'ont point résisté aux catastrophes qui ont bouleversé la croûte extérieure du globe...» (p. 171).

Dans son étude «Sur le grand SAURIEN fossile des carrières de Maestricht», $\mathrm{Cu}$ vier fait remarquer encore: "Quant à l'animal fossile de Monheim, que M. de Soemmering avoit aussi regardé comme identique avec celui de Maestricht, nous verrons à l'article suivant qu'il en diffère à plusieurs égards» (p. 310, note(1). Et à propos de l'Ichtyosaurus et du Plésiosaurus, il se plaît à écrire: «Nous voici arrivés à ceux de tous les reptiles, et peut-être de tous les animaux fossiles, qui ressemblent le moins à ce que l'on connoit, et qui sont le plus faits pour surprendre le naturaliste par des combinaisons de structures qui, sans aucun doute, paroîtroient incroyables à quiconque ne seroit pas à portée de les observer par lui-même, ou à qui il pourroit rester la moindre suspicion sur leur authenticité. Dans le premier genre, un museau de dauphin, des dents de crocodile, une tête et un sternum de lézard, des pattes de cétacés, mais au nombre de quatre, enfin des vertèbres de poissons; dans le second cas, avec ces mêmes pattes de cétacés, une tête de lézard, et un long cou semblable au corps d'un serpent: voilà ce que l'ichtyosaurus et le plésiosaurus sont venus nous offrir...» (p. 445).

Cependant, il semble de nouveau prêt, dans un passage de ses réflexions, à douter de lui-même. A propos du «Proteus (proteus anguinus Laurenti)», il écrit en effet:

«Si les expériences par lesquelles on dit que M. de Schreibers cherche à vérifier si ce (le proteus ) ne seroit pas une salamandre modifiée par son séjour dans l'obscurité venoient à réussir, on auroit à changer toutes les idées que l'on s'est jamais faites sur la constance des races, et sur la force qui les maintient dans leurs caractères primitifs» (ibid., p. 427).

Cuvier aurait-il été disposé, à certains moments de sa carrière, à admettre les idées de Lamarck, comme son frère Frédéric semblait le faire? L' «éloge» qu'il fit de Lamarck, à la mort de celui-ci, ne permet pas de le croire.

C'est par Cuvier que nous avons commencé l'histoire des relations entre la paléontologie (les paléontologies) et la théorie transformiste ou évolutionniste. C'est par lui aussi que nous finirons, car il a survécu à Lamarck. Nous n'irons pas cependant audelà de 1824, car Lamarck n'ayant pas écrit après 1822, le «dialogue» a évidemment été interrompu à cette date. De plus, comme ses contemporains l'avaient remarqué, Cuvier lui-même ne s'est pas beaucoup renouvelé dans ses études au-delà de cette 
époque. Commentant la parution de la deuxième édition du Règne animal de Cuvier (1829-1830), Deshayes remarquait qu' «elle produisit beaucoup de déceptions, car on s'aperçut facilement combien Cuvier, mêlé depuis bien des années aux affaires politiques, étoit peu au courant de ce qui s'étoit fait autour de lui» ${ }^{76}$.

Cuvier d'ailleurs l'avait annoncé lui-même en 1825, à la fin du dernier tome de la troisième édition des Recherches: «Je termine donc ici cette édition, écrivait-il, probablement la dernière qu'il me sera possible de publier, et laissant à mes successeurs à cultiver un champ que je n'ai fait qu'ouvrir, et qui bien certainement leur donnera encore des moissons plus riches que toutes celles que j'ai pu recueillir; je vais désormais consacrer ce qui me restera de temps et de forces à publier des recherches déjà faites sur l'histoire des poissons, mais surtout à terminer et à publier mon Traité général d'Anatomie comparée».

Assez ironiquement, ce sont les «successeurs» de Lamarck qui vont «cultiver» le champ bien plus vaste ouvert par l'adversaire de Cuvier dans l'étude des Invertébrés. La masse de «pièces justificatives» que Lamarck avait amassée a continué en effet à s'accumuler dans les décennies suivantes, avec les innombrables études menées par les invertébristes. Gérard-Paul Deshayes nous informe encore que, parmi eux, les conchyliologistes, c'est-à-dire ceux qui étaient à même de recueillir le plus d'espèces fossiles analogues, suivaient justement la «méthode» de Lamarck dans leurs recherches: «Lorsqu'en 1835 , écrivait-il en 1845 , j'entrepris la nouvelle édition des animaux sans vertèbres de Lamarck, les Zoologistes en France étaient encore partagés en deux camps: les uns avaient adopté la méthode et la nomenclature de Cuvier; les autres, et plus particulièrement les Conchyliologistes, avaient adopté sans restriction la méthode de Lamarck. Cette méthode, comme celle de Linné, inspirait une sorte de vénération, et peu de personnes osaient y apporter des modifications» ${ }^{77}$. Cette nouvelle édition du maître ouvrage de Lamarck fut jugée elle aussi à cette époque «unentbehrlich» par la revue allemande Archiv für Naturgeschichte ${ }^{78}$. Certains conchyliologistes pratiquaient d'ailleurs, selon la méthode de Lamarck, la recherche des espèces «analogues», avec un tel enthousiasme dont nous avons eu déjà le témoignage en $1811^{79}$, qu'ils en qualifiaient jusqu'à l'exagération, et que Deshayes dut, à plusieurs reprises, leur faire remarquer qu'ils allaient trop loin.

L'historien des sciences qui reconstruit l'histoire de la paléontologie et de l'évolution d'après les textes historiques, et non d'après des présupposés idéologiques, ne

76 Deshayes, G.P. et DAUDEBARD de FÉRUSSAC, A. (1820-1851), Histoire naturelle générale et particulière des Mollusques terrestres et fluviatiles, Paris, t.1, (entièrement de DESHAYES), p. 170.

77 DEShAYES, G. P. (1845), Lettre à l'éditeur du Zeitschrift für Malakozoologie, année 1845, 44-47; p. 45.

78 WiEgmann, Archiv für Naturgeschichte, année 1837, p. 267.

79 Cf. plus haut p. 170-171. 
ressent alors aucune surprise en lisant en 1834 le témoignage d'Ami Boué, un des fondateurs de la Société Géologique de France, qui affirme que le catastrophisme était récusé par la plupart de ses collègues: «Aujourd'hui le système des cataclysmes et des déluges, des coups de théâtre créateurs, et des hypothèses, est abandonné par tout le monde: tout le monde est entré enfin dans la voie philosophique de la marche du connu à l'inconnu» ${ }^{80}$. Il ne ressent pas davantage de surprise en lisant le témoignage de Camille Dareste, qui en 1859 atteste que la théorie transformiste de Lamarck a largement pénétré les milieux scientifiques français: «Nous voyons aujourd'hui, assure-t-il, les hommes les plus éminents entrer dans la voie ouverte par Lamarck, et faire de l'idée de la variabilité limitée des espèces le point de départ de leurs théories scientifiques» ${ }^{81}$.

L'historien sourcilleux se demande cependant pourquoi ce dialogue riche et passionné, bourré de documents paléontologiques, poursuivi sur un quart de siècle, et continué au-delà, qui constitue une page d'histoire unique et fondamentale, a été ignoré, en particulier par les «historiens» anglo-saxons? Est-ce seulement parce qu'ils ne savent pas lire les textes français?

80 BouÉ, A. (1834), «Résumé des progrès des sciences géologiques pendant l'année1833», Bulletin de la Société géologique de France, 5, VII-518; p. 494.

81 DARESTE, C. (1859), Biographie de Lamarck, dans Nouvelle Biographie générale, de Hoefer, 29 , 55-62; p. 62. Il convient de préciser que l'Origine des espèces de Darwin n'était.pas encore paru à ce moment... 